TAILORED PIEZOELECTRIC THIN FILMS FOR ENERGY HARVESTER

Xin Wan 


\section{Thesis committee members:}

Chairman and secretary

Prof. dr. G. van der Steenhoven University of Twente

Promotor

Prof. dr. ing. A.J.H.M. Rijnders University of Twente

Assistant promotor

Dr. ir. G. Koster

University of Twente

Members

Prof. dr. P. Muralt

EPFL, Switzerland

Prof. dr. B. Noheda Pinuaga

University of Groningen

Dr. R. van Schaijk

Holst Centre / IMEC

Prof. dr. ing. D.H.A. Blank

University of Twente

Prof. dr. ir. R.G.H. Lammertink

University of Twente

The work described in this thesis was performed at the Inorganic Materials Science group, MESA+ Institute for Nanotechnology, Faculty of Science and Technology at University of Twente in Enschede, and the Holst Centre / IMEC-NL in Eindhoven.

\section{Wan}

Tailored piezoelectric thin films for energy harvester

Ph.D. thesis, University of Twente, Enschede, The Netherlands.

ISBN: 978-90-365-1423-1

Printed by Wöhrmann Print Service, Zutphen, The Netherlands.

Copyright (C) X. Wan, 2013, All rights reserved. 


\title{
TAILORED PIEZOELECTRIC THIN FILMS FOR ENERGY HARVESTER
}

\author{
DISSERTATION
}

to obtain

the degree of doctor at the University of Twente, on the authority of the rector magnificus, prof.dr. H. Brinksma, on account of the decision of the graduation committee, to be publicly defended

on Friday the $17^{\text {th }}$ of May 2013 at 16:45

by

\section{Xin Wan}

Born on the $14^{\text {th }}$ of August, 1983

in Changchun, China 
This dissertation has been approved by:

Promotor: $\quad$ Prof. dr. ing. A.J.H.M. Rijnders

Assistant promotor: $\quad$ Dr. ir. G. Koster 


\section{Contents}

Chapter 1 Introduction and motivation 1

1.1 Introduction 1

1.2 Outline of this thesis 4

1.3 References 6

Chapter 2 PiezoMEMS--from principle to device 9

$\begin{array}{ll}2.1 \text { Introduction } & 10\end{array}$

2.2 Piezoelectric materials for energy harvester $\quad 12$

$\begin{array}{ll}2.2 .1 \text { Ferroelectricity and piezoelectricity } & 12\end{array}$

2.2.2 PiezoMEMS in theory 15

$\begin{array}{ll}\text { 2.2.3 Strain in epitaxial thin films } & 17\end{array}$

$\begin{array}{ll}2.2 .4 \text { Focused application } & 18\end{array}$

2.3 Thin film growth and characterization $\quad 20$

2.3.1 Principle of pulsed laser deposition technique 20

$\begin{array}{ll}\text { 2.3.2 Growth conditions of the thin films } & 21\end{array}$

2.4 Thin film characterization $\quad 22$

2.4.1 Structural characterization $\quad 22$

2.4.1.1 Basic principles of reciprocal space mapping 23

$\begin{array}{ll}2.4 .1 .2 \text { Ewald sphere } & 25\end{array}$

2.4.2 Compositional characterization $\quad 26$

$\begin{array}{ll}2.4 .3 \text { Electronic characterization } & 27\end{array}$

2.4.4 Mechanical characterization 29

2.5 References 31

Chapter 3. Crystallographic properties of (110) $\mathrm{PbZr}_{\mathrm{x}} \mathrm{Ti}_{(1-\mathrm{x})} \mathrm{O}_{3}$ epitaxial thin films under substrate induced strain $\quad 35$

3.1 Introduction $\quad 36$

3.2 Crystallographic studies of (110) $\mathrm{PbZr}_{\mathrm{x}} \mathrm{Ti}_{(1-\mathrm{x})} \mathrm{O}_{3}$ epitaxial thin films on 37 $\mathrm{SrTiO}_{3}$ substrates

$\begin{array}{ll}3.2 .1 \text { Reciprocal space mapping } & 37\end{array}$

3.2.2 Domain structure and domain tilting 42

3.3 Crystallographic studies of (110) $\mathrm{PbZr}_{\mathrm{x}} \mathrm{Ti}_{(1-\mathrm{x})} \mathrm{O}_{3}$ epitaxial thin films on 45 
Silicon substrates

$\begin{array}{ll}3.4 \text { Conclusions } & 50\end{array}$

3.5 References $\quad 52$

Chapter 4. Ferroelectric and piezoelectric properties of (110) $\operatorname{PbZr}_{\mathrm{x}} \mathrm{Ti}_{(1-\mathrm{x})} \mathrm{O}_{3}$ epitaxial thin films on Si substrates

4.1 Introduction 56

4.2 Experimental $\quad 58$

4.3 Characterization of crystallinity structure $\quad 59$

4.3.1 X-ray diffraction measurements $\quad 59$

4.3.2 Scanning Electron Microscopy measurements 62

$\begin{array}{ll}4.4 \text { Functional properties } & 63\end{array}$

4.4.1 Ferroelectricity $\quad 63$

4.4.2 Piezoelectricity $\quad 66$

$\begin{array}{ll}4.5 \text { Conclusions } & 67\end{array}$

4.6 References $\quad 68$

Chapter 5. Soft-doping and hard-doping of $\operatorname{PbZr}_{\mathrm{x}} \operatorname{Ti}_{(1-\mathrm{x})} \mathrm{O}_{3}$ epitaxial thin films

5.1 Introduction $\quad 72$

$\begin{array}{ll}\text { 5.1.1 Dopants categories } & 73\end{array}$

$\begin{array}{ll}\text { 5.1.2 Dopants selection } & 74\end{array}$

5.2 (110) orientated PZT films with $\mathrm{Nb}$ and Fe dopants 75

5.2.1 Sample fabrication and crystallographic structure $\quad 75$

$\begin{array}{ll}\text { 5.2.2 Ferroelectricity and piezoelectricity } & 78\end{array}$

$\begin{array}{ll}\text { 5.2.3 Discussions } & 80\end{array}$

5.3 (001) orientated PZT films with $\mathrm{Nb}$ and Fe dopants 82

5.3.1 Sample fabrication and crystallographic structure 82

$\begin{array}{lll}\text { 5.3.2 Ferroelectricity and piezoelectricity } & 82\end{array}$

5.3.3 Mechanisms of imprint effects $\quad 85$

5.4 Conclusions and outlook 90

5.5 References $\quad 91$

Chapter 6 Integration of epitaxial PZT thin films into energy harvesting devices

6.1 Introduction 96 
6.2 Generic vibration model $\quad 97$

6.3 Fabrication and experimental procedure $\quad 98$

$\begin{array}{ll}6.4 \text { Stress compensation } & 101\end{array}$

6.5 Electric measurements 102

6.6 Measurements of energy harvester 104

$\begin{array}{ll}\text { 6.6.1 The properties of energy harvesters with textured PZT films } & 104\end{array}$

$\begin{array}{ll}\text { 6.6.2 The properties of energy harvesters with epitaxial PZT films } & 108\end{array}$

6.7 Conclusions 113

6.8 References 114

$\begin{array}{ll}\text { Summary } & 117\end{array}$

$\begin{array}{ll}\text { Samenvatting } & 121\end{array}$

$\begin{array}{ll}\text { Acknowledgments } & 125\end{array}$ 



\section{Chapter 1}

\section{Introduction and motivation}

\subsection{Introduction}

Nowadays, the proliferation in using renewable power supplies has enabled the development of the energy harvester. A more efficient and environmental friendly power device is clearly required, to replace electrochemical batteries as well as to lengthen the lifetime of portable electronic devices ${ }^{1}$. The main concept of these kinds of power devices is to gain electrical energy from the ambient energy in the surrounding. Current energy harvesting technology is mainly focused on natural resources, such as solar, wind and thermal power. However, these energy sources are not optimal in case of specialized sensor device. Since mechanical energy from vibrations or movement is present almost everywhere ${ }^{1,2,3}$, for a more ubiquitous wireless sensor system, vibrational energy harvesting is a viable energy source. 
Piezoelectric materials are excellent materials to transfer mechanical energy into electrical energy which can be stored and used to power other devices ${ }^{4}$. The technique to fabricate MEMS (micro-electromechanical systems) with piezoelectric material is called piezoMEMS. There have been a few studies on the energy harvesting piezoMEMS consist of piezoelectric materials ${ }^{5,6}$. The combination of silicon wafer processing and piezoelectric thin film technology has led to a variety of miniaturized device ${ }^{7,8}$. To understand the material performance in piezoMEMS devices, extensive knowledge of a couple of characteristic properties, such as the electric mechanical coupling factors, dielectric constant and piezoelectric coefficients, is crucial. Some studies have already described the determination of the thin film piezoelectric coefficients $d_{33}$ and $\mathrm{e}_{31}{ }^{9,10}$. On the other hand, the power output of harvester devices are governed by the coupling factors $\mathrm{k}$ and the dielectric constants $\varepsilon^{11}$. While most of the mechanical energy transform to electrical energy, part of the energy dissipated or transformed to other energy. The dielectric loss $(\delta)$ explains this phenomenon. In the harvesting devices, the power output is proportional to the figure of merit $\left(\mathrm{FOM}=\mathrm{e}_{31}{ }^{2} / \varepsilon_{0} \varepsilon_{33}\right)$. Thus modification of the piezoelectric materials in order to reach a large figure of merit is important for energy harvesting device ${ }^{12}$.

In the past, many piezoelectric materials have been used to harvest vibration energy. The chosen piezo electric material was often not optimized for energy harvesting application and/or the fabrication method is not suitable for induction scale production. The work of $\mathrm{Hu}$ et al. presented the growth of $\mathrm{ZnO}$ textured films for nanogenerators. A self-powered system is build up based on a polymer substrate $^{13}$. In epitaxial films, a giant piezoelectricity is measured in $\mathrm{Pb}\left(\mathrm{Mg}_{1 / 3} \mathrm{Nb}_{2 / 3}\right) \mathrm{O}_{3}-\mathrm{PbTiO}_{3}$ (PMN-PT) grown on $\mathrm{SrTiO}_{3}$ buffered silicon substrates by Baek et al. ${ }^{14}$. An enhanced figure of merit is measured, which predicts a large power output in harvester. However, from the application point of view, silicon on insulator (SOI) wafers are the most compatible substrates in semiconductor manufacturing, especially in microelectronics systems. Both AlN and PZT materials have been fabricated on SOI wafer for energy harvesting devices ${ }^{15,16}$. A variety of device designs with different resonance frequencies 
were discussed ${ }^{17,18}$. The fabrication and packaging techniques are improved in their studies, but to achieve a large power output and scale up the harvester applications, the physical properties of the materials need to be tailored and improved.

Pulsed laser deposition (PLD) is a versatile technique for thin films depositions both on chip scale as well as on wafer scales ${ }^{19}$. It can transfer materials stoichiometrically from a multi-component target to a substrate maintaining epitaxial growth along a certain direction. In this way, the physical properties of epitaxial PZT thin films can be optimized without undesirable defects. In this thesis, the focus is on improving the efficiency of PZT piezoelectric harvesting devices by controlling the film crystalline quality, film compositions (different ratios between zirconium and titanium) and by introducing dopants. Different from bulk materials, the strain in thin films can induce interesting changes in ferroelectric and piezoelectric properties. Moreover, oxide electrodes acted as a sink to consume extra defects in epitaxial films ${ }^{20}$, which lead to novel physical properties.

The aim of this project is to generate energy at microwatt power scale with piezoelectric MEMS technology. The piezoelectric vibration energy harvesting device consists of a bulk mass attached to a cantilever ${ }^{6,11}$. To get optimal electric output, the performance of material itself becomes more and more interesting to both the scientific and the industrial world. Thin films of ferroelectric PZT $\left(\mathrm{Pb}(\mathrm{Zr}, \mathrm{Ti}) \mathrm{O}_{3}\right)$ perovskite ceramic material have been studied a lot in harvesting devices, due to their excellent piezoelectric properties ${ }^{21}$. Besides these modeling and calculations ${ }^{3,22}$, much more work needs to be done to tailored the material properties and harvest the energy in a more efficient way. PZT thin films with different zirconate titanate compositions and different dopants ${ }^{23}$ show a variety of dielectric and piezoelectric properties. In the end, the epitaxial vibration harvesting devices are discussed. 


\subsection{Outline of this thesis}

The state of the art of the piezoMEMS is discussed in chapter 2 . The theory to incorporate the ferroelectric and piezoelectric properties to a real device is given. A model of energy vibration harvesting devices with its potential application in industry is described in detail. The epitaxial films in this thesis were fabricated by pulsed laser deposition. The principles of the structural and compositional analysis are given, and the electrical and mechanical analysis technique are described. In this chapter, with a thorough understanding of piezoMEMS devices, from the physical principles up to device fabrication, a systemic overview framework is built up in this thesis.

In chapter 3, the domain structure and domain tilting of (110) $\mathrm{PbZr}_{\mathrm{x}} \mathrm{Ti}_{(1-\mathrm{x})} \mathrm{O}_{3}$ epitaxial thin films were studied by X-ray diffraction. Both $\mathrm{SrTiO}_{3}$ and Silicon substrates were used. Different crystallographic properties were obtained under substrate induced strain. For (110) $\mathrm{PbZr}_{\mathrm{x}} \mathrm{Ti}_{(1-\mathrm{x})} \mathrm{O}_{3}$ epitaxial thin films grown on $\mathrm{SrTiO}_{3}$ substrates, 6 different domain tilting directions were observed in tetragonal phase. For (110) $\mathrm{PbZr}_{\mathrm{x}} \mathrm{Ti}_{(1-\mathrm{x})} \mathrm{O}_{3}$ epitaxial thin films grown on silicon substrates, 2 domain tilting, with a 10 degree in plane rotations are presented. Furthermore, both the lattice parameters and the tilt angles of various composited $\mathrm{PbZr}_{\mathrm{x}} \mathrm{Ti}_{(1-\mathrm{x})} \mathrm{O}_{3}$ thin films are calculated and compared. A nano domains region was observed in $\mathrm{x}=0.4-0.45$ in (110) PZT films grown on silicon substrates.

In chapter 4, piezoelectric, ferroelectric and structural properties of epitaxial pseudocubic (110) oriented $\mathrm{PbZr}_{\mathrm{x}} \mathrm{Ti}_{1-\mathrm{x}} \mathrm{O}_{3}$ thin films were studied as function of composition. The x-dependence of the measurement data can be explained by an abrupt transition from the rhombohedral $r$-phase to the tetragonal $c_{45} / a$-phase if $\mathrm{x}$ becomes smaller than $x \approx 0.40$. In the $r$-phase the polarization vector easily rotates in the (110)-plane, perpendicular to the substrate under the influence of an external electrical or stress field, resulting in a rapidly increasing measured piezoelectric parameter $e_{31, \mathrm{f}}$ and dielectric parameter $\varepsilon_{33}$, peaking near the $r-c_{45} / a$ 
phase boundary. This interpretation is consistent with earlier models for multidomain (001)- oriented clamped films by Kukhar et $a l .^{24}$. The reliable growth of (110) oriented films with a large $e_{31, f}$ is of great significance for Si-based piezoMEMS. The largest value of the FOM for such devices is found for $x=0.4$, with a $F O M=e_{31}^{2} / \epsilon_{0} \epsilon_{33}=24.0 \mathrm{GPa}$.

The functional properties of $\mathrm{Nb}$-doped and Fe-doped PZT thin films are discussed in chapter 5. Here, both (110) orientation and (001) orientation films were grown on silicon substrates. The functional properties of epitaxial thin films were modified by adding dopants. FOM is calculated for each film. The $\mathrm{Nb}$-doped PZT films give the highest piezoelectric coefficient $\mathrm{e}_{31, f}$, while the Fedoped PZT gives the lowest $\mathrm{e}_{31, f}$. The mechanism of properties changes in doped thin films is discussed. A giant imprint behavior was obtained in (001) orientated epitaxial thin films. Under the epitaxial growth, the defect dipoles, which were induced by dopants, are aligned in one direction. Thus the imprint PE loops are obtained. Here, the build in bias reduces the dielectric constant at zero bias. In this case, the highest figure of merit is obtained in (001) orientated Nb-doped PZT thin films grown on STO buffered silicon substrates.

In the last chapter, the fabrication and testing of the epitaxial $\mathrm{PbZr}_{0.4} \mathrm{Ti}_{0.6} \mathrm{O}_{3}$ vibration harvesting devices are discussed. The results were compared with textured PZT harvester and AIN harvester. The maximum power output in epitaxial harvester was $78 \mu \mathrm{w}$ at $0.75 \mathrm{~g}$ acceleration, with a resonance frequency of $624 \mathrm{~Hz}$. The sensitivity of this devices is $124.45 \mu \mathrm{W} / \mathrm{g}$, which is significant higher than the devices described in literature. After normalizing the power output $\left(\mathrm{P}_{\text {norm }}\right)$, a comparison between different devices can be draw. A $\mathrm{P}_{\text {norm }}$ of $33 \%$ is reached in unpackaged epitaxial PZT harvesters, which is five times higher than the unpackaged AIN harvester. Thus epitaxial PZT thin films are proven to be a promising materials in the field of vibration energy harvesting. 


\subsection{References}

S. Roundy, E. S. Leland, J. Baker, E. Carleton, E. K. Reilly, E. Lai, B. Otis, J. M. Radaey, and K Wright, IEEE Communications Society and IEEE ComSoc, 28 (2005).

R. J. M. Vullers, R. van Schaijk, I. Doms, C. Van Hoof, and R. Mertens, Solid-State Electronics 53 (7), 684 (2009).

Steven R. Anton and Henry A. Sodano, Smart Materials and Structures 16 (3), R1 (2007).

P. Muralt, R. G. Polcawich, and S. Trolier-Mckinstry, MRS Bulletin 34, 658 (2009).

M. Renaud, K. Karakaya, T. Sterken, P. Fiorini, C. Van Hoof, and R. Puers, Sensors and Actuators A: Physical 145-146, 380 (2008).

R. Elfrink, T. M. Kamel, M. Goedbloed, S. Matova, D. Hohlfeld, Y. van Andel, and R. van Schaijk, Journal of Micromechanics and Microengineering 19 (9), 094005 (2009).

A.M. Flynn, L.S. Tavrow, S. F. Bart, and R. A. Brooks, AIM-1269, 20 (1991).

Jacek Baborowski, Journal of Electroceramics 12, 33 (2004).

J. E. A. southin, S. A. Wilson, D. Schmitt, and R.W. Whatmore, Journal of Physics D: Applied Physics 34, 1456 (2001).

Klaus; Muralt Prume, Paul; Schmitz-Kempen, Thorsten; Tiedke, Stephan, Proceedings of SPIE 6526 (65260G) (2007).

K. Karakaya, M. Renaud, M. Goedbloed, and R. Van Schaijk, Journal of Micromechanics and Microengineering (2008).

S. Trolier-McKinstry and P. Muralt, Journal of Electroceramics 12, 7 (2004).

Y. Hu, Y. Zhang, C. Xu, L. Lin, R. L. Snyder, and Z. L. Wang, Nano Letters 11 (6), 2572 (2011).

S. H. Baek, J. Park, D. M. Kim, V. A. Aksyuk, R. R. Das, S. D. Bu, D. A. Felker, J. Lettieri, V. Vaithyanathan, S. S. Bharadwaja, N. BassiriGharb, Y. B. Chen, H. P. Sun, C. M. Folkman, H. W. Jang, D. J. Kreft, S. K. Streiffer, R. Ramesh, X. Q. Pan, S. Trolier-McKinstry, D. G. 
Schlom, M. S. Rzchowski, R. H. Blick, and C. B. Eom, Science 334 (6058), 958 (2011).

A. Lei, R. Xu, A. Thyssen, A. C. Stoor, T. L. Christiansen, K. Hansen, E. V. Thomsen, and K. Birkelund, MEMS 2011 January (2011).

R. Elfrink, M. Renaud, T. M. Kamel, C. de Nooijer, M. Jambunathan, M. Goedbloed, D. Hohlfeld, S. Matova, V. Pop, L. Caballero, and R. van Schaijk, Journal of Micromechanics and Microengineering 20 (10), 104001 (2010).

Robert Andosca, T. Gus McDonald, Vincent Genova, Steven Rosenberg, Joseph Keating, Cole Benedixen, and Junru Wu, Sensors and Actuators A: Physical 178, 76 (2012).

M. Renaud, Katholieke Universiteit Leuven, 2009.

Minh D. Nguyen, Matthijn Dekkers, Evert Houwman, Ruud Steenwelle, Xin Wan, Andreas Roelofs, Thorsten Schmitz-Kempen, and Guus Rijnders, Applied Physics Letters 99 (25), 252904 (2011).

Matthijn Dekkers, Minh D. Nguyen, Ruud Steenwelle, Paul M. te Riele, Dave H. A. Blank, and Guus Rijnders, Applied Physics Letters 95 (1), 012902 (2009).

Henry A. Sodano, D. J. Inman, and G. Park, Strain Journal 40 (2) (2004).

Y. C. Shu and I. C. Lien, Journal of Micromechanics and Microengineering 16 (11), 2429 (2006).

Maxim I. Morozov and Dragan Damjanovic, Journal of Applied Physics 104 (3), 034107 (2008).

V. Kukhar, N. Pertsev, H. Kohlstedt, and R. Waser, Physical Review B 73 (21) (2006). 
Chapter 1

Page $\mid 8$ 


\section{Chapter 2}

\section{PiezoMEMS--from principle to device}

\section{Abstract}

In this chapter, the state of the art of piezo-microelectromechanical systems (piezoMEMS) is discussed. The theory to bring the ferroelectricity and piezoelectricity to a real device is given. A model of energy vibration harvesting devices with their potential application in industry is described in detail. Furthermore, the techniques for device fabrication and characterization are discussed. All the epitaxial films are fabricated by pulsed laser deposition. The principles of the structural and compositional analysis is mentioned, and the electrical and mechanical analysis technique are described. With a thorough understanding of piezoMEMS devices, from the physical principles up to devices fabrications, systematic framework is built up in this thesis. 


\subsection{Introduction}

In the last decade, a large effort in the technology for renewable power supplies has been taken place. Many of these devices rely on a compact, low-cost and lightweight energy source, which enables the desired portability and energy autonomy $^{1,2}$. To decrease in size and cost compared to electrochemical batteries and to lengthen the lifetime of portable electronic devices, more environmental friendly power supply devices are needed. The main concept of these kinds of devices is to gain electrical energy from the ambient energy surrounding. The range of the power output of a harvesting device is a typical value used in wireless sensor nodes. There are many energy sources from ambient we can harvest, for example, vibration energy, thermal energy, light or RF radiation ${ }^{3}$. Table 2.1 gives the output power that could be obtained from environmental sources when using optimized devices built with the currently available transducer technology. Different ambient situations are considered for different energy sources. They correspond to various levels of source power, as well as the harvesting power. From table 2.1, it is seen that a relatively large energy output can be expected from the outdoor light source. However, the harvesting power of indoor light, vibration, and thermal energy is in the same range. In the industrial environment and transport sectors, we have this free vibration to spare. It would be interesting if we can harvest this energy and convert it to useful electric power.

One way to harvest mechanical vibration energy is to use MEMS devices in which a piezoelectric material can transform the mechanical energy into electrical energy ${ }^{4}$. We chose $\mathrm{PbZr}_{\mathrm{x}} \mathrm{Ti}_{(1-\mathrm{x})} \mathrm{O}_{3}(\mathrm{PZT})$ piezoelectric materials in this study, because of its good piezoelectric properties. After fabrication, PZT thin films can be integrated on a silicon on insulator (SOI) wafer, sandwiched between top and bottom electrodes. A robust and freestanding piezoMEMS device is drawing a lot of interest. Moreover, epitaxial thin films show unique behavior from the materials science point of view. To apply the epitaxial thin 
films into a real piezoMEMS device will build a milestone in semiconductor industry.

\begin{tabular}{|l|l|l|}
\hline \multicolumn{2}{|l|}{ Source } & Harvested power \\
\hline \multirow{2}{*}{ Light } & Indoor & $10 \mu \mathrm{W} / \mathrm{cm}^{2}$ \\
\cline { 2 - 3 } & Outdoor & $10 \mathrm{~mW} / \mathrm{cm}^{2}$ \\
\hline Vibration/motion & Human & $4 \mu \mathrm{W} / \mathrm{cm}^{2}$ \\
\cline { 2 - 3 } & Industrial & $100 \mu \mathrm{W} / \mathrm{cm}^{2}$ \\
\hline \multirow{2}{*}{ Thermal energy } & Human & $30 \mu \mathrm{W} / \mathrm{cm}^{2}$ \\
\cline { 2 - 3 } & Industrial & $1-10 \mu \mathrm{W} / \mathrm{cm}^{2}$ \\
\hline RF & Cell phone & $0.1 \mu \mathrm{W} / \mathrm{cm}^{2}$ \\
\hline
\end{tabular}

Table 2.1 Overview of all the harvesting source in ambient, and their electric harvested power ${ }^{3}$.

In spite of lots of advancements, the research focused on piezoelectric MEMS devices based on epitaxial PZT thin films is rarely reported. Reilly et al. first reported on vibrational energy harvesters based on epitaxial thin films grown by pulsed laser deposition ${ }^{5}$. However the power of their epitaxial devices was significantly reduced due to the degradation in the epitaxial PZT film during the fabrication process. Their devices were fabricated on chip-scale silicon substrates. Nguyen et al. successfully demonstrated epitaxial PZT cantilevers with conductive oxide SRO electrodes, achieving long-term stability and reliability of the devices with small cantilever sizes ${ }^{6}$. Recently, Morimoto et al. designed and fabricated energy harvester composed of epitaxial PZT films transferred onto stainless steel cantilevers to enhance output power efficiency and to improve structural toughness ${ }^{7}$. However, the fabrication throughput, reproducibility and device miniaturization seem to be limited; and the epitaxial PZT films were not directly grown on silicon substrates, but on $\mathrm{MgO}$ substrates. 
From all these overviews, we conclude that there are still challenges to realize the epitaxial piezoMEMS devices, such as, control of the thin film quality, enhancement of the power output by optimizing the piezoelectric material, complexity of the fabrication, and how to scale up the process, increasing the yield and diminishing the cost, etc.

The aim of this chapter is to give a general overview about piezoMEMS from theoretical background to application aspects. The first part of this chapter is dedicated to the state of the art in energy harvesting and piezoMEMS. Both challenges and expectations are mentioned. In section 2.2, more details about piezoelectric materials for energy harvesting piezoMEMS device are presented. Section 2.2.1 discusses the general background of ferroelectricity and piezoelectricity. In section 2.2.2, the theory of piezoMEMS is studied. Different harvesting models are discussed. Section 2.2.3 talks about the unique behavior of epitaxial thin film and the strain theory. And some applications will be mentioned in 2.2.4. The pulsed laser deposition (PLD) technique used for growing epitaxial oxide thin films will be addressed in section 2.3 , followed by an overview of all the analytical tools used in characterization in section 2.4.

\subsection{Piezoelectric materials for energy harvester}

\subsubsection{Ferroelectricity and piezoelectricity}

Ferroelectricity refers to a property of certain materials, which have a spontaneous polarization that can be reversed by applying an external electric field $^{8,9,10}$. Also, ferroelectric materials undergo a structural phase transition from a paraelectric phase to a ferroelectric phase upon cooling through the Curie temperature $\left(T_{C}\right)$. Above $T_{C}$, the crystal has a centrosymmetric structure and has no spontaneous polarization. Below $T_{C}$, the crystal shows ferroelectricity properties and the crystal structure undergoes a change in the symmetry of the unit cell and becomes non-centrosymmetric. When the ferroelectric perovskite 
unit cell is cooled below $T_{C}$, the central ion in the unit cell within the oxygen octahedral moves from its equilibrium position, while a spontaneous polarization is created. Consequently, a perovskite ferroelectric material transforms from a paraelectric centrosymmetric structure into a ferroelectric non-centrosymmetric structure $^{11,12}$. For PZT, it will be either tetragonal or rhombohedral. Below the phase transition temperature, there are at least two directions along which the spontaneous polarization can exist in a stable state. The spontaneous polarization in PZT, lies along $<100>$ directions in the tetragonal phase and along $<111>$ directions in the rhombohedral phase. Figure 2.1 shows the phase diagram and the direction of spontaneous polarization in different ferroelectric phases. The arrow indicates the direction of spontaneous polarization in different phases. The boundary between tetragonal and rhombohedral structures is called the morphtropic phase boundary (MPB) ${ }^{13}$. Generally, in PZT materials, both piezoelectric and dielectric properties enhanced in the MPB region, because of the easy rotations in polarization directions ${ }^{14,15}$.

Typically in a ferroelectric crystal, the spontaneous polarization is not uniformly aligned along the same direction. The directions along which the polarization will develop depend on the electrical and mechanical boundary conditions imposed on the sample. The regions of the crystal with uniformly oriented spontaneous polarization are called ferroelectric domains. The region between two domains is called the domain wall. Depending on the different orientations of polarization in the neighborly domains, different types of domains are observed, such as $180^{\circ}$ domain walls and $90^{\circ}$ domain walls in the tetragonal phase . 


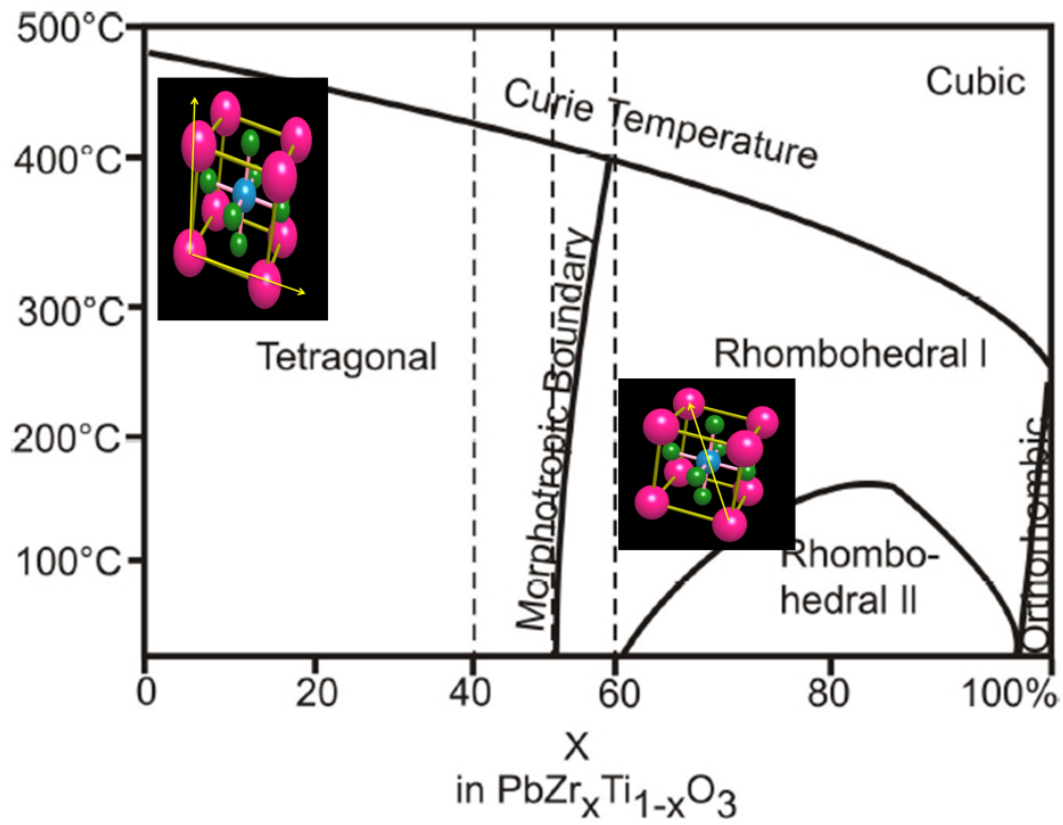

Figure 2.1 Phase diagram of ferroelectric PZT thin film with both rhombohedral phase and tetragonal phase. The arrow indicates the directions of spontaneous polarization in different phases.

(a)

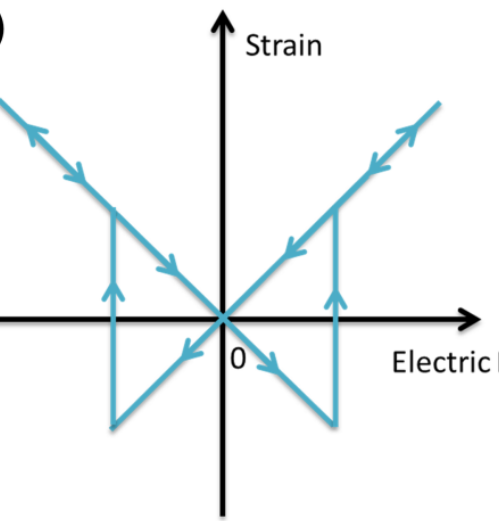

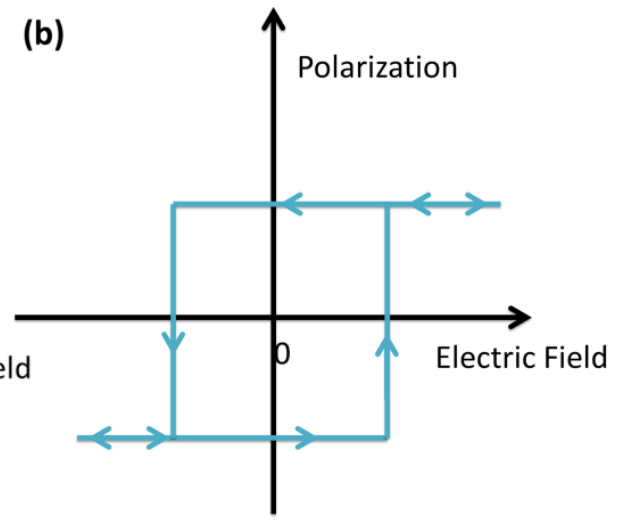

(b)

Figure 2.2 Strain-electric field hysteresis loops and polarization-electric field hysteresis loop in ideal ferroelectric materials. 
The interplay between ferroelectricity and piezoelectricity under varying boundary conditions is generally well described by Landau-GinzburgDevonshire theory ${ }^{16,17}$. The most important property of ferroelectric materials is the polarization hysteresis loop, which shows that the polarization can be reversed by an external electric field. Figure 2.2 (b) shows an ideal symmetrical hysteresis loop. Besides the polarization electric field hysteresis loop, the polarization switching in ferroelectric thin films will also lead to strain electric field hysteresis, see figure 2.2 (a). Piezoelectric materials can be polarized by applying a mechanical stress, and can change dimensions in response to an applied electric field. The piezoelectric effect is a linear coupling between electrical and mechanical properties. Piezoelectricity is defined in terms of the direct and converse piezoelectric effects. When stress is applied to a piezoelectric material, an electric polarization is induced.

Considering the converse piezoelectric effect, the strain is linearly proportional to the applied electric field when the piezoelectric coefficient is constant. When the electric field is parallel to the polarization, the strain increases as the electric field increases and the maximum strain occurs at the maximum electric field ${ }^{18}$. The loop clearly shows piezoelectric response as well as polarization switching under a bipolar electric field. In general, the sign of the strain depends on the relative directions of the polarization and the electric field. When the field and polarization are parallel, the lattice expands and the strain is positive. When the field and polarization directions are antiparallel, the lattice contracts and the strain is negative. A significant change in the strain occurs due to polarization switching. The electromechanical response is in general reversible. The piezoelectric coefficients are calculated from the slope of in the loop ${ }^{19,7}$.

\subsubsection{PiezoMEMS in theory}

There has been much interest in the piezoelectric properties of the epitaxial ferroelectric thin films, because of their high piezoelectric coefficients as compared to the poly crystalline and amorphous films. Depending on the application, different device geometries are used, such as cantilevers and 
membranes ${ }^{20}$. The cantilever type of structures with a free standing beam can be used in AFM, biosensors, energy harvesting device, etc ${ }^{20,21,22}$. The membrane structure can be used in, for example, micropumps and pressure sensors. Typically, piezoMEMS structures refer to piezoelectric materials sandwiched between two electrodes, integrated with SOI wafers, which is compatible with the MEMS fabrication processes. During the mechanical bending of the beam area, a large strain is generated by piezoelectric thin films. Currently, most of the designs of piezoMEMS devices are based on polycrystalline PZT thin films, which allow the operations in either longitudinal piezoelectric mode or transverse piezoelectric mode. The longitudinal piezoelectric mode is also called 33 mode. And the transverse piezoelectric mode is called 31 mode. In the 31 mode, a force is applied in the direction perpendicular to the poling direction, an example of which is a bending beam that is poled on its top and bottom surfaces. In the 33 mode, a force is applied in the same direction as the poling direction, such as the compression of a piezoelectric block that is poled on its top and bottom surfaces. An illustration of each mode is presented in figure 2.3. In tetragonal materials, there is a third coefficient, the shear piezoelectric coefficient $\left(\mathrm{d}_{15}\right)$, which is the shear strain developed when an electric field is applied parallel to the plane of the surface.

In ferroelectric thin films, piezoelectric coefficients in directions 31 or 33 to the film surface are measured while an electric field is applied along the film thickness directions. Baker et al. did some studies by comparing a piezoelectric stack operating in the 33 mode with a cantilever beam operating in the 31 mode of equal volumes, and it was shown that, the stack (33 mode) was more robust and had a higher coupling coefficient than the cantilever. However, the cantilever (31 mode) produced two orders of magnitude more power under the same vibration input. Therefore, it was concluded that in a small force, low vibration level applications, the 31 configuration cantilever proved to be most efficient. In this work, we will also focus on the 31 cantilever mode devices. 


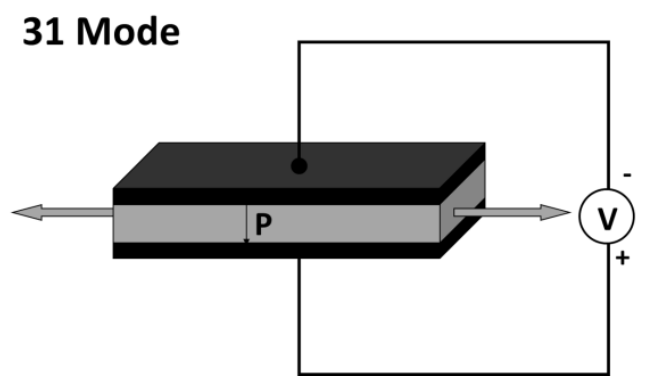

33 Mode

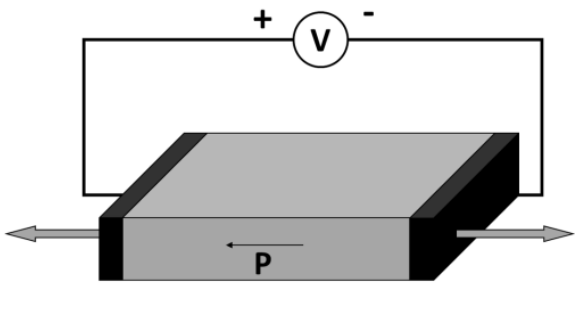

Figure 2.3 Different operation modes in piezoMEMS structures.

\subsubsection{Strain in epitaxial thin films}

PiezoMEMS devices based on epitaxial PZT thin films is under investigated, because of their excellent properties, well controlled growth, high yield and high reliability. It is well known that the physical properties of epitaxial thin films can be substantially different from those of bulk and non-epitaxial films. The interaction between the substrates and the films will play a role. Different strain and stress conditions in epitaxial thin films lead to different mechanical, crystallographic, ferroelectric domain, electrical behaviors, as well as the position of the MPB. All these properties are crucial for the device performance from the application point of view. Therefore further study is needed to improve the film growth and quality, in order to optimize their properties. Different buffer layers can be applied to seek for the best quality of epitaxial PZT thin films ${ }^{23}$.

Here, the epitaxial PZT thin films were grown at $600^{\circ} \mathrm{C}$ in the cubic phase. Epitaxial strain is created in the substrate and film interface due to the lattice mismatch between the substrates and the films at the deposition temperature ${ }^{24}$. The strain is relaxed by defects when the films grow thicker than $100 \mathrm{~nm}$. Afterwards, the film is cooled down to room temperature. Because of the difference in thermal expansion coefficients between the film materials and the substrate materials, thermal strain will be generated. Since the thin films are clamped firmly by the substrates, a clamping effect will limit in-plane 
deformations ${ }^{25,26}$. All these unique behaviors in strain and relaxation make epitaxial thin films more interested for device applications.

\subsubsection{Focused application}

Nowadays, wireless autonomous sensors receive more and more attention and become widely used because they are small, cheap and deliver long lasting power without recharge. This kind of self-powered technology makes the periodic battery replacement obsolete. It is therefore attractive for portable or inaccessible devices. Generally speaking, this kind of energy scavenging devices can be used in lots of industrial applications, for example, remote monitor, home automation, implantable sensors, long range tracking, etc. In particular, depending on different resonant frequency and power output, various applications were studied ${ }^{27,3}$.

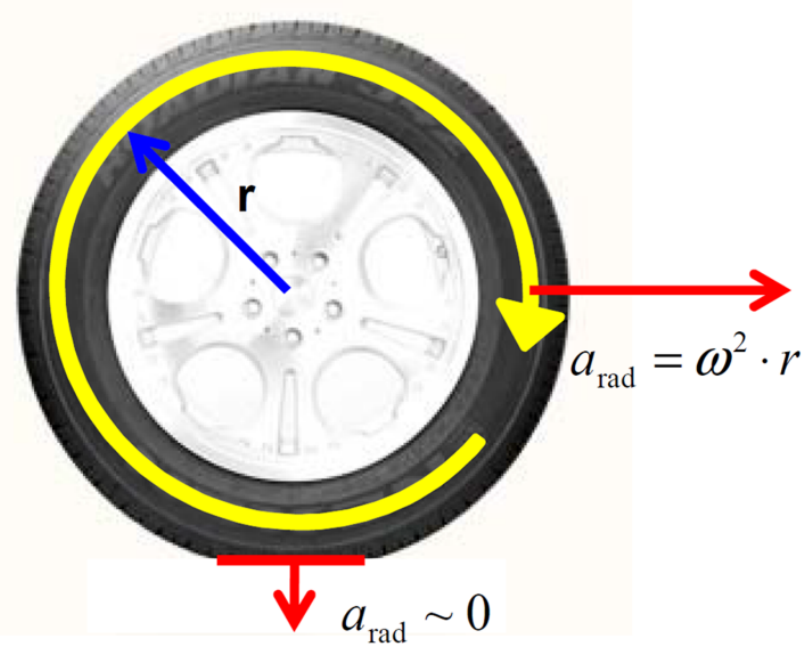

Figure 2.4. A high amplitude shock is generated when the tire contacts road. Every points on a rotation tire have acceleration $\left(a_{\text {rad }}\right) . \omega$ is the angular velocity and $r$ is the vector directed from the centre of the circle ${ }^{28}$.

For our energy harvesting devices, we focus on the application of tire pressure sensors, which will harvest the vibrational energy inside tires. From the previous Page $\mid 18$ 
section, we discussed integration in a piezoMEMS configuration. After growing piezoMEMS structure, different fabrication and packaging steps can be applied. These piezoMEMS structure are integrated in a free standing energy scavenging device. Elfrink et al. reported on AlN-based vibration energy harvesting device for car tire applications by both measurements and simulations ${ }^{28,}{ }^{29}$. By comparing the characterization results of sinusoidal vibration and shock excitation measurements, they report devices with good sensitivity and high power output.

Tire rotation time $\mathrm{T}$ [ms]

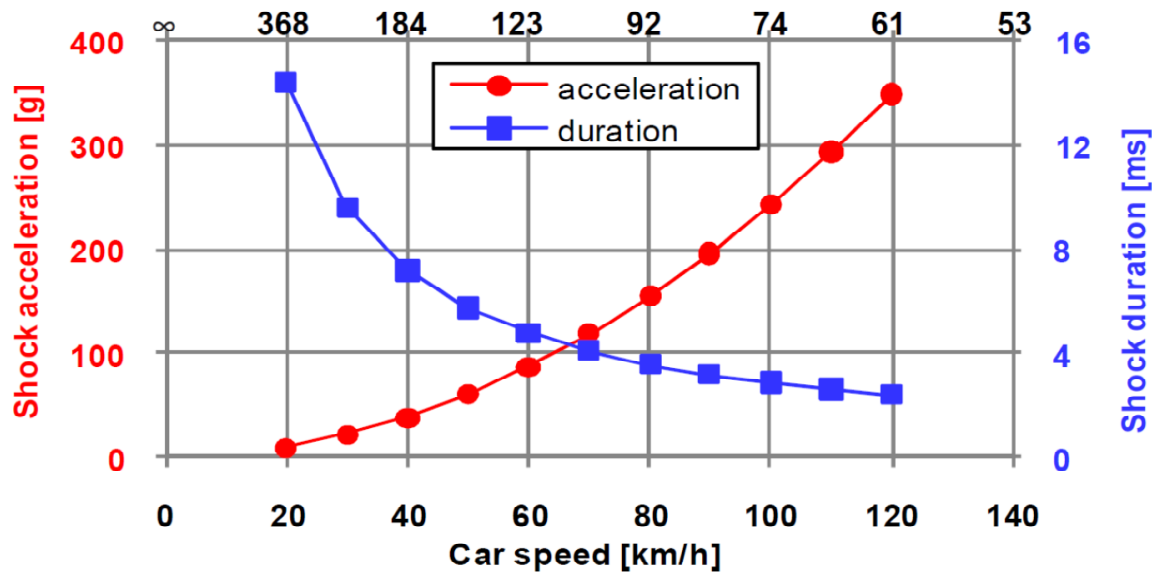

Figure 2.5 The shock amplitude, duration and tire rotation plots as a function of car speed variation ${ }^{28}$.

The general operation principle of a vibration energy harvester is based on the amplification of a sinusoidal input vibration by its quality factor $Q$ at its resonance frequency $f_{\text {res }}$. During the occurrence of vibration, the mechanical energy of the resonating mass is converted into electrical energy by the piezoMEMS structure . A high quality factor $\mathrm{Q}$ is essential in order to generate a high output power at a relatively low input vibration energy. Some device testing has been done at the laboratory level, where frequency and amplitude of the sinusoidal inputs can be very well controlled, and provide a good method for comparing different devices. In the case of shock in a car tire, we can expect 
every point on a rotating car tire has a radial acceleration $\mathrm{a}_{\text {rad }}$. The acceleration is proportional to the square of the car velocity, see figure 2.4. The amplitude can be a few hundred $g$ at high car velocities, see figure 5. For the area where the tire is in contact with underground, the contact patch, $a_{\mathrm{rad}}$ is small for a duration inversely proportional with the car velocity. Their results show shock duration is in the millisecond range. From figure 2.5, we know what kinds of acceleration we can expect during the driving, in order to calculate the real power output in applications.

\subsection{Thin film growth and characterization}

\subsubsection{Principle of pulsed laser deposition technique}

Pulsed laser deposition is a physical vapor deposition technique that uses a high energy laser beam to ablate material from target which is subsequently transferred to a substrate. When the laser beam hits the target, a dense plasma of material is formed. Due to the high pressure inside the plasma, it expands away from the target and forms a plume. After placing a substrate inside or near the plume, part of the ablation species will form a thin film on the substrate surface. Many parameters such as the absorption coefficient and reflectivity of the target material, the pulse duration, wavelength and energy of the laser beam influence the characteristics of the plume and thus the properties of the deposited film. The processes in the plume during transport are influenced by the parameters of background gas. In order to have a high quality thin film, it is important to control the kinetic energy of the arriving particles and the substrates temperature. In this way, thin film growth can be manipulated ${ }^{30,31}$.

In the PLD setup, the laser we use is a pulsed excimer $\mathrm{KrF}$ laser with wavelength of $248 \mathrm{~nm}$. The maximum energy per pulse is $1000 \mathrm{~mJ}$ and the duration of the laser pulse is about $25 \mathrm{~ns}$. The pressure in the vacuum system during deposition is controlled by an effective pump speed and the total gas

Page $\mid 20$ 
mass flow $(0-40 \mathrm{ml} / \mathrm{min})$. For the background gas, both inert gas (Ar) and reactive gases $\left(\mathrm{O}_{2}\right)$ can be used. The amount of material ablated from the target surface is determined by the energy density and the spot size of the laser. The laser beam is focused onto the target using a lens with a focal length $\sim 453 \mathrm{~mm}$. The target holder can hold up to 3 targets.

\subsubsection{Growth conditions of the thin films}

From the device integration point of view, silicon is becoming a very promising substrate materials due to its compatibility with industrial standards and relatively low cost. In this project, both (001) silicon and SOI wafer were chosen as substrates to stabilized epitaxial PZT film with different orientations and different compositions. Si substrates were cleaned by acetone and isopropyl alcohol instead of HF solution. In this case, a more ordered surface with a couple of monolayer native oxide is presented on the substrate, which will benefit the coherent growth of yttria-stabilized zirconia (YSZ) buffered layer. After optimizing the growth conditions with the silicon substrate, the growth process is transferred to the SOI wafer .

By using PLD technique, thin films of PZT were grown on (001) silicon substrates. Sintered ceramic targets with different $\mathrm{Zr} / \mathrm{Ti}$ ratios were used to investigate the optimal piezoelectric properties. $\mathrm{SrRuO}_{3}(\mathrm{SRO})$ was chosen as an electrode material because of its high electrical conductivity and its perovskite structure with lattice parameters close to the PZT materials. Moreover, to overcome the large mismatch between SRO and the Si substrate, $\mathrm{YSZ}$ and $\mathrm{CeO}_{2}$ were used as a first and second buffer layer ${ }^{32}$. YSZ grows epitaxial on silicon and will scavenge the native oxide on silicon surface. This allows reproducible coherent growth on non-HF dipped Si substrates ${ }^{33}$. The deposition parameters are shown in table 2.2. By selecting the growth conditions of the first $4 \AA$ of the bottom electrode, both (001) and (110) orientated SRO films can be obtained, which is verified via X-ray diffraction (XRD) measurements. For the growth of SRO and PZT film, a typical target to substrate distance between 50 to $60 \mathrm{~mm}$ and $0.1-0.13$ mbar process pressures were used. The fluence is very crucial for 
SRO films, since too low fluence will result in many particles on the film ${ }^{34}$, which will induce additional leakage in the capacitor device.

\begin{tabular}{|l|l|l|l|l|l|}
\hline Parameters & $\mathrm{YSZ}$ & $\mathrm{CeO}_{2}$ & $\mathrm{Pt}$ & $\mathrm{SrRuO}_{3}$ & $\mathrm{PZT}$ \\
\hline $\begin{array}{l}\text { Deposition } \\
\text { temperature }\left({ }^{\circ} \mathrm{C}\right)\end{array}$ & 800 & 800 & $\mathrm{RT}$ & 600 & 600 \\
\hline $\begin{array}{l}\text { Process pressure } \\
(\mathrm{mbar})\end{array}$ & $\begin{array}{l}\mathrm{P}_{\mathrm{Ar}}=0.02 / \\
\mathrm{P}_{\mathrm{O} 2}=0.02\end{array}$ & $\mathrm{P}_{\mathrm{O} 2}=0.02$ & $\mathrm{P}_{\mathrm{Ar}}=0.01$ & $\mathrm{P}_{\mathrm{O} 2}=0.13$ & $\mathrm{P}_{\mathrm{O} 2}=0.13$ \\
\hline $\begin{array}{l}\text { Target-substrate } \\
\text { distance }(\mathrm{mm})\end{array}$ & 58 & 58 & 48 & 54 & 58 \\
\hline Spot size $\left(\mathrm{mm}^{2}\right)$ & 3.35 & 3 & 2 & 3 & 3 \\
\hline Fluency $\left(\mathrm{J} / \mathrm{cm}^{2}\right)$ & 2.1 & 2.1 & 5 & 2.5 & 2.5 \\
\hline Mask $\left(\mathrm{mm}{ }^{2}\right)$ & $98(7$ holes $)$ & $98(7$ holes $)$ & 102 & 92.5 & 92.5 \\
\hline Frequency $(\mathrm{Hz})$ & 7 & 7 & 20 & 4 & 10 \\
\hline Time $($ Seconds) & $32 / 148$ & 180 & 500 & 900 & 3600 \\
\hline Thickness $(\mathrm{nm})$ & 20 & 20 & 100 & 100 & 1000 \\
\hline
\end{tabular}

Table 2.2 Table of deposition parameters for different layers

\subsection{Thin film characterization}

\subsubsection{Structural characterization}

Scanning Electron Microscopy (SEM) is used to determine the thin films structure. SEM is a kind of electron microscope to image the sample surface by scanning with a high energy electron beam. During measurement, the electrons interact with electrons in the sample, which produce a secondary electron signals that can be detected and distinguished. Information on the sample surface topography and composition can be obtained. Film growth and film thickness analysis can also be performed using cross section SEM. The SEM work in this thesis was done on a Zeiss-1550 HRSEM, operated between 0.2 and $30 \mathrm{kV}$. 
The crystal structure of PZT thin films was analyzed by X-ray diffraction (XRD) measurements. The measurements were performed on either Bruker D8 Discover or PANalytical X'Pert diffractometer, using $\mathrm{Cu} \mathrm{K \alpha 1}$ radiation. The films and substrates were analyzed using $\theta-2 \theta$ scans, rocking curve scans and reciprocal space map, to determine the crystal structure, roughness, growth orientations domain structure and lattice tilting. Using a reciprocal space map (HL scan and HK scan), the in-plane and out-of-plane lattice parameters, and the domain tilt can be determined. More details about reciprocal space measurement results will be discussed in Chapter 3 .

\subsubsection{Basic principles of reciprocal space mapping}

Reciprocal space refers to a space in which the Fourier transform of a wave function is represented ${ }^{35}$. Before talking about reciprocal space, we first go back to the basic and essential formula, Bragg's law,

$$
n \lambda=2 d \sin \theta
$$

Where $\mathrm{n}$ is an integer, $\lambda$ is the wavelength of the incident wave, $\mathrm{d}$ is the spacing between the equivalent lattice planes, and $\theta$ is the angle between the incident beam and the scattering planes. When using the Bragg's law, we consider diffraction in terms of the crystallographic planes $h \mathrm{kl}$. Moreover, the vector $\vec{H}_{h k l}$ perpendicular to the planes $h k l$ is introduced to define the orientation of the plane, as shown in figure 2.6. $\vec{b}_{1}, \vec{b}_{2}$ and $\vec{b}_{3}$ are the reciprocal vectors of the real space lattice vector $\vec{a}_{1}, \vec{a}_{2}$ and $\vec{a}_{3}$. Since $\mathrm{H}_{h k l}$ is perpendicular to the $h k l$ planes, the $\mathrm{d}$ spacing can be written as

$$
d_{h k l}=\frac{1}{\left|\vec{H}_{h k l}\right|}
$$

When all the $\vec{H}_{\text {hkl }}$ vectors are drawn for all values of the indices $h k l$, the terminal points form a new lattice. This lattice is called the reciprocal lattice. And the reciprocal lattice of a reciprocal lattice is the original real space lattice. 
Bragg's law can also be expressed by using the vector $\vec{H}_{h k l}$. As shown in figure 2.6, if $\vec{k}_{0}$ and $\vec{k}$ are the unit vectors in the directions of the primary and diffracted beams, angle $\theta$ is the angle between the diffraction planes and vector $\vec{k}_{0}$. Then the relation between vector $\vec{k}$ and vector $\vec{H}_{h k l}$ is,

$$
\frac{\vec{k}-\vec{k}_{0}}{\lambda}=\vec{H}_{h k l}
$$

When we take into account angle $\theta$,

$$
\left|\frac{\vec{k}-\vec{k}_{0}}{\lambda}\right|=\frac{2 \sin \theta}{\lambda}
$$

In this case, the equation becomes,

$$
\left|\vec{H}_{h k l}\right|=\frac{1}{d_{h k l}}=\frac{2 \sin \theta}{\lambda}
$$

which is equivalent to the Bragg's law. Figure 2.6 is a simple graphical, which tells us that by satisfying Bragg's law, one obtains the reciprocal lattice. And the reciprocal lattices turn out to be extremely useful in the analysis of crystal diffraction studies.

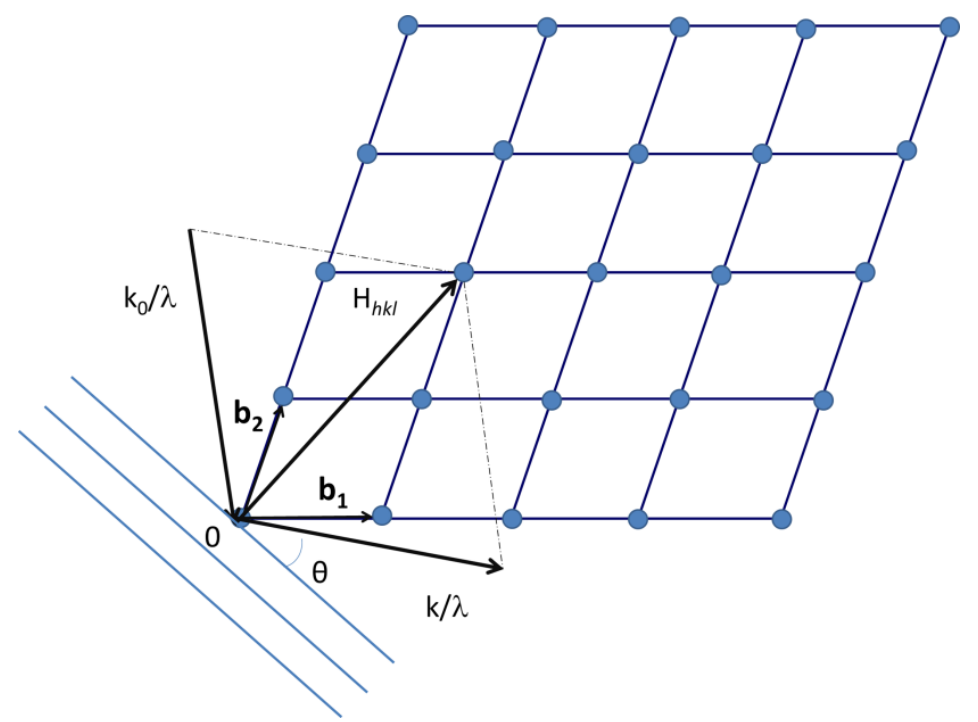

Figure 2.6 Reciprocal lattice representation of the Bragg's law. 


\subsubsection{Ewald sphere}

As we shown in the previous section, the reciprocal lattice provides a simple graphical representation of the satisfying the Bragg's law. Another powerful and useful way to satisfy Bragg's law is the Ewald sphere construction.

The reciprocal lattice is represented schematically in two dimensions, see figure 2.7 (a). The direction of the primary beam is shown. A vector of length $1 / \lambda$ terminates on the origin of the reciprocal lattice. A sphere of radius $1 / \lambda$ centered on the original crystal. For a diffraction point in reciprocal space to be in diffraction condition, it must lie on the surface of the Ewald sphere. The calculations of Bragg's law in the sphere reflection is in the same condition as the reciprocal lattice point $h k l$, which falls on the surface of the sphere. Even though this schematic drawing is in two dimensions, the Ewald sphere is valid in three dimensions.

Here, we should also notice that not all the $h k l$ planes can be visible in XRD. It depends on how much the crystal can rotate in order to reach that diffraction plane. For thick samples, absorption of either the incident beam or the diffracted beam will restrict access to the reflection geometry in reciprocal space. The forbidden areas are shown in $(0 \mathrm{kl})$ plane, see figure $2.7(\mathrm{~b})$, where each red cross corresponds to a crystal plane. During the measurements, different values in the reciprocal lattice can be chosen, which define different reflection planes. For an ideal perfect epitaxial thin film, a single spot can be expected in reciprocal space mapping, which corresponds to a sharp peak in a one dimensional theta2theta scan. If the epitaxial films contains some defects, an elongated spot can be expected in the reciprocal space map. This is different with a textured film. In a textured film, the out of plane is aligned, while the in plane orientation is random. Thus a parts of a circle can be expected in two dimensional reciprocal map, while no peak will be shown in phi scan. Phi angle is the in-plane rotation angle, more details about phi scan, see figure 3.7. If the sample is a randomly 
orientated polycrystalline, a full range of circle ring will be detected in 2 dimensional reciprocal space.

(a)

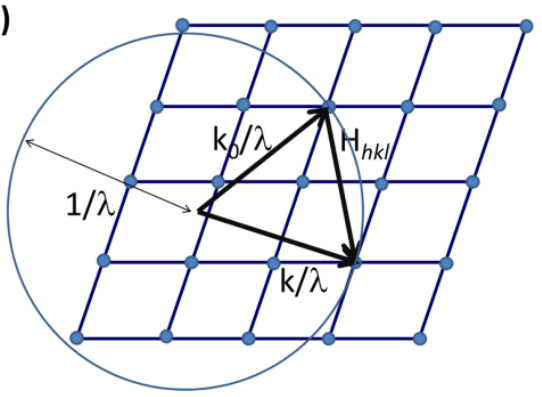

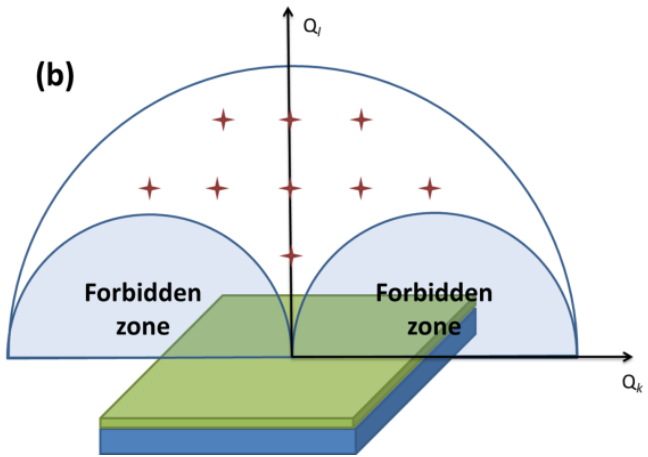

Figure 2.7 Schematic drawing of 2 dimensional (a) Ewald sphere, (b) reciprocal lattice mapping with the forbidden areas.

\subsubsection{Compositional characterization}

The compositional analysis of doped PZT thin films was done by either X-ray fluorescence (XRF) spectroscopy and/or energy-dispersive X-ray (EDS) spectroscopy to study the ratio of elements composition.

\section{Photoelectron}

\section{Electron}

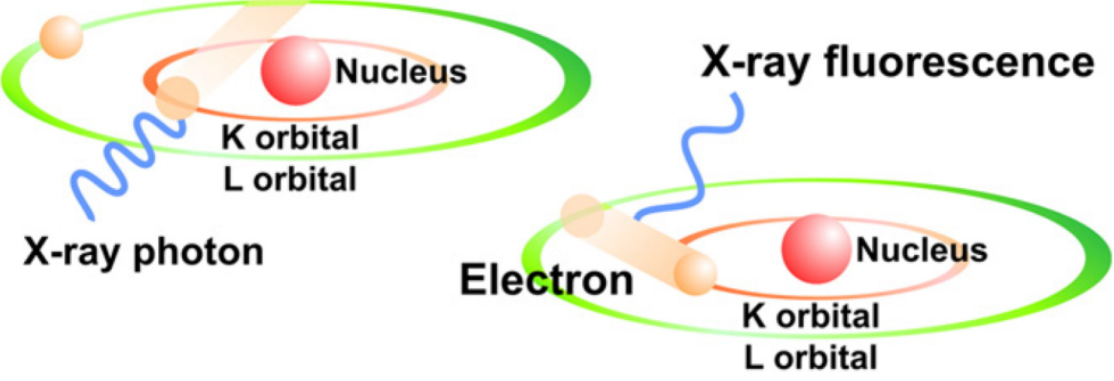

Figure 2.8 Principle of X-ray fluorescence spectroscopy ${ }^{36}$. 
$\mathrm{XRF}$ is a widely used technique for the analysis of materials. When a specimen is irradiated with high energy X-ray photons, particles such as X-ray photons and electrons with sufficient energy are ejected from the atoms. In this case, a hole in the shell is created. By forming an extra hole, the atom becomes an unstable ion. In order to restore the ground state, the holes in inner shells are filled by transferring electrons from outer orbitals. Since outer shells have a higher energy than inner shells, such electron transitions are accompanied by energy emission in the form of secondary X-ray photons, which is referred to as fluorescence (Figure 2.8) ${ }^{36}$. The radiated energy of an electron depends on the shell it occupies (i.e. K, L, M-shells) and the atom to which it belongs. Therefore we get different emission spectra for different elements ${ }^{37,38}$. The intensity of each line in a fluorescence spectrum is related to the concentration of an element. Moreover, for a multilayer thin film specimen composed of more than one element, the results also depend on its configuration absorption and scattering effects within each layer, between layers and between layers and substrate.

Energy- dispersive X-ray spectroscopy (EDS) is another powerful analytical tool used for elemental analysis and chemical characterization. The results rely on the unique atomic structure of each element, which gives unique set of peaks on its X-ray spectrum. The principle of EDS is similar to XRF. The incident beam excites and electron in an inner shell ejecting it from the shell as well as creating an hole. Then an electron from an outer (higher) energy shell will fill this hole. The energy differences between higher-energy shell and the lower-energy shell will be measured in the form of X-ray by an energy dispersive spectrometer. Here the electron beam excitation can be used in scanning electron microscopy (SEM) and transmission electron microscopy (TEM). Within these techniques, both the surface and the cross-section of thin films can be analyzed.

\subsubsection{Electronic characterization}

The out-of-plane polarization vs. electric field P-E hysteresis loops are recorded using a wave function at a frequency of $10-2000 \mathrm{~Hz}$ and an amplitude of $\pm 200 \mathrm{kV} / \mathrm{cm}$. Both the P-E loop and the fatigue (switching cycles) measurements 
in this thesis are performed using the aixACCT Analyzer TF2000. During the testing, the built in leakage current is compensated in the system.

The dielectric constant $(\varepsilon)$, and the dielectric loss $(\tan \delta)$ were calculated from the capacitance, which is measured value of ferroelectric thin films between upperelectrode and lower electrode, using the formulas:

$$
\begin{aligned}
\varepsilon & =\frac{C d}{\varepsilon_{0} A} \\
\tan \delta & =\frac{G}{2 \pi f C}
\end{aligned}
$$

Here $C$ is the capacitance, $A$ is the area of the capacitor, $d$ is the film thickness, $\varepsilon_{0}\left(=8.854 \times 10^{-12} \mathrm{~F} / \mathrm{m}\right)$ is the dielectric constant in free space, $f$ is the frequency and $G$ is the conductance. The capacitance measurements are performed on a Süss Micro Tech PM 300 manual probe station equipment with a Keithley 4200 Semiconductor characterization system.

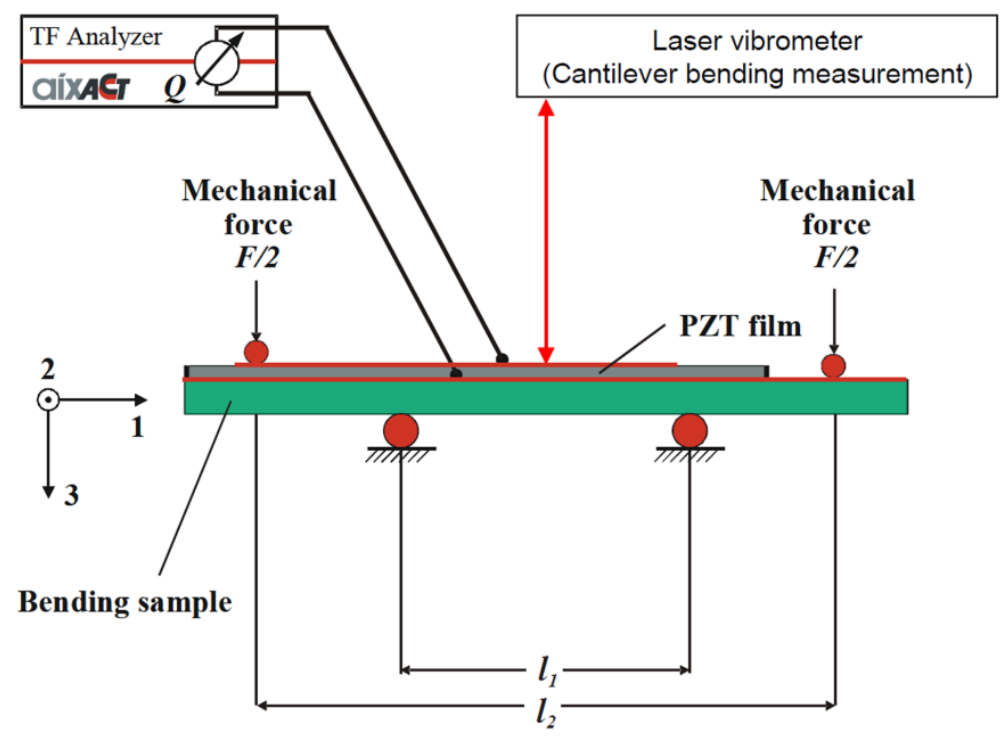

Figure 2.9 Schematic drawing of four point bender setup ${ }^{39}$. 


\subsubsection{Mechanical characterization}

In order to determine the piezoelectric coefficient of ferroelectric thin films in 31 mode $\left(\mathrm{e}_{31, \mathrm{f}}\right)$, a four-point bender set-up is used (aix 4PB, aixACCT). Figure 2.9 is the schematic drawing of the system itself. To perform the measurements, the sample needs to be fabricated in a desirable geometry $\left(3 \times 25 \mathrm{~mm}^{2}\right)$. The TF analyzer (TF 2000, aixACCT) is used as the main control unit. As shown in figure 2.9 , the four point bender system is connected to the TF analyzer, with a laser vibrometer as a bending detector. Four cylindrical supporters are placed on both sides of the sample, which can generate a pre-strain to the samples, by turning micro-manipulator up and down. Besides induced pre-strain, the two top cylindrical parts, presented as two contacts, will also measure the charge transfer from the top electrode to the bottom electrode. The bending of the sample is determined with a laser vibrometer system. The laser beam is reflecting of the back of the sample, and then goes back to the sensor by creating an interference pattern. When the sample bends, the interference pattern changes and this can be measured with high accuracy. In this way, the laser detector measures the bending of the sample, which is indicated by sample bending $\left(\mathrm{u}_{3, \text { cant }}\right)$. Afterwards, the piezoelectric coefficient $\left(\mathrm{e}_{31}\right)$ can be calculated using:

$$
\left|e_{31, f}\right|=\frac{Q l_{1}^{2}}{4 A h u_{3, \text { cant }}\left(1-v_{S i, f}\right)}
$$

Here $l_{1}$ is the fixed distance between two bottom cylindrical supports, $\mathrm{A}$ is the electrode area, $\mathrm{h}$ is the substrate thickness, and $v_{\mathrm{Si}, \mathrm{f}}$ is the Poisson coefficient of the silicon substrates. The charge $\mathrm{Q}$ and the bending $\mathrm{u}_{3 \text {,cant }}$ are measured by the system, and the $\mathrm{e}_{31, \mathrm{f}}$ value can be easily calculated.

The characterization of piezoelectric harvester device is performed on a shaker system, which is connected to a signal generator and amplifier, see figure 2.10. Here, the shaker system was used as a input vibration source. A digital 
multimeter (Agilent 34410A) is connected to measure the electrical output. When a harvester is placed on a vibration source, the harvester mass will vibrate with a certain amplitude, which will result in a stress in the piezo capacitor areas. In this case, a voltage is generated and measured. The power consumed in the load resistor can be calculated. The shaker is TIRAvib of type S522 with the signal amplifier of type BAA500, the signal generator is from Vibration Research Corporation type 8500.

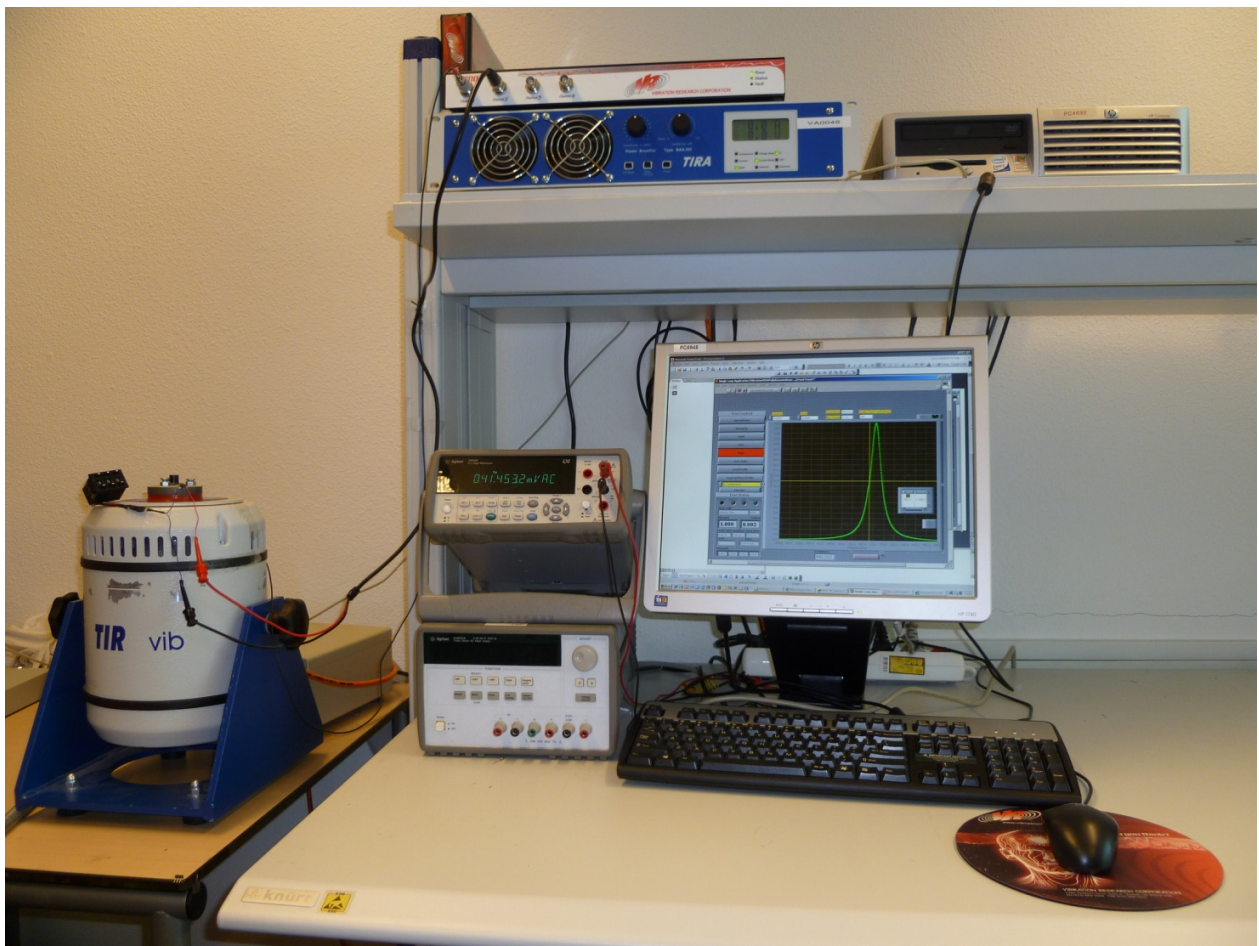

Figure 2.10 The measurement set up for energy harvesting devices. 


\subsection{References}

1 S. Roundy, P. K. Wright, and J. M. Rabaey, Energy scavenging for wireless sensor networks. (Kluwer Academic Publishers Group, 2004).

J. baker, S. Roundy, and P wright, Proceeding 3rd International Energy Conversion Engineering Conference, 959 (2005).

R. J. M. Vullers, R. van Schaijk, I. Doms, C. Van Hoof, and R. Mertens, Solid-State Electronics 53 (7), 684 (2009).

M. Renaud, Katholieke Universiteit Leuven, 2009.

P. D. Mitcheson, E. K. Reilly, T. Toh, P. K. Wright, and E. M. Yeatman, Journal of Micromechanics and Microengineering 17 (9), S211 (2007).

H. Nazeer, M. D. Nguyen, L. A. Woldering, L. Abelmann, G. Rijnders, and M. C. Elwenspoek, Journal of Micromechanics and Microengineering 21 (7), 074008 (2011).

Keiji Morimoto, Isaku Kanno, Kiyotaka Wasa, and Hidetoshi Kotera, Sensors and Actuators A: Physical 163 (1), 428 (2010).

W. Kanzig, Solid State Physics. 4. (1957).

M. E. Lines, A. Alastair, and A. Glass, Principles and applications of ferroelectrics and related materials. (1977).

J. Valasek, Physical Review 17 (4), 475 (1921).

K. M. Rabe, C. H. Ahn, and J. M. Triscone, physics of ferroelectrics. (2007).

E. T. Jaynes, Ferroelectricity. (1953).

3 B. Noheda, D.E. Cox, G. Shirane, J. A. Gonzalo, L. E. Cross, and S-E. Park, Applied Physics Letters 74 (14), 2059 (1999).

B. Noheda, J. A. Gonzalo, A.C. Caballero, C Moure, D.E. Cox, and G. Shirane, Ferroelectrics 237, 237 (2000).

B. Noheda, Current Opinion in Solid State\&Materials Science 6, 27 (2002).

V. Koukhar, N. Pertsev, and R. Waser, Physical Review B 64 (21) (2001).

A. N. Morozovska, E. A. Eliseev, S. L. Bravina, and S. V. Kalinin, Journal of Applied Physics 110 (5), 052011 (2011). 
Pierre-Eymeric Janolin, Journal of Materials Science 44 (19), 5025 (2009).
M. D. Nguyen, H. Nazeer, K. Karakaya, S. V. Pham, R. Steenwelle, M. Dekkers, L. Abelmann, D. H. A. Blank, and G. Rijnders, Journal of Micromechanics and Microengineering 20 (8), 085022 (2010).

Sangmin Jeon and Thomas Thundat, Applied Physics Letters 85 (6), 1083 (2004).

K. Karakaya, M. Renaud, M. Goedbloed, and R. Van Schaijk, Journal of Micromechanics and Microengineering (2008).

Yanjun Tang, Ji Fang, Xiaodong Yan, and Hai-Feng Ji, Sensors and Actuators B: Chemical 97 (1), 109 (2004).

Minh D. Nguyen, Matthijn Dekkers, Evert Houwman, Ruud Steenwelle, Xin Wan, Andreas Roelofs, Thorsten Schmitz-Kempen, and Guus Rijnders, Applied Physics Letters 99 (25), 252904 (2011).

D. Lee and T. W. Noh, Philosophical transactions. Series A, Mathematical, physical, and engineering sciences 370 (1977), 4944 (2012).

R. Steenwelle, E. Houwman, X. Wan, M. Dekkers, M. D. Nguyen, and G. Rijnders, (2013).

R. Steenwelle, University of Twente, 2012.

P. Muralt, R. G. Polcawich, and S. Trolier-Mckinstry, MRS Bulletin 34, 658 (2009).

R. Elfrink, S. Matova, C. De Nooijer, M. Jambunathan, M. Goedbloed, and R. Van Schaijk, (2012).

R. Elfrink, M. Renaud, T. M. Kamel, C. de Nooijer, M. Jambunathan, M. Goedbloed, D. Hohlfeld, S. Matova, V. Pop, L. Caballero, and R. van Schaijk, Journal of Micromechanics and Microengineering 20 (10), 104001 (2010).

G. Rijnders, G. Koster, D. H. A. Blank, and H Rogalla, Applied Physics Letters 70, 1888 (1997).

G. Koster, G. Rijnders, D. H. A. Blank, and H Rogalla, Applied Physics Letters 74, 3729 (1999).

Matthijn Dekkers, Minh D. Nguyen, Ruud Steenwelle, Paul M. te Riele, Dave H. A. Blank, and Guus Rijnders, Applied Physics Letters 95 (1), 012902 (2009). 
S.J. wang, C. K. Ong, L. P. You, and S.Y. Xu, Semiconductor Science and Technology 15, 836 (2000).

Daisuke Kan and Yuichi Shimakawa, Applied Physics Letters 99 (8), 081907 (2011).

A. Boulle, F. Conchon, and R. Guinebretiere, Acta Crystallogr A 62 (Pt 1), 11 (2006).

J. A. M. Vrielink, R. M. Tiggelaar, J. G. E. Gardeniers, and L. Lefferts, Thin Solid Films 520 (6), 1740 (2012).

L. M. van der Haar, C. Sommer, and M. G. M. Stoop, Thin Solid Films 450 (1), 90 (2004).

M. Mantler, Analytica Chimica Acta 188, 25 (1985).

39

Klaus; Tiedke Prume, Stephan; Schmitz-Kempen, Thorsten, Mikroniek 4, 31 (2010). 
Chapter 2

Page | 34 


\title{
Chapter 3
}

\section{Crystallographic properties of (110) $\operatorname{PbZr}_{x} \operatorname{Ti}_{(1-x)} O_{3}$ epitaxial thin films under substrate induced strain}

\begin{abstract}
The domain structure and domain tilting of (110) $\mathrm{PbZr}_{\mathrm{x}} \mathrm{Ti}_{(1-\mathrm{x})} \mathrm{O}_{3}$ epitaxial thin films were studied by X-ray diffraction. Both $\mathrm{SrTiO}_{3}$ and Silicon substrates are used. Different crystallographic properties are obtained under substrate induced strain. For (110) $\mathrm{PbZr}_{\mathrm{x}} \mathrm{Ti}_{(1-\mathrm{x})} \mathrm{O}_{3}$ epitaxial thin films grown on $\mathrm{SrTiO}_{3}$ substrates, 6 different domain rotation directions are observed in the tetragonal phase, while 4 rotations in $a$ domain and 2 rotations in $c$ domain. For (110) $\mathrm{PbZr}_{\mathrm{x}} \operatorname{Ti}_{(1-\mathrm{x})} \mathrm{O}_{3}$ epitaxial thin films grown on silicon substrates, 2 domain rotations are presented in $a$ domain and 2 rotations in $c$ domain. The lattice parameters and the tilt angles of various composite $\mathrm{PbZr}_{\mathrm{x}} \mathrm{Ti}_{(1-\mathrm{x})} \mathrm{O}_{3}$ thin films are calculated and compared.
\end{abstract}




\subsection{Introduction}

PiezoMEMS have developed and are attracting great interest in the past two decades ${ }^{1}$. This technique can successful integrated thousands of devices into one silicon wafer, and is compatible with industrial fabrication steps ${ }^{2,3}$. Epitaxial thin films become a very promising materials for piezoMEMS, as it can be integrated on silicon substrates with high densities, single crystalline orientation, good functional properties and relatively low $\operatorname{cost}^{4,5,6}$. Lots of work has been done to grow high quality epitaxial $\mathrm{PbZr}_{\mathrm{x}} \mathrm{Ti}_{(1-\mathrm{x})} \mathrm{O}_{3}$ (PZT) thin films on SOI devices for various applications ${ }^{7,8,9}$. To figure out what is the mechanism behind the premium properties of epitaxial thin films, the growth modes and the crystallographic properties of those films become more interesting to study.

Epitaxial PZT thin films can be grown by controlled orientations with different buffered layers by pulsed laser deposition ${ }^{10}$. High quality films can be grown on various substrates, with different misfit strain ${ }^{11,12}$. The growth temperature is typically around $600^{\circ} \mathrm{C}$, which is in the cubic phase for PZT materials. After deposition, the samples are cooled down to room temperature, and will pass through the phase transition temperature (Tc). Due to the clamping effect and the different thermal expansion coefficients between the substrates and the films, an induced strain is expected in the film. Sequentially, domain structures will form, for example, in tetragonal structural PZT films, $c$ and $a$ domains are generated. Within each domain, the tilting and rotation angles can be formed, due to the different strain relaxation. In literature ${ }^{13,14}$, lots of discussions are going on about the domain tilting in (001) PZT thin films, but rarely in (110) PZT thin films. Since the (110) PZT thin films show a premium functional properties above other films (the details will be discussed in chapter 4), it would be beneficial to study the intrinsic properties of those films, such as their crystallographic properties. 
X-ray diffractometry (XRD) is widely used for characterization and analysis of the structure of epitaxial thin films ${ }^{15}$. Specifically, reciprocal space mapping (RSM) gives detailed information about the film growth, domain structure, film orientations, rotations, tilting and defect ${ }^{16}$. By applying different rotation angles, various diffraction planes can be reached, both lattice parameters and domain information can be obtained from these measurements.

In this chapter, a detailed study of the crystallographic property of PZT (110) thin films on STO (110) and Si (001) is presented. First of all, the basic principle of XRD reciprocal space is discussed. Afterwards, the first experimental measurements and analysis are done on (110) epitaxial $\mathrm{PbZr}_{\mathrm{x}} \mathrm{Ti}_{(1-}$ ${ }_{x} \mathrm{O}_{3}$ thin films grown on (110) STO substrates. Different film compositions as well as different domain structures are compared and discussed. In the last part of this chapter, (110) ) epitaxial $\mathrm{PbZr}_{\mathrm{x}} \mathrm{Ti}_{(1-\mathrm{x})} \mathrm{O}_{3}$ thin films grown on (001) silicon substrates are presented. Different domain structures are obtained and discussed. In each case, the lattice parameters and tilt angles are calculated and compared with the value in literatures.

\subsection{Crystallographic studies of (110) $\mathrm{PbZr}_{\mathrm{x}} \mathrm{Ti}_{(1-\mathrm{x})} \mathrm{O}_{3}$ epitaxial thin films on $\mathrm{SrTiO}_{3}$ substrates}

\subsubsection{Reciprocal space mapping}

In order to study the growth behavior and crystal structure of (110) $\mathrm{PbZr}_{\mathrm{x}} \mathrm{Ti}_{(1-}$ ${ }_{x} \mathrm{O}_{3}$ thin films, XRD reciprocal space mapping is used. As discussed previously, PZT thin films under different induced strain will form different domains with certain tilt angles. Much study has been done on (001) PZT thin film, but rarely on (110) PZT thin films. The crystallographic structures of (110) thin films are more complex than that of the (001) films. This gives greater interests to figure out how the crystalline and the domain structures are arranged in (110) PZT thin films. 
To start with the measurements, (110) orientated $\mathrm{SrTiO}_{3}$ (STO) substrates were chosen, because it is a robust single crystalline substrate, and has less misfit strain between the substrate and the film. After sample alignment, and theta2theta scans, rocking curve scans were measured. The out of plane information is gathered within these scan. However, if we want to know more details about the in-plane parameters, reciprocal lattice mapping around an asymmetric plane is essential.
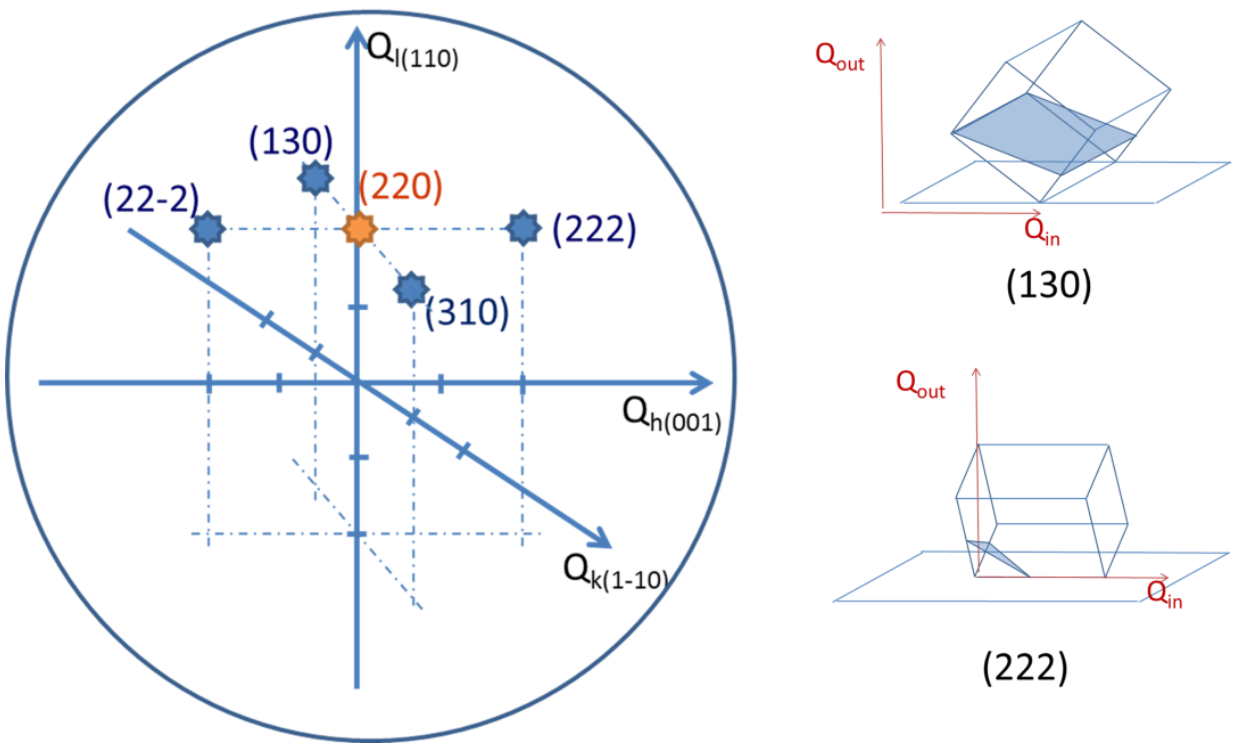

(222)

Figure 3.1 Different reflection planes in reciprocal space and in real space.

The growth orientation of PZT films is (110), which means two different inplane lattice parameters are expected from RSM, with lengths of $a \sqrt{2}$ and a, respectively. In low $\mathrm{Zr}$ content PZT materials, a tetragonal structure exits, where both $c$ domains and $a$ domains are present, see figure 3.1. In case of the $c$ domain, the polarization along the long axis is 45 degrees out of plane, while for $a$ domain, the long axis is in-plane. In order to analysis both in-plane lattice parameters, which are 90 degrees from each other, four different reflection planes were chosen, (130), (310), (222), and (22-2). As shown in figure 3.1, in 
reciprocal space these four spots are located 90 degrees from each other, while centered with a symmetric spot (220). All those five spots are in the same out of plane value $\left(\mathrm{Q}_{l}\right)$.

(220)
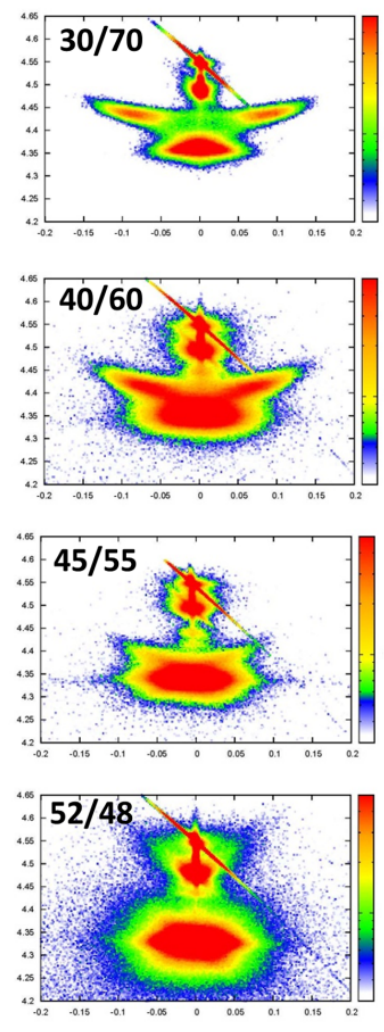

(310)
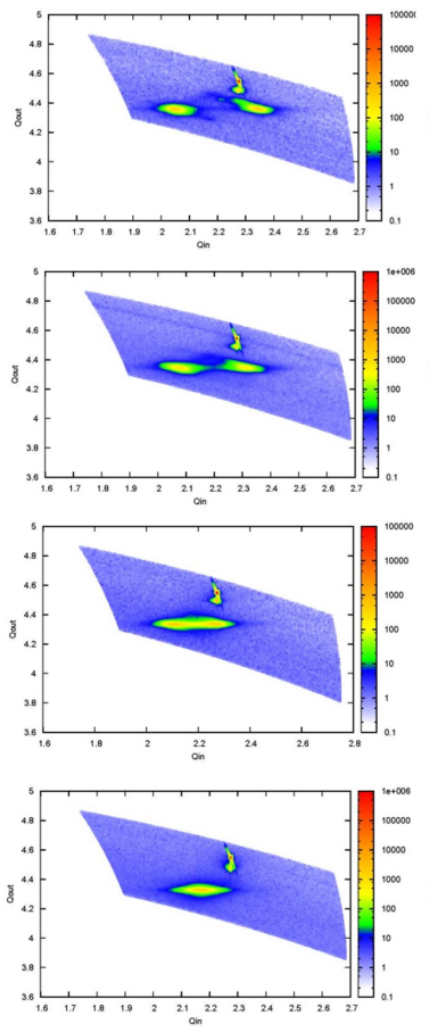

(222)
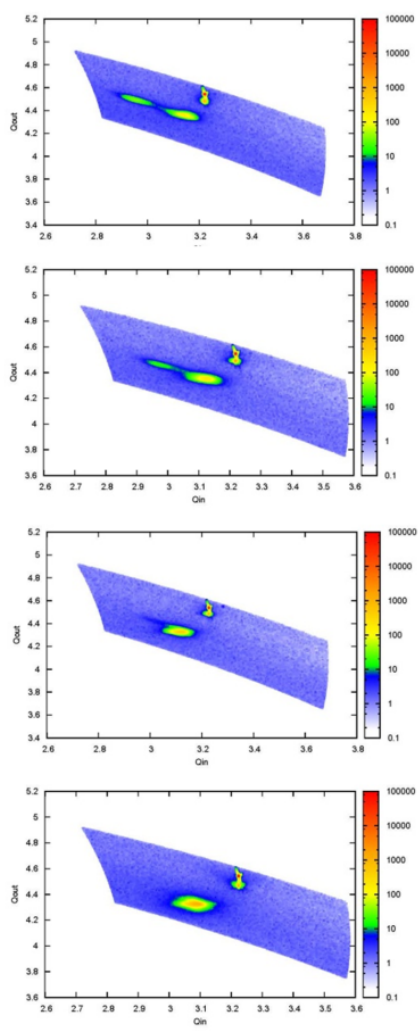

Figure 3.2 (220) Refection of $\mathrm{PbZr}_{\mathrm{x}} \mathrm{Ti}_{(1-\mathrm{x})} \mathrm{O}_{3}$ thin films on $\mathrm{STO}$ (110) substrates.

Figure 3.2 shows the results of all the measurements. The four RSM images in the first column are the scans around the symmetric plane (220), and the data analysis is on a logarithm scale. The main peaks on the top of each image is the substrate peak, followed by a $\mathrm{SrRuO}_{3}$ electrode peak underneath. On the bottom, the big peaks are from the $\mathrm{PbZr}_{\mathrm{x}} \mathrm{Ti}_{(1-\mathrm{x})} \mathrm{O}_{3}$ thin films. For example, in the $\mathrm{PbZr}_{0.3} \mathrm{Ti}_{0.7} \mathrm{O}_{3}$ thin films, three PZT peaks with different $\mathrm{Q}_{\text {out }}$ values are clean seen. We assume the top two peaks with bigger $\mathrm{Q}_{\text {out }}$ are from the contribution of 
$a$ domains, since a larger $\mathrm{Q}_{\text {out }}$ corresponds to a larger theta angle, which means a smaller $\mathrm{d}_{\mathrm{out}}$ from the Bragg's law. The bottom peak is from the contribution of $c$ domains, as shown in figure 3.3. The presence of two $a$ domain peaks indicate the (220) plane of these domains are slightly tilted compared to the substrates reflections. When the $\mathrm{Zr}$ concentration increases in the PZT thin film, the out of plane values of the (220) reflection of the $a$ domain and $c$ domain peaks become closer and they merge into one peak after $\mathrm{PbZr}_{0.45} \mathrm{Ti}_{0.55} \mathrm{O}_{3}$.
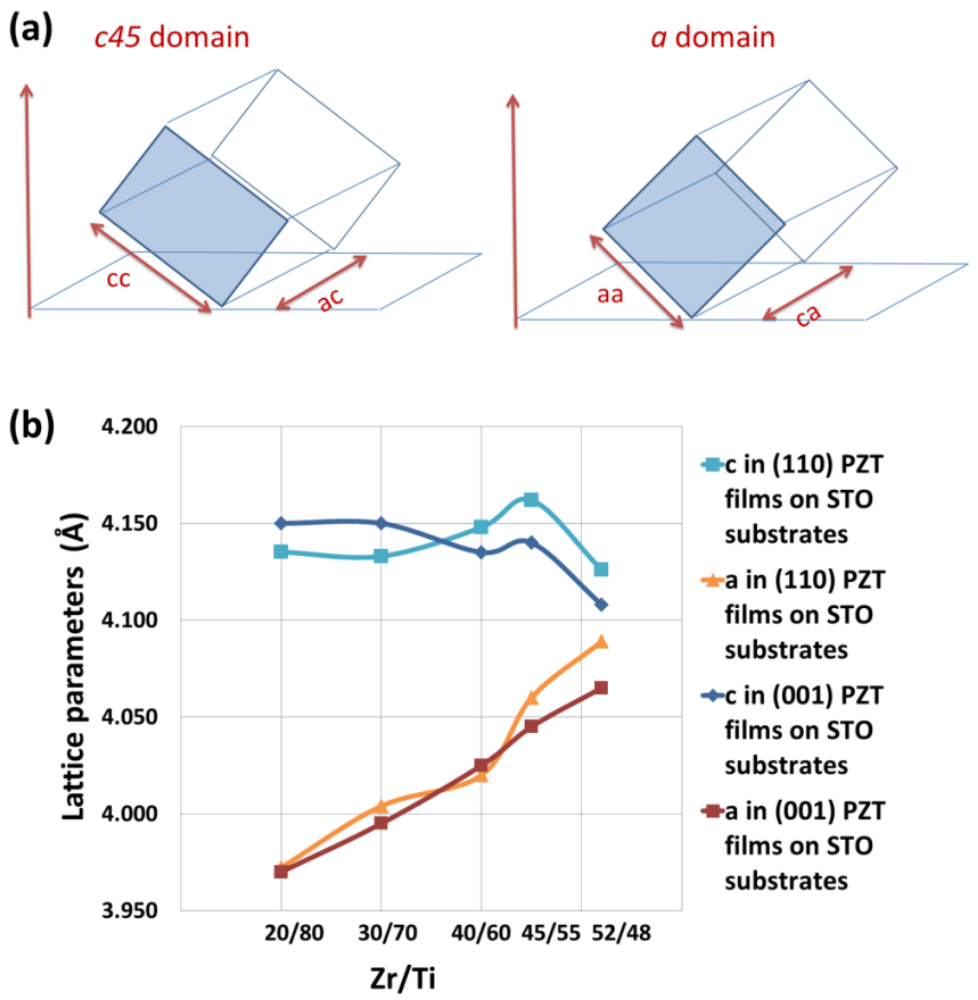

$$
\begin{aligned}
& -c \text { in (110) PZT } \\
& \text { films on STO } \\
& \text { substrates } \\
& -a \text { in (110) PZT } \\
& \text { films on STO } \\
& \text { substrates } \\
& -c \text { in (001) PZT } \\
& \text { films on STO } \\
& \text { substrates } \\
& =\text {-a in (001) PZT } \\
& \text { films on STO } \\
& \text { substrates }
\end{aligned}
$$

Figure 3.3 (a) Schematic drawing of $c 45$ domain and a domain, where cc is the long axis length in $c 45$ domain, ac is the short axis length in $c 45$ domain, ca is the long axis length in $a$ domain, and aa is the short axis length in $a$ domain. (b) from RSM, the in-plane and out of plane lattice parameters of (110) $\mathrm{PbZr}_{\mathrm{x}} \mathrm{Ti}_{(1-\mathrm{x})} \mathrm{O}_{3}$ thin films in both $a$ domain and $c$ domain were calculated. All these films are grown on STO substrates. 
As discussed previously, asymmetric peaks of $\mathrm{PbZr}_{\mathrm{x}} \mathrm{Ti}_{(1-\mathrm{x})} \mathrm{O}_{3}$ thin films are also measured. The first row in figure 3.2, shows the x-ray diffraction reciprocal space mapping around the (220), (310) and (222) reflections. Besides these results, the (130) and (22-2) (in phi 180 degrees difference) have also been measured. They follow the same behavior as (310) and (222), respectively, and are not shown in this graph. In the (310) and (222) reciprocal space mapping of $\mathrm{PbZr}_{0.3} \mathrm{Ti}_{0.7} \mathrm{O}_{3}$ thin films, only two PZT film peaks are shown, which is different from the three peaks observed in (220) plane. This is because we have tilt angles in different domains. In the symmetric peak (220), we observed the domain tilt in both directions. When we go to high orders, the tilt angles become larger. In this case, in the high order asymmetric scan, one of these two tilt domains is out of the scanning range. Thus, the two film peaks we observed are one of the two $a$ domain peak and one $c$ domain peak.

From the reciprocal space mapping, the lattice parameters can be calculated. The difference between (110) films and (001) films is that the in-plane and out-ofplane values do not correspond directly to $\mathrm{a}, \mathrm{b}$ and $\mathrm{c}$ lattice parameters. Moreover, the different domains in the films make the description complex. In order to clarify the interpretation, a schematic drawing is shown in figure 3.3 (a). Two domain categories are defined, where " $c_{45}$ " domain describes the domain with long axis out of plane, and the " $a$ " domain describes the domain with long axis in-plane. Here, $c_{c}$ and $a_{c}$ are the long axis length and short axis length of the $c_{45}$ domain, respectively, and $\mathrm{c}_{\mathrm{a}}$ and $\mathrm{a}_{\mathrm{a}}$ are the long axis and short axis of the $a$ domain. The lattice parameters were calculated from the reciprocal space mapping. The tilting angles in each domain were considered in our calculation model. In figure 3.3 (b), the in-plane and out of plane lattice parameters of (110) PZT thin films are plotted. It appears that the lattice parameters $a_{a}, a_{c}$ and $c_{a}, c_{c}$ are equal within measurement accuracy. Therefore we take the average values a and c. The lattice parameters of (001) PZT thin films is from our previous works $^{12}$. As we can see, the lattice parameters of (110) PZT thin films on STO substrates clearly matches with the values of (001) PZT thin films on STO substrates. Actually in the case of (001) PZT thick films, the measured lattice parameters are in good approximation independent of the substrates (such as 
STO, KTO, DSO $)^{12}$. Compared with the bulk lattice parameters in literatures, both type of films show no strain in thick films. The results indicate when cooling down the films through $\mathrm{T}_{\mathrm{C}}$, the domain fractions of $a$ domain and $c 45$ domain adapt to relax the stress in the films. In the end, unstrained PZT thin films are achieved on STO substrates.

\subsubsection{Domain structure and domain tilting}

In order to investigate in more detail the $a$ domain and $c$ domain structures, inplane reciprocal space mappings were done for different samples, as shown in figure 3.4. The left sides of the images are the out of plane RSMs, with $\mathrm{Zr} / \mathrm{Ti}$ ratio 30/70, 40/60 and 45/55, respectively. The right hand pictures give the various in plane RSMs in different compositions. When different $\mathrm{Q}_{l}$ values are chosen in the XRD measurement program, both $a$ domain and $c$ domain hk-maps are reached.

As we can see, a more complicated domain structure shows up in these measurements. Different from the two domains in the out of plane measurements, there are six tilt domains in one film, which is four tilts of the $a$ domains and two tilts of the $c$ domains. When we do the calculation, for example, on PZT (30/70), the in plane rotation between two tilt $a$ domains is about $\pm 72^{\circ}$, and $\pm 108^{\circ}$, respectively, as shown in figure 3.4. From the h-axis the orientation angle of the $c$ domains is about $180^{\circ}$. Interestingly, the tilt angle in type $a$ domain actually fit in the diagonals of the (110) plane, which is parallel to the substrate. As shown in figure 3.5, we obtain the orientation angle of PZT (30/70), where $c=4.15 \AA, a=4.00 \AA$. Then the angle $\phi$ can be calculated as,

$$
\phi=2 \times \tan ^{-1}\left(\frac{c}{a \sqrt{2}}\right)=71.53^{\circ} \approx 72^{\circ}
$$


(a)
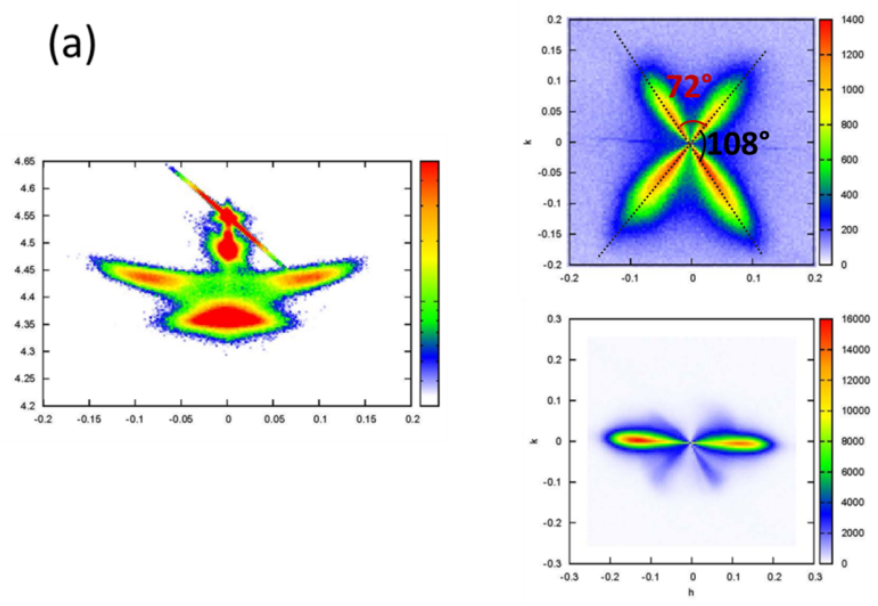

(b)
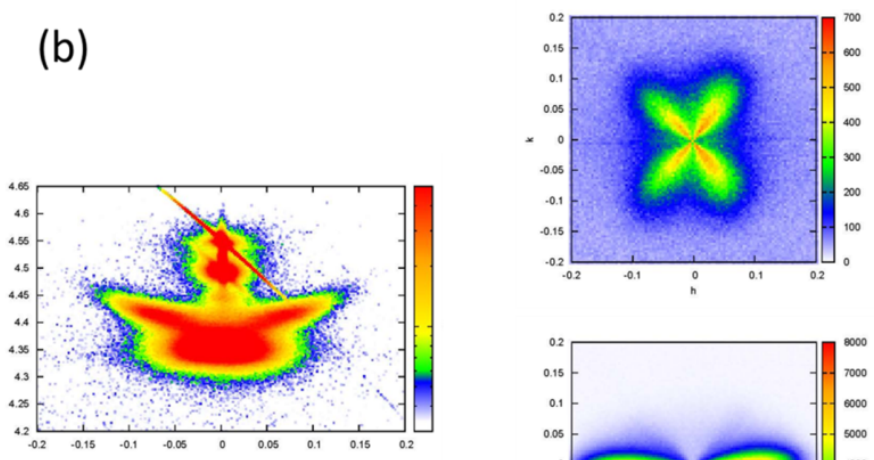

(c)
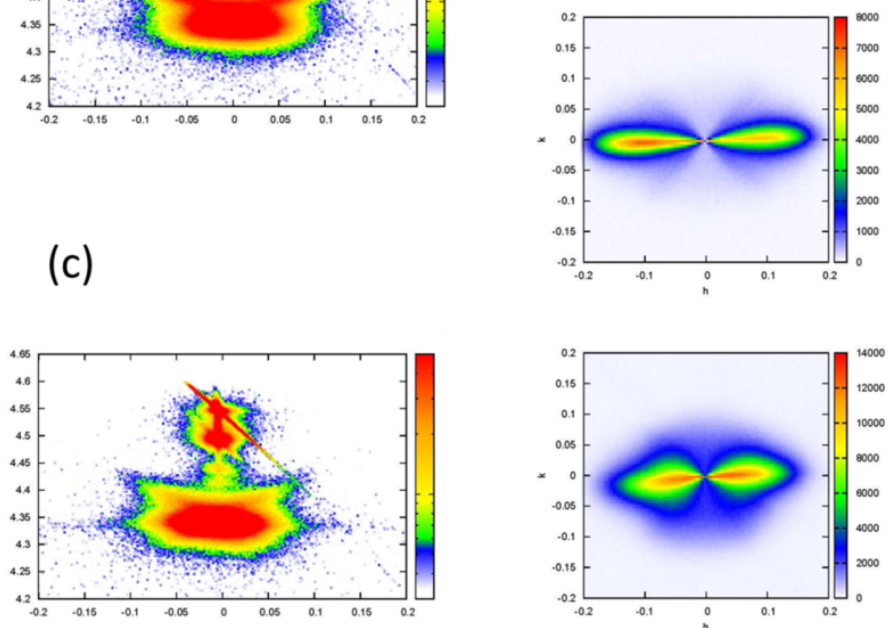

Figure 3.4 XRD reciprocal space mapping around (220) diffractions for (110) $\operatorname{PbZr}_{x} \operatorname{Ti}_{(1-x)} \mathrm{O}_{3}$ thin film grown on STO substrates. The left images are hl scan in reciprocal space, and the right images are hk scan in reciprocal space, while the upper one in on $a$ domain, and the lower on the on $c$ domain. (a) $x=0.3,(b) x=0.4$, and $(c) x=0.45$. 
In this case, we assume that all the tilts of an $a$ domain are along the two directions of each diagonal in (110) plane. The two tilts of the $c$ domains are along the a axis in plane, which is $180^{\circ}$ from each other, as shown in figure 3.5. The tilt angles of each domain are calculated from the in plane RSMs, and given in figure 3.6. We can see that the tilt angle decreases as the tetragonality decreases. The larger tilt is obtained for the $c$ domain, which is around 1.4 degrees.

From the discussion above, we obtain a detailed and comprehensive study about the growth of (110) $\mathrm{PbZr}_{\mathrm{x}} \mathrm{Ti}_{(1-\mathrm{x})} \mathrm{O}_{3}$ thin films on crystalline STO substrates. Reciprocal space mappings in different planes with both in plane and out of plane scanning are done with different compositions of PZT. A complex domain rotation mode is discussed, and domain tilt angles and lattice parameters are obtained. In the next section, the crystal structures of $\mathrm{PbZr}_{\mathrm{x}} \mathrm{Ti}_{(1-\mathrm{x})} \mathrm{O}_{3}$ thin films grown on silicon substrates will be discussed.

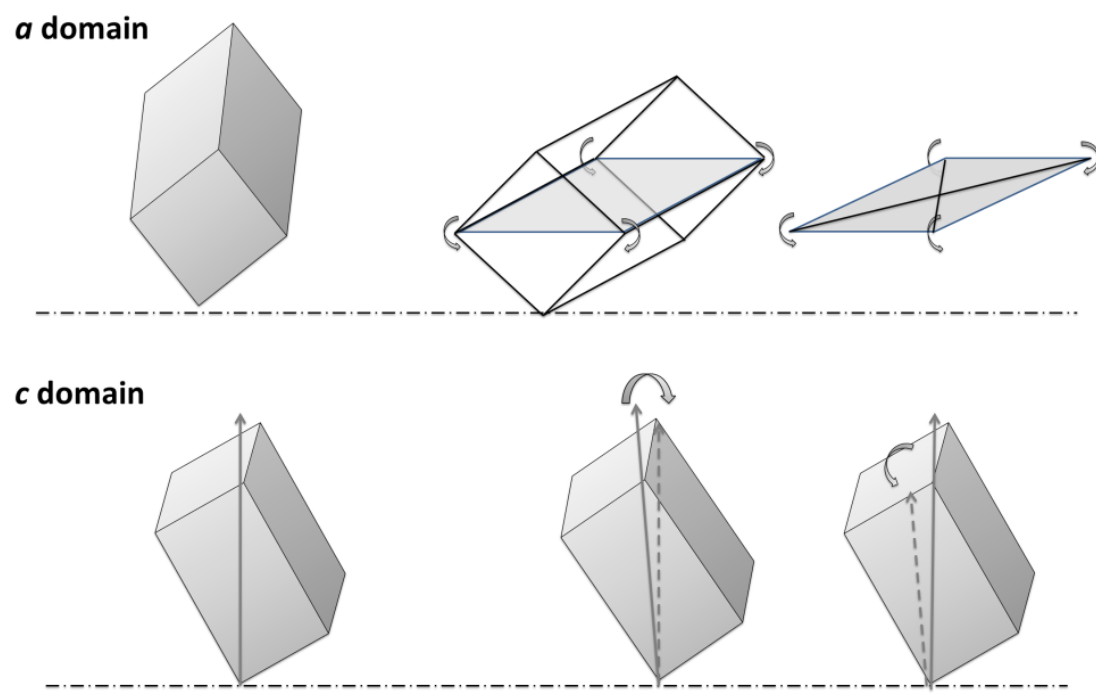

Figure 3.5 Schematic drawing of the domain tilting. 


\subsection{Crystallographic studies of (110) $\mathrm{PbZr}_{\mathrm{x}} \mathrm{Ti}_{(1-\mathrm{x})} \mathrm{O}_{3}$ epitaxial thin films on Silicon substrates}

Typically, $\mathrm{PbZr}_{\mathrm{x}} \mathrm{Ti}_{(1-\mathrm{x})} \mathrm{O}_{3}$ thin films grown on $\mathrm{STO}$ substrates show better crystalline properties, as compared with films grown on silicon substrates. This is because crystalline STO substrates have the less misfit between the film and substrate, and a smooth and flat surface with a step structure. However, from the application point of view, silicon is a widely used material, as it is compatible with MEMS fabrications and less costly. In this sense, it is very interesting to study the growth and the domain structure of $\mathrm{PbZr}_{\mathrm{x}} \mathrm{Ti}_{(1-\mathrm{x})} \mathrm{O}_{3}$ thin films on silicon substrates.

As shown from previous work $^{10}$, in order to achieve epitaxial (110) PZT thin films on silicon substrates, YSZ is used as buffer layer. After the YSZ growth, both the $\mathrm{SrRuO}_{3}$ electrode and $\mathrm{PbZr}_{\mathrm{x}} \mathrm{Ti}_{(1-\mathrm{x})} \mathrm{O}_{3}$ thin films show a 10 degrees in plane rotation in two directions. This phenomena can be understand from the schematic drawing in figure 3.7 .

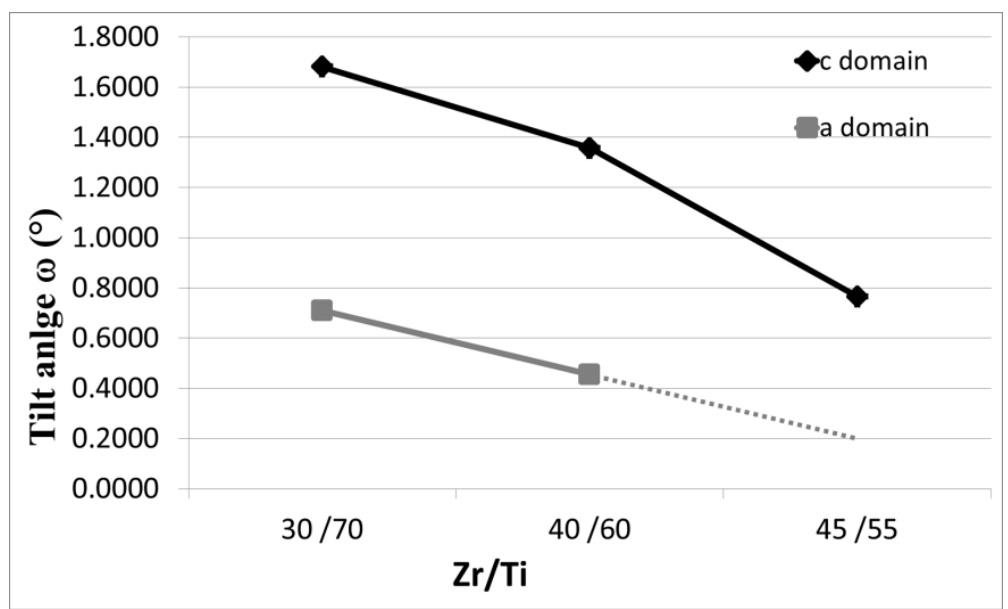

Figure 3.6 Tilt angle of different domains calculated from the in plane RSMs. 

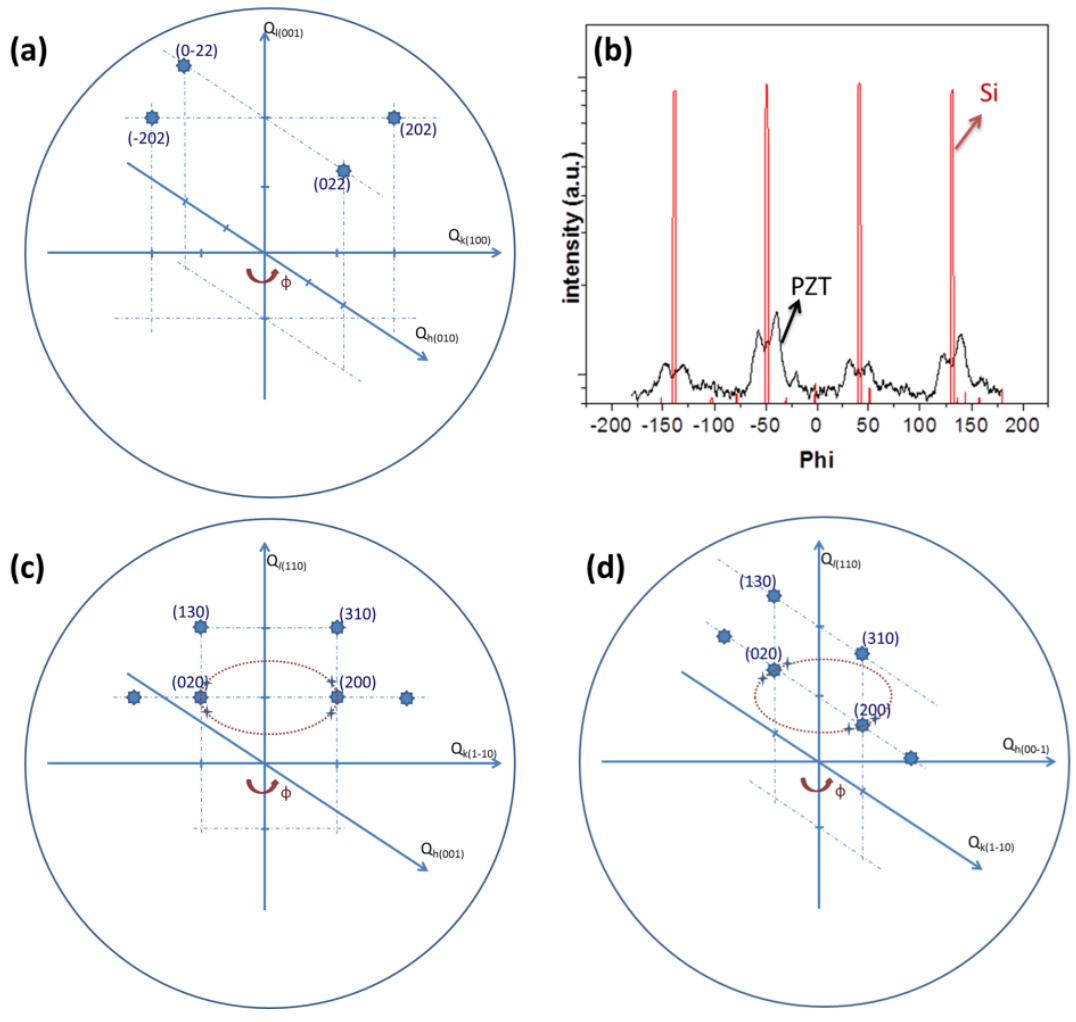

Figure 3.7 Schematic explanations in reciprocal space and phi scans of 10 degrees rotations in (110) PZT thin film on silicon substrate. (a) $<202>$ reflections of silicon in reciprocal space. (b) phi scan of (110) PZT (black) thin films on (001) Si substrate (red). (c) $l k$ reciprocal space of (110) PZT materials. (d) $l h$ reciprocal space of (110) PZT materials.

Figure 3.7 (b) shows the graph of phi scan measurements for both the silicon substrate and the $\mathrm{PbZr}_{\mathrm{x}} \mathrm{Ti}_{(1-\mathrm{x})} \mathrm{O}_{3}$ thin films. Phi scan is the X-ray scanning where both the omega and the 2 theta angle are fixes at the desired value of a certain peak, while the in plane angle phi is rotated 360 degrees. In this case, the in plane orientation is obtained. For example, the silicon substrates are in the (001) orientation. In order to get the in plane information, the chi angle is rotated to 45 degrees to reach the (220) plane. Because of the four-fold symmetry, four peaks are obtained in the measurements, see figure 3.7 (b). The explanation in 
reciprocal space is shown in figure 3.7 (a). (022), (202), (0-22) and (-202) are located 90 degrees from each other. The phi scan makes a circle in the $l=2$ plane, centered at (002), with a radius of 2. Each spot corresponds with a peak in the measurements. The PZT films have (110) orientation, thus after chi $=45^{\circ}$ rotations, (200) planes are reached in the PZT films. As shown in figure 3.7 (c) and (d), when the out of plane reflection corresponds to $Q_{(220)}$, both $(020)$ and (200) are reachable. The results of phi scan show two peaks which are about 10 degrees rotated with respect to the silicon substrate peak. The crosses in figure 3.7 (c) and (d) correspond to the real peak positions in the films. This results also indicates that the PZT thin films show 90 degrees in plane twining, as one could expect from the cubic substrate symmetry.

X-ray diffraction RSMs of $\mathrm{PbZr}_{\mathrm{x}} \mathrm{Ti}_{(1-\mathrm{x})} \mathrm{O}_{3}$ thin films on silicon substrates are shown in figure 3.8, where the left hand images are the out of plane RSMs of (220) symmetric peaks, and the right hand images are the in-plane HK scans of both $a$ domain and $c$ domain structures in PZT thin films. As we can see, both $\mathrm{PbZr}_{0.2} \mathrm{Ti}_{0.8} \mathrm{O}_{3}$ (a) and $\mathrm{PbZr}_{0.3} \mathrm{Ti}_{0.7} \mathrm{O}_{3}$ (b) in figure 3.8, show a clear $a$ domain and $c$ domain peaks, while in $\mathrm{PbZr}_{0.4} \mathrm{Ti}_{0.6} \mathrm{O}_{3}$ (c), those two peaks merge into one. Here, we notice a different trend between the PZT films on STO and on silicon substrates in terms of domain tilts. First of all, the substrate induced strain is much different, where STO always causes a compressive strain, silicon induces a tensile strain in the film. More details about the relation between induced strain and PZT compositions will be discussed in chapter 4. Secondly, as we discussed, the PZT thin films grown on silicon substrates always shows \pm 10 degrees inplane rotation with respect to the substrate, as well as $90^{\circ}$ twining. Those inplane rotation can restrict the possibilities of the domain rotations. Thus, less rotations are obtained in PZT films on silicon substrates. 


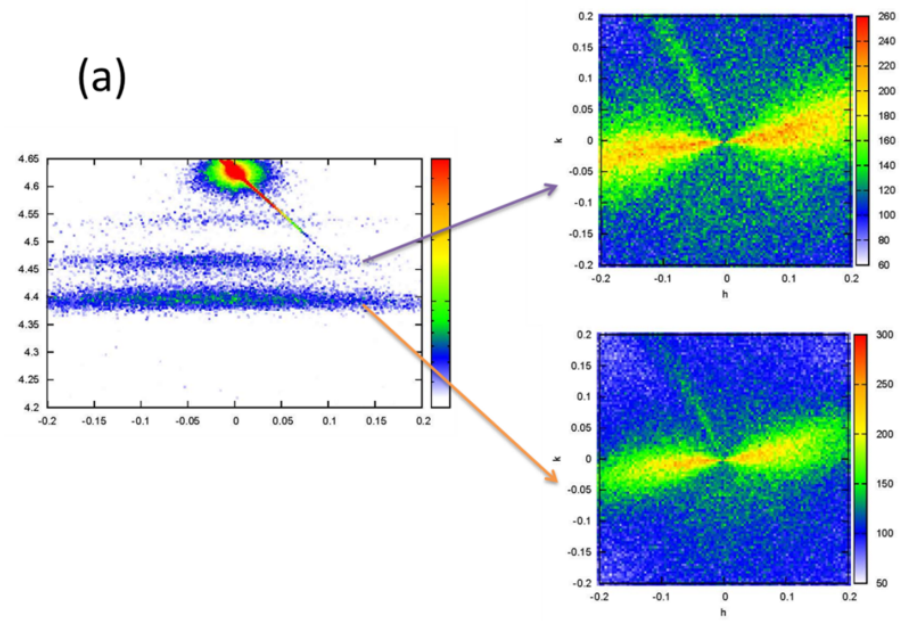

(b)
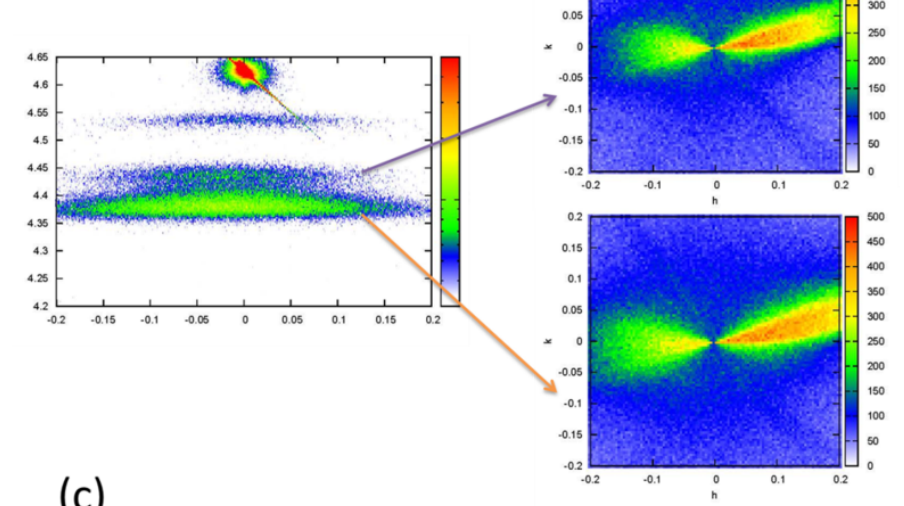

(c)
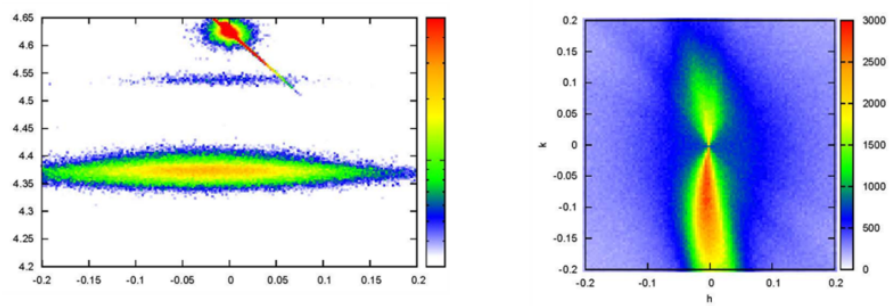

Figure 3.8 XRD RSMs of (110) $\mathrm{PbZr}_{\mathrm{x}} \mathrm{Ti}_{(1-\mathrm{x})} \mathrm{O}_{3}$ thin films grown on silicon substrates, where (a) is $\mathrm{PbZr}_{0.2} \mathrm{Ti}_{0.8} \mathrm{O}_{3}$, (b) is $\mathrm{PbZr}_{0.3} \mathrm{Ti}_{0.7} \mathrm{O}_{3}$ and (c) is $\mathrm{PbZr}_{0.4} \mathrm{Ti}_{0.6} \mathrm{O}_{3}$. 
The in-plane RSMs indicate two small tilting angles, which are in in-plane direction opposing each other. The small line along the diagonal in the in-plane RSMs is an artifact signal from the system, since it is present in every graph. In the in-plane RSMs, the 90 degrees domain difference between figure 3.8 (b) and (c) is because of the mounting direction of the sample itself. From the in-plane RSMs, we can also read the tilt in one direction, is more than that in the other direction, for example in figure 3.8 (c), the tilt angles difference between left and right is about 0.5 degrees.

From the reciprocal space mapping, the lattice parameters are calculated for (110) PZT thin films on silicon substrates. The fitting model is the same as we used for (110) PZT films on STO substrates, where $c$ is the average of $c_{a}$ and $c_{c}$, and $a$ is the average of $a_{a}$ and $a_{c}$, as shown in figure 3.9. Different lattice parameters are obtained in PZT films grown on both silicon substrates and STO substrates, which indicates a different mechanism in both types of films. As discussed previously, the PZT films on STO substrates were shown to have no strain in the films, because the strain can be relaxed by changing the domain fractions. However, the case of (110) PZT on Si is different. For $\mathrm{x} \leq 0.3$, the bulk lattice parameters are still obtained, indicating that the unit cells are strain free and ferroelectric domains are large. For larger Zr-content the unit cell appears nearly cubic. As shown in our previous work ${ }^{17}$, this can be explained by the existence of nanodomains in tetragonal strain free unit cells, which cannot be resolved anymore by XRD. The existence of nanodomains goes together with easily displaceable domain walls, as well as the easy rotation of the polarization vector. Therefore the large piezoelectric coefficients can be expected in nanodomain regions. This results was obtained in (110) PZT on Si and not on (110) STO substrates. We ascribe this result to the different grain structure, which is well-aligned along STO crystal axes, but is in-plane of much more polycrystalline nature on Si. 


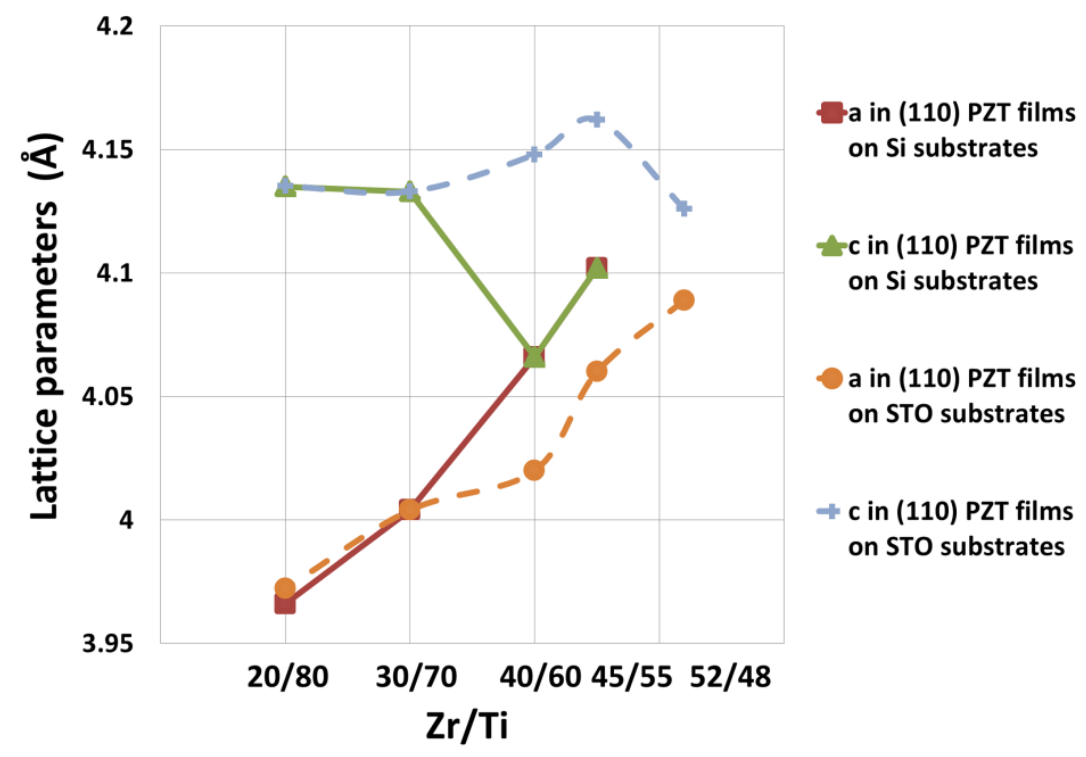

Figure 3.9 The in-plane and out of plane lattice parameters of (110) $\operatorname{PbZr}_{x} \operatorname{Ti}_{(1-x)} \mathrm{O}_{3}$ thin films grown on silicon substrates were calculated. These lattice parameters were compared with (110) PZT thin films on STO substrates.

\subsection{Conclusions}

In conclusion, a systematic XRD reciprocal space mapping study of (110) $\mathrm{PbZr}_{\mathrm{x}} \mathrm{Ti}_{(1-\mathrm{x})} \mathrm{O}_{3}$ thin films is discussed. Both crystalline STO substrates and silicon substrates are used. The experiments of in-plane RSM in both $a$ domain and $c 45$ domain shows the unique domain rotations in (110) PZT films on STO substrates. The different domain structures in each case are because of the substrate induced strain and different growth mode. The PZT films grown on STO substrates show nearly no strain in the films. The changes in domain fractions between $a$ domains and $c 45$ domains can relax the PZT films during cooling down. From the comparison between the lattice parameters of PZT films grown on silicon substrates and STO substrates, more strain is observed in PZT films on silicon substrates. The PZT thin films grown on silicon substrates have 
10 degrees in-plane rotations in both positive and negative directions. These 10 degrees in-plane rotations can restrict the domain rotations to some extent, which make the domain less mobile to relax the stress. Furthermore, both the lattice parameters and the tilt angles of various composite $\mathrm{PbZr}_{\mathrm{x}} \mathrm{Ti}_{(1-\mathrm{x})} \mathrm{O}_{3}$ thin films are calculated and compared. The nano domains region is observed in $\mathrm{x}=0.4-0.45$ in (110) PZT films grown on silicon substrates. From the study above, a thorough understanding of the crystallographic properties of (110) $\mathrm{PbZr}_{\mathrm{x}} \mathrm{Ti}_{(1-\mathrm{x})} \mathrm{O}_{3}$ epitaxial thin films is established, which benefits the understanding of the functional properties in the following chapters. 


\subsection{References}

1

S. Tadigadapa and K. Mateti, Measurement Science and Technology 20 (9), 092001 (2009).

S. Trolier-McKinstry and P. Muralt, Journal of Electroceramics 12, 7 (2004).

P. Muralt, R. G. Polcawich, and S. Trolier-Mckinstry, MRS Bulletin 34, 658 (2009).

D. Isarakorn, École Polytechnique Fédérale de Lausanne, 2011.

Pavlo Zubko, Stefano Gariglio, Marc Gabay, Philippe Ghosez, and JeanMarc Triscone, Annual Review of Condensed Matter Physics 2 (1), 141 (2011).

6 J. F. M. Cillessen, M. W. J. Prins, and R. M. Wolf, Journal of Applied Physics 81 (6), 2777 (1997).

D. Isarakorn, D. Briand, P. Janphuang, A. Sambri, S. Gariglio, J. M. Triscone, F. Guy, J. W. Reiner, C. H. Ahn, and N. F. de Rooij, Smart Materials and Structures 20 (2), 025015 (2011).

Paul Muralt, Journal of the American Ceramic Society 91 (5), 1385 (2008).

Minh D. Nguyen, Hung N. Vu, Dave H. A. Blank, and Guus Rijnders, Advances in Natural Sciences: Nanoscience and Nanotechnology 2 (1), 015005 (2011).

Matthijn Dekkers, Minh D. Nguyen, Ruud Steenwelle, Paul M. te Riele, Dave H. A. Blank, and Guus Rijnders, Applied Physics Letters 95 (1), 012902 (2009).

Minh D. Nguyen, Matthijn Dekkers, Evert Houwman, Ruud Steenwelle, Xin Wan, Andreas Roelofs, Thorsten Schmitz-Kempen, and Guus Rijnders, Applied Physics Letters 99 (25), 252904 (2011).

R. Steenwelle, University of Twente, 2012.

Sriram Venkatesan, B. J. Kooi, J. T. M. De Hosson, A. H. G. Vlooswijk, and B. Noheda, Journal of Applied Physics 102 (10), 104105 (2007).
A. H. G. Vlooswijk, B. Noheda, G. Catalan, A. Janssens, B. Barcones, G. Rijnders, D. H. A. Blank, S. Venkatesan, B. Kooi, and J. T. M. de Hosson, Applied Physics Letters 91 (11), 112901 (2007). 
Crystallographic properties of (110) $\mathrm{PbZr}_{x} \mathrm{Ti}_{(1-x)} \mathrm{O}_{3}$ epitaxial thin films under substrate induced strain

15 A. Boulle, F. Conchon, and R. Guinebretiere, Acta Crystallogr A $62(\mathrm{Pt}$ 1), 11 (2006).

16 V. Holy, J. H. Li, G. Bauer, and H. J. Herzog, Journal of Applied Physics 78, 5013 (1995).

17 R. Steenwelle, E. Houwman, X. Wan, M. Dekkers, M. D. Nguyen, and G. Rijnders, (2013). 
Chapter 3

Page | 54 


\title{
Chapter 4
}

\section{Ferroelectric and piezoelectric properties of (110) $\operatorname{PbZr}_{x} \operatorname{Ti}_{(1-x)} O_{3}$ epitaxial thin films on Si substrates}

\begin{abstract}
Piezoelectric, ferroelectric and structural properties of epitaxial pseudocubic (110) orientated $500 \mathrm{~nm}$ thick $\mathrm{PbZr}_{\mathrm{x}} \mathrm{Ti}_{1-\mathrm{x}} \mathrm{O}_{3}$ (PZT) thin films, prepared by pulsed laser deposition on (001) silicon substrates, were measured as function of composition. The x-dependence of the measurement data can be explained by an abrupt transition from the rhombohedral $r$-phase to the tetragonal $c_{45} / a$-phase if $\mathrm{x}$ becomes smaller than $x \approx 0.40$. In the $r$-phase the polarization vector easily rotates in the (110)-plane, perpendicular to the substrate under the influence of an external electrical or stress field, resulting in a rapidly increasing measured piezoelectric parameter $\mathrm{e}_{31, f}$ and dielectric parameter $\varepsilon_{33}$, peaking near the $r-c_{45} / a$ phase boundary. This interpretation is consistent with earlier models for multidomain (001) orientated clamped films by Kukhar et al. The reliable growth of (110) orientated films with a large $e_{31, f}$ is of great significance for Si-based piezo-microelectromechanical systems, in particular energy harvesters. The largest value of the figure-of-merit for such devices is found at the r-side of the phase boundary for $x=0.4, F O M=e_{31}^{2} / \epsilon_{0} \epsilon_{33}=24.0 \mathrm{GPa}$.
\end{abstract}




\subsection{Introduction}

Piezoelectric thin films based on lead zirconate titanate (PZT) material have been attracting significant interest in view of their applications in piezomicroelectromechanical systems (MEMS) ${ }^{1,2}$. One of these applications is the piezoMEMS micro scale energy harvester that converts vibrational energy into electrical energy, which potentially offers an ideal way to generate power for self-powered wireless sensor systems ${ }^{3,4}$. A critical performance benchmark for such an energy harvester device is the figure of merit $\left(F O M=e_{31, f}^{2} / \epsilon_{0} \epsilon_{33}\right)$, where $e_{31, f}$ is the relevant piezoelectric coefficient and $\varepsilon_{33}$ the dielectric constant. The FOM is directly proportional to its power output ${ }^{5,6}$. The piezoelectric coefficient $\mathrm{e}_{31, f}$ was widely studied for various films in the past few years ${ }^{7}$. A theoretical calculation of $\mathrm{e}_{31, f}$ in bulk ceramics PZT is given by Sherrit et al. ${ }^{8}$, where $\mathrm{e}_{3 l, f}$ are calculated to be $25 \mathrm{C} / \mathrm{m}^{2}$. Emmaneul et al. ${ }^{9}$ measured the $\mathrm{e}_{31}$ of the sputtered porous films, where a value of $1.7 \mathrm{C} / \mathrm{m}^{2}$ is obtained. The piezoelectric performance of sol-gel PZT films are well described by P. Muralt and S. Trolier-Mckinstry ${ }^{10}{ }^{11}$. An improvement in both dielectric and piezoelectric properties in their works is due to a homogeneous growth process. $\mathrm{Pb}(\mathrm{Mg}, \mathrm{Nb}) / \mathrm{PbTiO}_{3}$ and $\mathrm{Pb}(\mathrm{Yb}, \mathrm{Nb}) / \mathrm{PbTiO}_{3}$ thin films are also widely studied because of their high piezoelectric properties ${ }^{12,13}$. A giant piezoelectric coefficient was reported for epitaxial $\mathrm{Pb}(\mathrm{Mg}, \mathrm{Nb}) / \mathrm{PbTiO}_{3}$ thin films grown on silicon ${ }^{14}$. All these works indicate that a high-quality thin film with a perfect growth mode is the premise to reach enhanced material properties.

On the other hand, energy harvesters need to operate for a large number of cycles. An optimal deposition process is essential to produce reliable devices without significant aging. A strong research effort is being made to integrate PZT thin film on Si substrates using pulsed laser deposition (PLD) ${ }^{15}$, ${ }^{16}$ By applying different buffer layers, both (001) and (110) orientated epitaxial PZT thin films can be grown on Si (001) substrates. In this work, we focus on the piezoelectric and ferroelectric properties of (110) films on Si as function of the 
$\mathrm{Zr}$-fraction $\mathrm{x}$ in the $\mathrm{PbZr}_{\mathrm{x}} \mathrm{Ti}_{1-\mathrm{x}} \mathrm{O}_{3}$. A thorough understanding of the piezo material thin films in piezoMEMS devices, especially the relation between the crystalline structure and piezo properties is essential for optimizing the material properties $^{17}$.

Epitaxial PZT thin films, deposited at a high temperature $\left(600^{\circ} \mathrm{C}\right)$ and cooled down to room temperature, show residual stress depending on the substrates materials ${ }^{18}$. Because of the difference in thermal expansion coefficients between the films and substrates, various stress levels are induced in the PZT films, which lead to the differences in ferroelectric (FE) and piezoelectric (PE) properties $^{17,19}$. These effects have extensively been modeled by Pertsev et al. ${ }^{20}$ and Kukhar et al. ${ }^{21}$ for thick, (001) orientated, clamped films. Figure 4.4 shows a composition-strain phase diagram derived from Kukhar's work. The thermal stress in thick films at the tetragonal side of the phase diagram (at small Zrcontent) can be relaxed by $c / a$ domain formation and the FE/PE properties are largely determined by the change in the $c$-domain fraction, $\phi_{c}$, under influence of an external stress or electrical field. Only for very large strains, the crystallographic structure changes either to a $c$-domain phase (large compressive strain) or $a_{1} / a_{2}$ domain phase (large tensile strain). However, if the composition is near the bulk crystal Morphotropic Phase Boundary (MPB) ${ }^{22}$ ( $\mathrm{Zr}$-content $x=0.52$ ) between the bulk crystal rhombohedral and tetragonal phase, an additional $r$-phase (or $r_{1} / r_{2}$-phase in a multidomain structure) appears over a wide range of misfit strain in which the polarization can easily rotate in and switch between the (110) planes of the pseudocube under the influence of an external applied strain or electrical field. This r-phase can be attributed to the properties of the so-called adaptive phase, in which nanosized domains of the tetragonal unit cell exist ${ }^{23}$. The domain walls between these nanodomains can easily move. In XRD the adaptive phase shows up as an apparent rhombohedral (or monoclinic or nearly cubic) phase. Due to the easy rotation in polarization directions, the dielectric and PE properties are generally much larger in this phase, and diverge at the boundary of this phase with the $c / a$ phase ${ }^{12,13}$. We 
show that these features also apply qualitatively to the investigated (110)orientated films, resulting in a very large FOM at the phase boundary.

This chapter is organized as follows. First, the experimental part is discussed. Then, the samples are characterized and analyzed by X-ray diffraction and scanning electron microscope. From these measurements, the films qualities, orientations and misfit strains are obtained. Afterwards, both the ferroelectric and piezoelectric measurements of the films are discussed. Optimum PZT thin films with enhanced piezoelectric properties are achieved and discussed in the final section.

\subsection{Experimental}

PLD is used to deposit $100 \mathrm{~nm} \mathrm{SrRuO}_{3}$ (SRO) bottom electrode layer, $500 \mathrm{~nm}$ $\mathrm{PbZr}_{\mathrm{x}} \mathrm{Ti}_{1-\mathrm{x}} \mathrm{O}_{3}$ piezoelectric layer of the capacitor and 100nm Pt top electrode. The $Z r$-fraction was $\mathrm{x}=0.2,0.3,0.4,0.45,0.52,0.6$. For the $e_{31}$ bending tests, the capacitors have dimensions $2 \times 8 \mathrm{~mm}^{2}$ on a $500 \mu \mathrm{m}$ thick $3 \times 25 \mathrm{~mm}^{2}$ Si-strip. The sandwich capacitor structures were epitaxially grown on a Yttria-stabilized zirconia (YSZ) buffer layer deposited on the Si (001) substrates ${ }^{15}$. Crystalline properties were characterized by high-resolution X-Ray Diffraction (XRD, with a PANalytical X-pert system and Bruker D8). The polarization hysteresis (PE) loops were measured in an aixACCT Analyzer TF 2000. From the loops the characteristic ferroelectric parameters were determined, such as the remanent polarization $P_{r}$, coercive field $E_{c}$, and the saturation polarization $P_{s}$. The transverse piezoelectric coefficient $e_{31}$ was obtained by a 4-point bending measurement setup (aix $4 \mathrm{~PB}^{24}$ ) in combination with the $\mathrm{TF}$ analyzer, at $1 \mathrm{~Hz}$, and zero bias field. The dielectric constant $\varepsilon_{33}$ at zero applied electric field was obtained from capacitance-voltage (CV) measurements at $10 \mathrm{kHz}$ (Süss MicroTech PM300 probe station from SÜSS MicroTec Test Systems GmbH, equipped with a Keithley 4200 Semiconductor characterization system). 


\subsection{Characterization of crystallinity structure}

\subsubsection{X-ray diffraction measurements}

In order to investigate the crystalline properties of $\mathrm{PbZr}_{\mathrm{x}} \mathrm{Ti}_{1-\mathrm{x}} \mathrm{O}_{3}$ thin films, both the in-plane and out of plane X-ray diffractions were measured in these films. Figure 4.1 (a) shows the $\theta-2 \theta$ XRD patterns of a series of (110) $\mathrm{PbZr}_{\mathrm{x}} \mathrm{Ti}_{1-\mathrm{x}} \mathrm{O}_{3}$ thin films on $\mathrm{Si}$ substrates. it is concluded that all films are epitaxially grown on the silicon with (110) orientation. Figure 4.1 (b) shows that for $x=0.4-0.6$ there is a single reflection with the same narrow FWHM of approximately $0.2^{\circ}$. The peak shift reflects the change of the out-of-plane lattice parameter with $x$. There is an abrupt change in the reflections for the films with $x<0.4$. The FWHM approximately doubles and a second reflection appears, corresponding to a second, smaller out-of-plane lattice parameter. At the tetragonal side of the PZT phase diagram one expects crystallographic domains with the c-axis in the film plane (' $a$-domains') and domains with the $c$-axis under $45^{\circ}$ angle with the film surface (' $c_{45}$-domains'), explaining the appearance of two out-of-plane lattice parameters, see figure 4.2 (We use the sub index 45 to distinguish this domain type in (110) films from the $c$-domains in (001) films.) For $x=0.4-0.6$ films, the XRD show that the pseudocubes have a single out-of-plane lattice parameter throughout the film, which is an indication for the $r$-phase.

As discussed in chapter 3 , the XRD data for $x_{\mathrm{z1}} \geq 0.4$, is described by an rhombohedrally distorted PZT-pseudocube, which we ascribe to the nano domain formations. In the range $x_{\mathrm{zr}}<0.4$ two tetragonal pseudocubes are identified. The transition from the $c_{45} / a$-phase to $r_{1} / r_{2}$-phase at $x_{\mathrm{zr}} \approx 0.4$ for these $500 \mathrm{~nm}$ (110) films coincides with the phase boundary predicted by Kukhar \& Pertsev for thick, clamped (001) films ${ }^{11}$ and occurs at small lattice misfit strain $S_{m} \approx 0$, as shown in figure 4. 3 . 

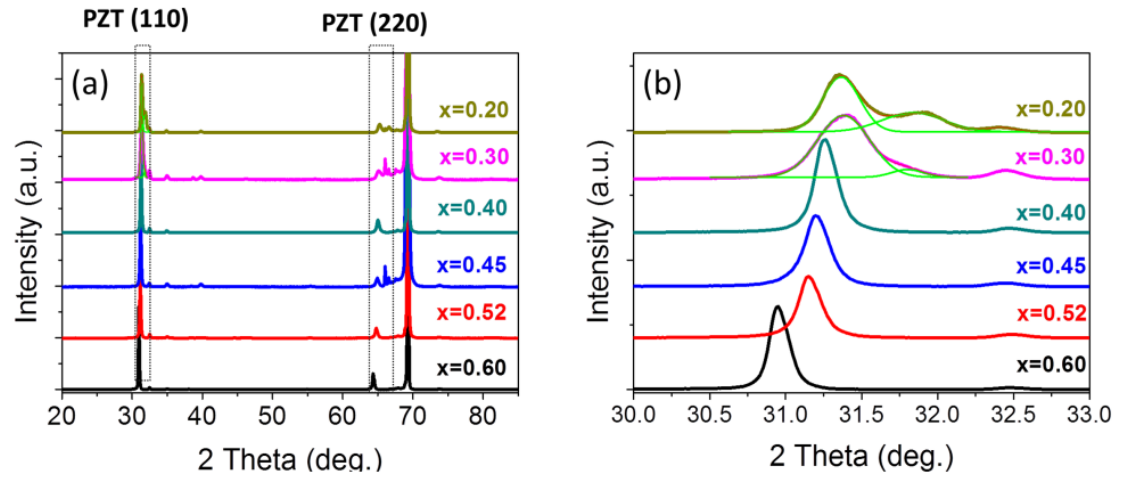

Figure 4.1 X-ray diffraction pattern of $\operatorname{PbZr}_{x} \operatorname{Ti}_{(1-x)} O_{3}$ (110) thin films on silicon substrates (a) full scan, (b) zoom in around (110) peak.

c45 domain

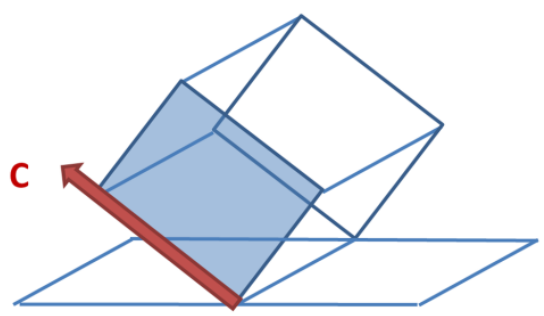

$a$ domain

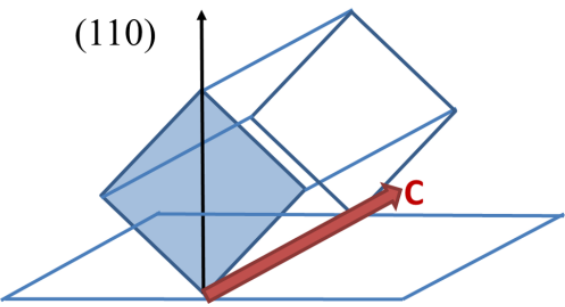

Figure 4.2 Schematic drawing of $c_{45}$ domain and $a$ domain.

In this study, the misfit strain is calculated from the difference between the pseudocubic lattice constant and the thin film lattice constant. The thin film lattice constant is derived from the X-ray diffraction data. The misfit strain $\left(\mathrm{S}_{\mathrm{m}}\right)$ defined as

$$
\mathrm{S}_{\mathrm{m}}=\left(\mathrm{a}-\mathrm{a}_{\mathrm{pc}}\right) / \mathrm{a}_{\mathrm{pc}}
$$

where $\mathrm{a}$ is the strained lattice constant and $\mathrm{a}_{\mathrm{pc}}$ is the pseudocubic lattice constant. For the considered (110) films we neglect the $10^{\circ}$ misalignment of the pseudocubes with the $\mathrm{Si}<001>$ axes and the small tilt of the pseudocubes with respect to the film normal, so that for the $\mathrm{c}_{45}$ domain structure the in-plane axes are $b=\sqrt{a^{2}+c^{2}}$ and a respectively, see figure 4.2. In this case, the strains in $\mathrm{c}_{45}$ domains are 


$$
\begin{aligned}
& \mathrm{S}_{\mathrm{c} 1}=\left(\mathrm{b}-\mathrm{a}_{\mathrm{pc}} \sqrt{2}\right) / \mathrm{a}_{\mathrm{pc}} \sqrt{2} \\
& \mathrm{~S}_{\mathrm{c} 2}=\left(\mathrm{a}-\mathrm{a}_{\mathrm{pc}}\right) / \mathrm{a}_{\mathrm{pc}}
\end{aligned}
$$

with the fraction $\phi_{\mathrm{c} 45} / 2 . \mathrm{S}_{\mathrm{c} 1}$ and $\mathrm{S}_{\mathrm{c} 2}$ are the misfit strains in the two in-plane directions of the $c_{45}$ domain. In the same case, for the a-domains, the strains are

$$
\begin{aligned}
& \mathrm{S}_{\mathrm{a} 1}=\left(\mathrm{a}-\mathrm{a}_{\mathrm{pc}}\right) / \mathrm{a}_{\mathrm{pc}} \\
& \mathrm{S}_{\mathrm{a} 2}=\left(\mathrm{c}-\mathrm{a}_{\mathrm{pc}}\right) / \mathrm{a}_{\mathrm{pc}},
\end{aligned}
$$

Here $S_{\mathrm{a} 1}$ and $\mathrm{S}_{\mathrm{a} 2}$ are the misfit strains in the two in-plane directions of the $a$ domains. The fraction weighted average misfit strain becomes,

$$
\mathrm{S}_{\mathrm{m}}=\left(\phi_{\mathrm{c} 45} / 2\right)\left(\mathrm{S}_{\mathrm{c} 1}+\mathrm{S}_{\mathrm{c} 2}\right)+\left(\left(1-\phi_{\mathrm{c} 45}\right) / 2\right)\left(\mathrm{S}_{\mathrm{a} 1}+\mathrm{S}_{\mathrm{a} 2}\right)
$$

This misfit strain was calculated with the measured tetragonal lattice constants for $\mathrm{x}=0.2$ and 0.3 and the domain fraction obtained from the polarization loops. In our study, the misfit strain values are $\mathrm{S}_{\mathrm{m}}=0.2\left(10^{-3}\right)$, and $\mathrm{S}_{\mathrm{m}}=0.8\left(10^{-3}\right)$, respectively. In the case of the rhombohedral unit cell there are only two inplane lattice constants $b=a_{p c} \sqrt{2} \sin \gamma$ and $a_{p c}$, each with fraction $1 / 2$.and the strain $\mathrm{S}_{\mathrm{m}}=1 / 2\left(\mathrm{~S}_{\mathrm{c} 1}+\mathrm{S}_{\mathrm{a} 1}\right)$.

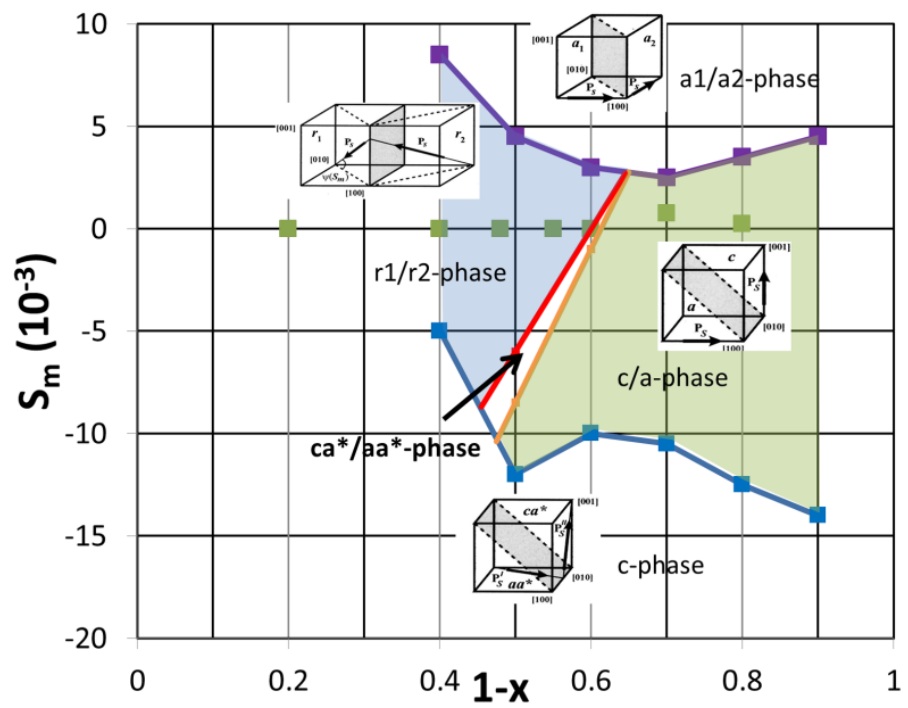

Figure 4.3 Room temperature phase diagram deduced from literature ${ }^{21}$, for a thick, clamped (001) film. The data points are obtained for the (110) $\mathrm{PbZr}_{\mathrm{x}} \mathrm{Ti}_{1-\mathrm{x}} \mathrm{O}_{3}$ films discussed in this chapter. 
The (110) PZT thin film can relax stress in several ways. Near the deposition temperature this occurs through misfit dislocations (grain boundaries, threading dislocations), but at lower temperatures linear strain and/or angular distortion of the pseudo cube may build up, and below the transition temperature strain can be relaxed by crystallographic domain configurations. The resulting strain is due to minimization of the free energy with respect to polarization domain structure and linear and angular strain. The strain values, calculated from measured lattice parameters and domain fractions, indicate that nanodomain formation is the energetically most favorable way to relax the strain for $x \geq 0.4$, whereas for the more tetragonal compositions it is by $c_{45} / a$ domain formation. The fact that the phase transition in the (110) films coincides with the computed phase transition for strain free (001) films suggests that it is not sensitive to the orientation of the plane in which the strain conditions are applied. In the following we show that the phase change is reflected in a divergence of the dielectric, ferroelectric and piezoelectric properties at the phase boundary, similarly as predictions by the models for (001) films.

\subsubsection{Scanning Electron Microscopy measurements}

Besides the x-ray diffraction analysis, scanning electron microscopy was also used to study the crystalline structure and the film compositions. Figure 4.4 (a) shows the cross section image of a $\mathrm{PbZr}_{0.4} \mathrm{Ti}_{0.6} \mathrm{O}_{3}$ thin film on a silicon substrate. A firmly dense PZT thin film with columnar structure was achieved by applying a thin YSZ buffer layer. The film thickness is $500 \mathrm{~nm}$. Figure 4.4 (b) is the top view of the PZT thin film. In order to study the film compositions, energy dispersive X-ray spectroscopy technique is used for elemental analysis. From figure 4.4 (c), we can see the $\mathrm{Zr}-\mathrm{L}, \mathrm{Pb}-\mathrm{M}$, Ti-K and Si-K peaks are presented. When we do the quantitative study, we can get the elemental composition in weight percentage, atomic percentage, etc. From this measurement, we obtained an atomic ratio of $\mathrm{Zr} / \mathrm{Ti}$ is 0.73 (corresponded to $\mathrm{PbZr}_{0.42} \mathrm{Ti}_{0.58} \mathrm{O}_{3}$ ), which is slightly different from the desired target $\mathrm{PbZr}_{0.4} \mathrm{Ti}_{0.6} \mathrm{O}_{3}$. The difference could be caused be the accuracy of the equipment and the measurement technique. As we 
know, the accuracy of EDS spectrum can be affected by various factors, such as, film thickness, spot size and selected measured areas, inhomogeneity and the roughness of the surface, etc.

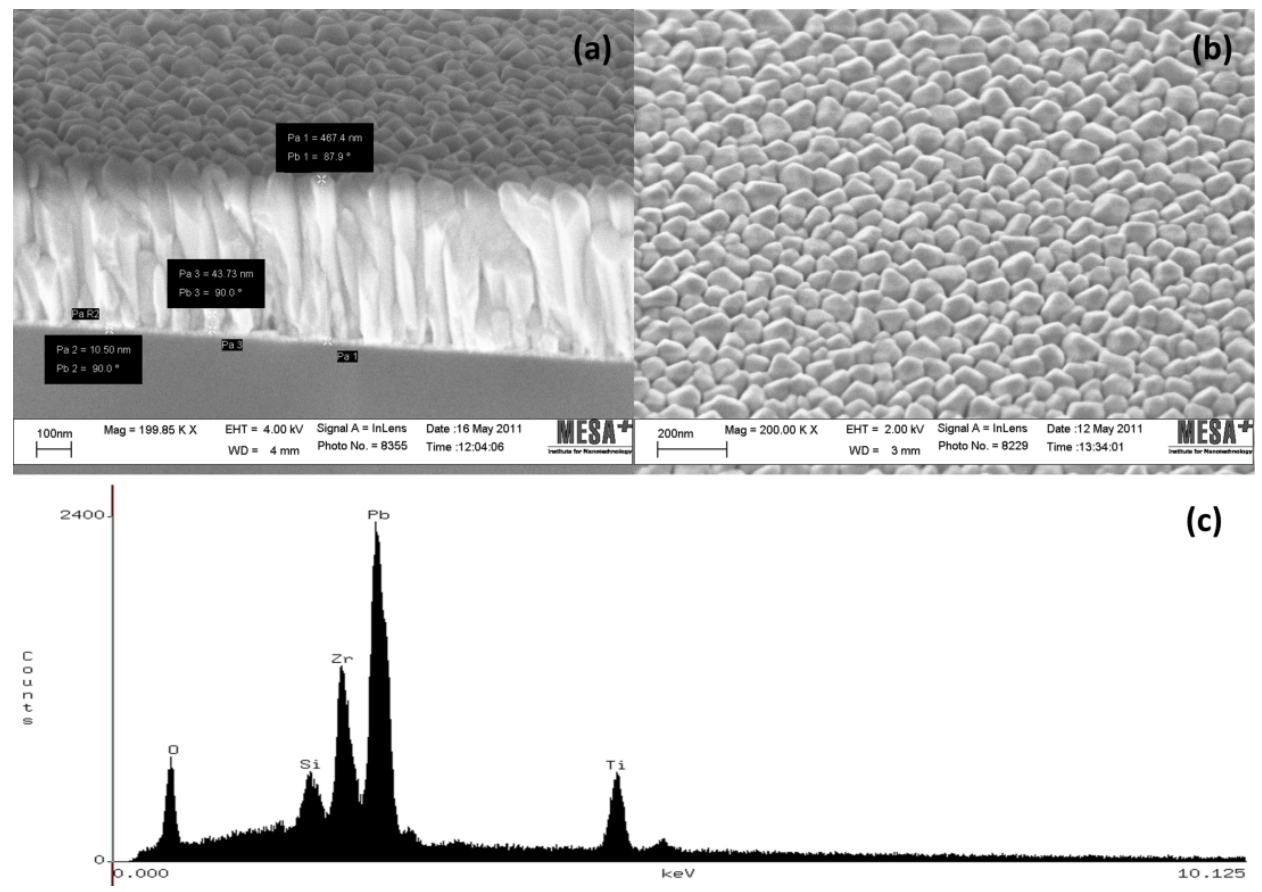

Figure 4.4 SEM imaging of $\mathrm{PbZr}_{0.4} \mathrm{Ti}_{0.6} \mathrm{O}_{3}$ thin film grown on silicon substrates. (a) cross section imaging (b) top view imaging (c) Energy dispersive $\mathrm{X}$-ray spectra (EDS) analysis of $\mathrm{PbZr}_{0.4} \mathrm{Ti}_{0.6} \mathrm{O}_{3}$ thin film.

\subsection{Functional properties}

\subsubsection{Ferroelectricity}

Polarization hysteresis loops were measured after $10^{8}$ cycles, see figure 4.5. After an initial poling procedure no degradation of the loops is observed up to this number of cycles, which proves the aging stability of these devices. In figure 4.6, the loop saturation polarization $P_{s, \text { loop }}$ is determined from the P-axis cut off 
of the high-field tangent to the loops. For comparison, the literature values $P_{s}$ for the polarization is given from Haun's work ${ }^{25}$, which is plotted in the green line and red line in the figure 4.6. As we can see, the measured polarization values follows well with the literature calculations.

For the $r$-phase one expects that the polarization vector can easily rotate in the (11̄0) symmetry plane of the (110) orientated pseudocube, under influence of the applied field or by strain. The measured polarization is $P_{r, \text { meas }}(E=0)=P_{s} \cos \theta_{r}$, where $\theta_{r}$ is the angle of the polarization vector with the film normal. The curve $P_{r, \text { meas }}$ is drawn for a tilt $\theta_{r}=53^{\circ}$, which is the average for the four $r$-phase compositions. Note that the polarization vector in this case is rotated much further into the plane then if it were aligned along the body diagonal $\left(\theta_{r}=35^{\circ}\right)$, indicating a significant shear deformation in the $(1 \overline{1} 0)$ plane as well. For large fields the polarization is aligned along the field and $P_{s, \text { meas }}(E>>0)=P_{s}$. In the tetragonally distorted pseudocubic $c_{45} / a$ phase the saturation polarization is determined by the domain fraction $\phi_{c 45}$ of $c_{45}$-domains, $P_{s, \text { meas }}=\phi_{c, 45}(E>>0) P_{s}$. The domain fraction can hardly be changed by the electrical field, since this involves a large change in the elastic energy of the system. Therefore the domain fraction at zero field, $\phi_{c, 45}(E=0)$, determining the remnant polarization, is only slightly smaller. This behavior is clearly observed in figure 4.6. For $\mathrm{x}>0.4$ the measured $P_{s, \text { meas }}$ and $P_{r \text {,meas }}$ are well described by the values $P_{s}(x)$ and $P_{s}(x) \cos \left(\theta_{r}\right)$, whereas for $\mathrm{x}<0.4$ there is an abrupt jump in $P_{s, \text { meas }}$ and the difference between $P_{s, \text { meas }}$ and $P_{r \text {,meas }}$ is much less. The domain fractions are approximately $\phi_{c, 45}(E>>0) \approx 0.79$ and $\phi_{c, 45}(E=0) \approx 0.63$, indicating that approximately $14 \%$ of the $a$-domains change into $c_{45}$-domains under high field conditions. 


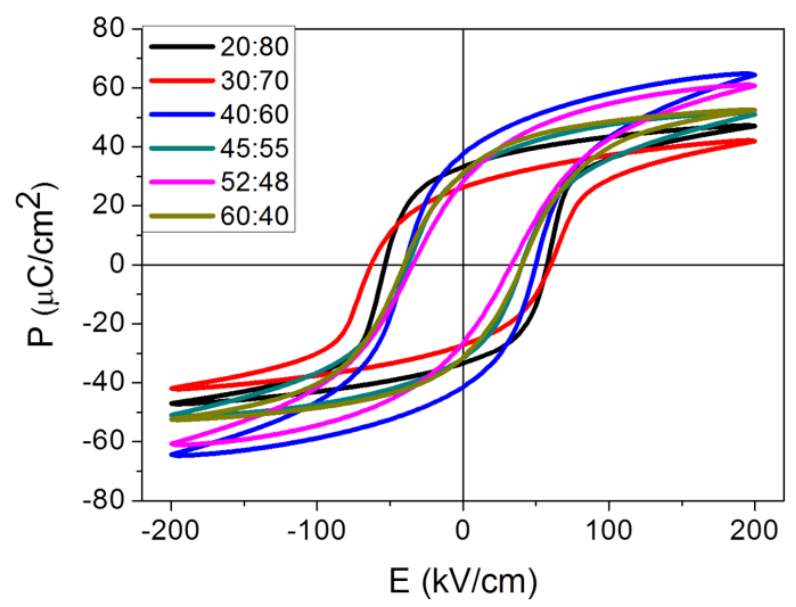

Figure 4.5 Polarization hysteresis (P-E) loops of (110) orientated $\mathrm{PbZr}_{\mathbf{x}} \mathrm{Ti}_{(1-\mathrm{x})} \mathrm{O}_{3}$ thin films, with the frequency of $1 \mathrm{kHz}$

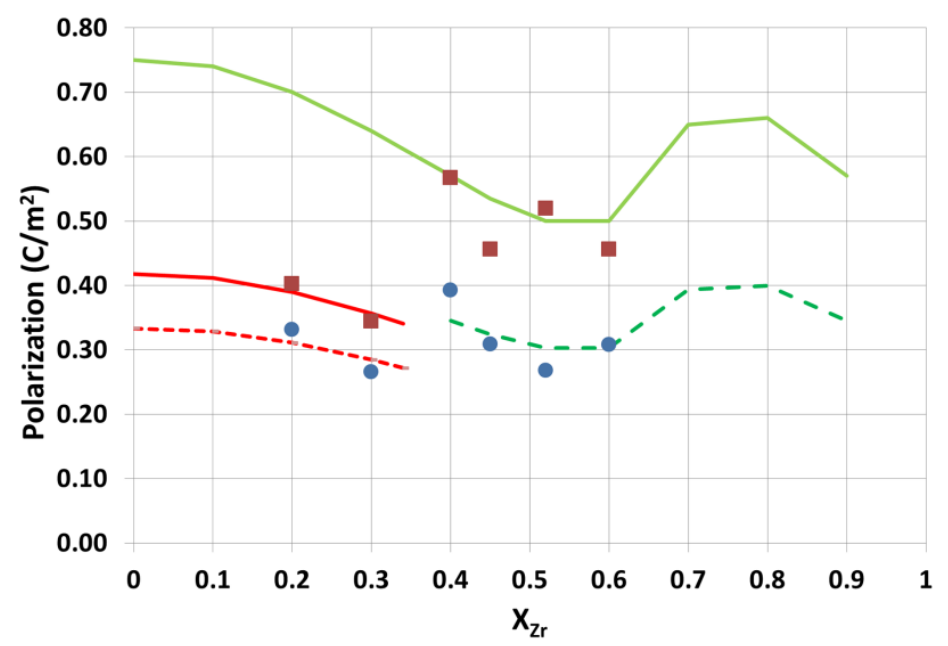

Figure 4.6 Modeled ${ }^{25}$ (lines) and measured saturation (red square) and remnant polarization (blue dot) as function of $\mathrm{Zr}$ fraction. Solid green line is the polarization values Ps of bulk crystal, which corresponds to the polarization vector aligned to applied field direction; Dashed green line is the saturation polarization in zero field direction, which close to body diagonal; Solid red is model for tetragonal (110) orientated macroscopic $c / a$ domain structure for $P(E>>0)=\phi c_{45}(P s / \sqrt{2})$, where 
$\phi c_{45}=0.79$; Dashed red is the model for tetragonal (110) orientated macroscopic c/a domain structure for $P(E=0)=\phi c_{45}(P s / \sqrt{2})$, where $\phi c_{45}=0.63$.

\subsubsection{Piezoelectricity}

The measured values of the effective piezoelectric parameter $e_{31}=<\mathrm{dD}_{3} / \mathrm{dS}_{1}>$, and the dielectric parameter $\varepsilon_{33}$ are shown in table 4.1. The $\mathrm{e}_{31, f}$ measurements were performed on $3 \times 25 \mathrm{~mm}^{2}$ devices, and have been repeated for different sets of devices, prepared in separate deposition runs, to confirm the reproducibility. With increasing $\mathrm{Zr}$ content, $e_{31, \text { eff }}$ strongly increases up to a very large value at $\mathrm{x}=0.4$, after which its value drops sharply, as shown in figure 4.7. There is also an increase of $\varepsilon_{33}$ at the $r$-phase side of the phase diagram going towards the phase boundary, as is also predicted for $\varepsilon_{33}$ by the model for (001) films ${ }^{21}$. This model also indicates that the properties only change gradually at the $c / a$ side of the phase diagram. With the obtained values the FOM values were calculated, see table 4.1, which shows an extreme FOM value of $24 \mathrm{GPa}$ at $\mathrm{x}=0.4$.

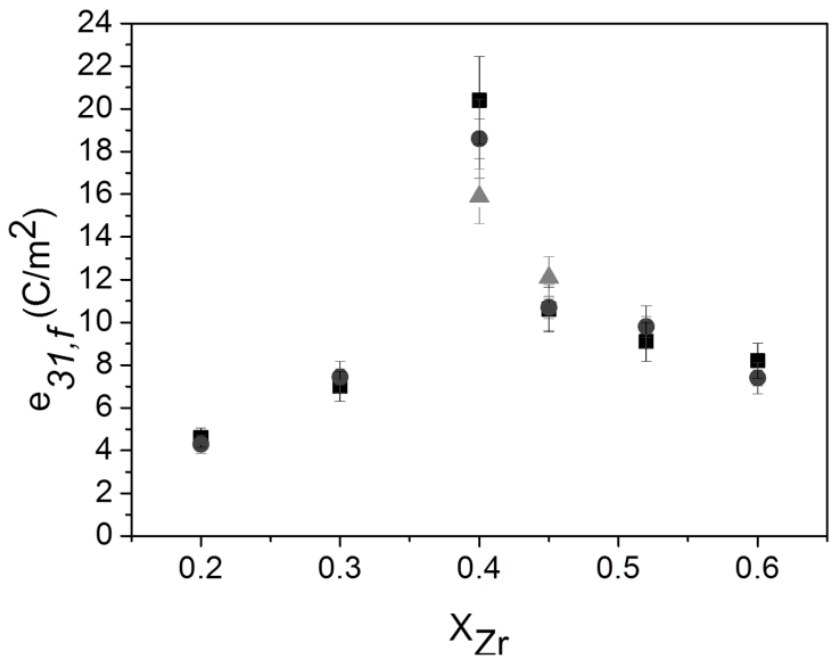

Figure 4.7 Piezoelectric coefficient $\mathrm{e}_{31, f}$ and dielectric constant of PZT thin films with various compositions. 


\begin{tabular}{|l|l|l|l|l|l|l|}
\hline $\mathrm{X}(\mathrm{Zr} \%)$ & 0.20 & 0.30 & 0.40 & 0.45 & 0.52 & 0.60 \\
\hline $\mathrm{e}_{31, f}\left(\mathrm{C} / \mathrm{m}^{2}\right)$ & 4.6 & 7.0 & 20.4 & 10.6 & 9.1 & 8.2 \\
\hline$\varepsilon$ & 677 & 839 & 1960 & 1376 & 1114 & 944 \\
\hline $\begin{array}{l}\mathrm{FOM} \mathrm{e}_{31}{ }^{2} / \varepsilon_{0} \varepsilon_{\mathrm{r}} \\
(\mathrm{GPa})\end{array}$ & 3.5 & 6.6 & 24.0 & 9.3 & 8.4 & 8.0 \\
\hline
\end{tabular}

Table 4.1 Dielectric constant and piezoelectric coefficients of epitaxial PZT thin films with different compositions.

\subsection{Conclusions}

In conclusion, $\mathrm{PbZr}_{\mathrm{x}} \mathrm{Ti}_{(1-\mathrm{x})} \mathrm{O}_{3}$ thin films with (110) orientation were successful grown on silicon substrates with $\mathrm{x}=0.2-0.6$. These films show excellent ferroelectric and piezoelectric properties. The strain states are discussed in each situation, which coincides with the phase boundary predicted by Kukhar \& Pertsev for thick and clamped (001) films. The morphotropic phase boundary shifts to the Ti-rich side of the phase diagram. We ascribe the observation to the formation of nanodomain in (110) PZT films on silicon substrates. Dielectric constant and piezoelectric coefficient are measured for different samples. An optimal $\mathrm{e}_{31, f}$ value of $20.4 \pm 3 \mathrm{C} / \mathrm{m}^{2}$ is measured in $\mathrm{PbZr}_{0.4} \mathrm{Ti}_{0.6} \mathrm{O}_{3}$ thin film with (110) orientation, where a giant figure of merit is achieved with the value of 24 GPa. As far as we know, such high e 31 .f value has not been reported before. An optimum PZT thin film with enhanced piezoelectric properties may significantly boost the development and implantation in mechanical energy harvester devices. 


\subsection{References}

1 P. Muralt, R. G. Polcawich, and S. Trolier-Mckinstry, MRS Bulletin 34, 658 (2009).

2 S. Trolier-McKinstry and P. Muralt, Journal of Electroceramics 12, 7 (2004).

3 R. J. M. Vullers, R. van Schaijk, I. Doms, C. Van Hoof, and R. Mertens, Solid-State Electronics 53 (7), 684 (2009).

4 K. Karakaya, M. Renaud, M. Goedbloed, and R. van Schaijk, Journal of Micromechanics and Microengineering 18 (10), 104012 (2008).

5 R. Elfrink, T. M. Kamel, M. Goedbloed, S. Matova, D. Hohlfeld, Y. van Andel, and R. van Schaijk, Journal of Micromechanics and Microengineering 19 (9), 094005 (2009).

6 S. Roundy, P. K. Wright, and J. M. Rabaey, Energy scavenging for wireless sensor networks. (Kluwer Academic Publishers Group, 2004).

7 B. Noheda, Current Opinion in Solid State\&Materials Science 6, 27 (2002).

$8 \quad$ Stewart Sherrit, Harvey D. Wiederick, and Benoy K. Mukherjee, 1997 (unpublished).

9 Emmanuel Defay, Christophe Zinck, Christophe Malhaire, Nicolas Baboux, and Daniel Barbier, Review of Scientific Instruments 77 (10), 103903 (2006).

10 R. A. Wolf and S. Trolier-McKinstry, Journal of Applied Physics 95 (3), 1397 (2004).

11 F. Calame and P. Muralt, Applied Physics Letters 90 (6), 062907 (2007).

12 Shintaro Yokoyama, Satoshi Okamoto, Hiroshi Funakubo, Takashi Iijima, Keisuke Saito, Hirotake Okino, Takashi Yamamoto, Ken Nishida, Takashi Katoda, and Joe Sakai, Journal of Applied Physics 100 (5), 054110 (2006).

13 N. Bassiri Gharb and S. Trolier-McKinstry, Journal of Applied Physics 97 (6), 064106 (2005). 
S. H. Baek, J. Park, D. M. Kim, V. A. Aksyuk, R. R. Das, S. D. Bu, D. A. Felker, J. Lettieri, V. Vaithyanathan, S. S. Bharadwaja, N. BassiriGharb, Y. B. Chen, H. P. Sun, C. M. Folkman, H. W. Jang, D. J. Kreft, S. K. Streiffer, R. Ramesh, X. Q. Pan, S. Trolier-McKinstry, D. G. Schlom, M. S. Rzchowski, R. H. Blick, and C. B. Eom, Science 334 (6058), 958 (2011).

Matthijn Dekkers, Minh D. Nguyen, Ruud Steenwelle, Paul M. te Riele, Dave H. A. Blank, and Guus Rijnders, Applied Physics Letters 95 (1), 012902 (2009).

Minh D. Nguyen, University of Twente, 2010.

Science 324, 367 (2009).

R. Steenwelle, University of Twente, 2012.

A. K. Sharma, J. Narayan, C. Jin, A. Kvit, S. Chattopadhyay, and C. Lee, Applied Physics Letters 76 (11), 1458 (2000).

N. Pertsev, V. Kukhar, H. Kohlstedt, and R. Waser, Physical Review B 67 (5) (2003).

V. Kukhar, N. Pertsev, H. Kohlstedt, and R. Waser, Physical Review B 73 (21) (2006).

B. Noheda, D.E. Cox, G. Shirane, J. A. Gonzalo, L. E. Cross, and S-E. Park, Applied Physics Letters 74 (14), 2059 (1999).

R. Steenwelle, E. Houwman, X. Wan, M. Dekkers, M. D. Nguyen, and G. Rijnders, (2013).

Klaus; Tiedke Prume, Stephan; Schmitz-Kempen, Thorsten, Mikroniek 4, 31 (2010).

M.J. Haun, E. Furman, S. Trolier-McKinstry, and L. E. Cross, (1989), Vol. 99, p. 27. 
Chapter 4

Page $\mid 70$ 


\title{
Chapter 5
}

\section{Soft-doping and hard-doping of $\operatorname{PbZr}_{\mathrm{x}} \mathbf{T i}_{(1-\mathrm{x})} \mathrm{O}_{3}$ epitaxial thin films}

\begin{abstract}
In this chapter, $\mathrm{Nb}$-doped and Fe-doped PZT thin films were grown on silicon substrates with both (110) orientation and (001) orientation by pulsed laser deposition. The functional properties of epitaxial thin films are modified by adding dopants. The figure of merit $\left(\mathrm{FOM}=\mathrm{e}_{31, f} / \varepsilon\right)$ is calculated for each film. $\mathrm{Nb}$-doped PZT films have the highest piezoelectric coefficient $\left(\mathrm{e}_{31, f}\right)$, while Fedoped PZT has the lowest $\mathrm{e}_{31, f}$. The doping mechanism is discussed. Giant imprint behavior is observed in (001) orientated epitaxial thin films. The dopants bring extra defect dipoles in the thin films. Under the epitaxial growth, the defect dipoles are aligned in one direction, which causes the imprint in PE loops. This build in bias reduces the dielectric constant at zero bias. In this case, the highest FOM is obtained in (001) orientated Nb-doped PZT thin films grown on STO buffered silicon substrates.
\end{abstract}




\subsection{Introduction}

Ferroelectric thin films, such as $\mathrm{PbZr}_{\mathrm{x}} \mathrm{Ti}_{(1-\mathrm{x})} \mathrm{O}_{3}(\mathrm{PZT})$ materials attract a great interest for the application of energy harvesting devices due to their large piezoelectric coefficient, and compatibility with MEMS fabrication ${ }^{1}$. Epitaxial PZT thin films have an enhanced and unique piezoelectric properties compared to non-epitaxial thin films and bulk materials ${ }^{2,3}$. In energy harvesting devices, the power output of the harvester is mainly limited by the figure of merit $\left(\mathrm{FOM}=\mathrm{e}_{31, \mathrm{f}}{ }_{\mathrm{f}}^{2} / \varepsilon\right)$, which is determined by both intrinsic and extrinsic properties of the films. It is therefore important to seek for the right materials with a large piezoelectric coefficient and a small dielectric constant. The material properties can be optimized by adding additional dopants in the films ${ }^{4}$.

Damjanovic et al..$^{5}$ performed the studies on acceptor and donor doped ceramic PZT materials. Dielectric responses show difference, which are related to ageing, hardening and softening in ceramic PZT. Niobiums doped PZT films deposited by a sol-gel method were discussed by Kwok et al. ${ }^{6}$ and Souza et al. ${ }^{7}$. Iron and Iron-Barium doped PZT ceramics and thin films were investigated by Bai et al. ${ }^{8}$ and Sangawar et al. ${ }^{9}$ The doping effect in both piezoelectric and dielectric properties were discussed in each case. A high piezoelectric coefficient was obtained in niobium doped PZT, while a high mechanical quality factor was found in iron doped PZT materials. A-site strontium doped PZT ceramics were grown and studied by Kozielski et al. ${ }^{10}$ In their work, the electrical properties of doped ceramics were studied in different temperature ranges. Most of the work related doped PZT materials was carried on polycrystalline thin films and bulk ceramics. The effect of dopants on epitaxial thin films has not been investigated much. Feigl et al. ${ }^{11}$ added chromium as a dopant in $\mathrm{PbZr}_{0.2} \mathrm{Ti}_{0.8} \mathrm{O}_{3}$ epitaxial thin films, while $\mathrm{SrTiO}_{3}$ was used as the substrate. They claimed the electrode properties were modified due to the creating local deformations and defect dislocations. From all the works above, we can see, dopants are commonly added to PZT thin films to adjust their properties. Dielectric, ferroelectric and 
piezoelectric properties changes were observed and discussed in different situations. However, the physical mechanisms have not been fully described. In term of epitaxial ferroelectric thin films, the electrical behaviors and the physical mechanisms can be different with the polycrystalline materials.

To understand the doping mechanism in epitaxial thin films, $\mathrm{Nb}^{5+}$ and $\mathrm{Fe}^{3+}$ were chosen, as one is a donor dopant and the other is an acceptor dopant. Epitaxial PZT thin films with either $1 \% \mathrm{~mol} \mathrm{Nb} \mathrm{s}^{5+}$ or $1 \% \mathrm{~mol} \mathrm{Fe}^{3+}$ dopants were grown on STO and silicon substrates. $\mathrm{SrRuO}_{3}$ was used as oxide electrodes for electrical measurements. YSZ was used as a buffer layer on silicon substrates. In this chapter, first of all, a general introduction and backgrounds were discussed, followed by a doping model in PZT perovskite materials and why we chose $\mathrm{Nb}^{5+}$ or $\mathrm{Fe}^{3+}$ as dopants. In section 5.2, the growth and properties of (110) orientated doped PZT thin films were discussed and studied. An enhanced piezoelectric coefficient was obtained in Nb-PZT thin films. In section 5.3, (001) orientated doped PZT thin films grown on both STO substrates and silicon substrates were studied. Large imprint P-E loops (asymmetric polarization switching) were achieved in (001) orientation films. A detailed analysis and comparisons are presented. The mechanisms of the imprint behaviors are discussed. A final conclusion is drawn in section 5.4.

\subsubsection{Dopants categories}

As discussed in the previous section, both ceramics and thin films PZT materials were grown with various dopants elements to tailor the electric and piezoelelctric properties for particular applications. For the broad range of selected dopants, Damjanovic et $a .^{4}{ }^{4}$ divided those materials into two categories of hard-doping and soft-doping materials. Here, hard-doping refers to acceptor doping, while soft-doping refers to donor doping.

PZT is a typical perovskite material with a $\mathrm{ABO}_{3}$ structure, where type " $\mathrm{A}$ " atom is at the cube corners, type " $\mathrm{B}$ " atom is at the body center position and the 
oxygen atoms are in face centers. In case of PZT materials, the charge of A is $2+$, and the charge of B is 4+. For "Hard" PZT refers to dopant $\mathrm{X}^{+}$in place of $\mathrm{A}^{2+}$ on the $\mathrm{A}$ site or $\mathrm{X}^{3+}$ in place of $\mathrm{B}^{4+}$ on the $\mathrm{B}$ site, which are called A-site acceptor doping, and B-site acceptor doping, respectively. In the same case, "Soft" PZT refers to $\mathrm{X}^{3+}$ in place of $\mathrm{A}^{2+}$, or $\mathrm{X}^{5+}$ in place of $\mathrm{B}^{4+}$, which corresponds to A-site donor doping, and B-site donor doping, respectively. When the ferroelectric material is doped with an acceptor dopant, a low valence atom is implanted. A positive charged oxygen vacancy $V_{O}^{*}$ is created to neutralize the induced charge. When the ferroelectric material is in a soft doping composition, additional electrons will create a lead vacancy $V_{P b}^{\prime \prime}$. The dipoles will be generated in the ferroelectric domains. As described by Jaffe et al. in the book Piezoelectric Ceramics ${ }^{12}$, the soft doping PZT materials possess high piezoelectric coefficients, high dielectric constant and losses, while the hard doping PZT behaves in the opposite way ${ }^{13}$. The reasons for the different properties between the soft and hard doping PZT materials are still not well understood. One explanation given by Damjanovic et al. ${ }^{14}$ is, in the perovskite structure $\mathrm{ABO}_{3}$, when considering the size difference between cations and anions, and the distance between two neighbor cations, one can understand that oxygen vacancy sites move more easily than the $V_{P b}^{\prime \prime}$ donor pairs. The mechanism of the hardening ferroelectric ceramics is given by Cart et al. ${ }^{15}$ and Robels et al. ${ }^{16}$ In a ferroelectric ceramics cube, the dipoles are randomly oriented, which may lie along any of the six equivalent directions (followed B-O bond). The polarizations directions in different domains are determined by the defect dipoles. Thus the domain wall becomes difficult to move under electric field, and the ceramic becomes hard.

\subsubsection{Dopants selection}

In this study, we focus on B-site doping. Both acceptor dopant $\left(\mathrm{Fe}^{3+}\right)$ and donor dopant $\left(\mathrm{Nb}^{5+}\right)$ are used for epitaxial thin film growth. In order to make sure the doped elements fit into the original lattices, the ionic radius is an important parameters to consider. Table 1 shows that the ionic radius of both $\mathrm{Nb}^{5+}$ and $\mathrm{Fe}^{3+}$ are closed to that of $\mathrm{Ti}^{4+}$ and $\mathrm{Zr}^{4+}$, which means $\mathrm{Nb}^{5+}$ and $\mathrm{Fe}^{3+}$ can be easily Page $\mid 74$ 
doped in the $\mathrm{B}$ site of this perovskite oxide structure. In this work, we used targets of $1 \%$ mol Nb${ }^{5+}$ doped on B-site of $\mathrm{PbZr}_{0.52} \mathrm{Ti}_{0.48} \mathrm{O}_{3}$ and $1 \% \mathrm{~mol} \mathrm{Fe}$ doped on $\mathrm{B}$-site of $\mathrm{PbZr}_{0.52} \mathrm{Ti}_{0.48} \mathrm{O}_{3}$, respectively. In this chapter, $\mathrm{Nb}$ doped PZT refers to $\mathrm{Pb}\left(\mathrm{Zr}_{0.52} \mathrm{Ti}_{0.48}\right)_{0.99} \mathrm{Nb}_{0.01} \mathrm{O}_{3}$, and $\mathrm{Fe}$ doped $\mathrm{PZT}$ refers to $\mathrm{Pb}\left(\mathrm{Zr}_{0.52} \mathrm{Ti}_{0.48}\right)_{0.99} \mathrm{Fe}_{0.01} \mathrm{O}_{3}$. (110) orientated doped-PZT films are grown on silicon substrates buffered with YSZ and SRO electrodes. (001) orientated doped-PZT films with the thickness of $500 \mathrm{~nm}$, are grown on both STO buffered silicon substrates and STO substrates. SRO was used as top and bottom electrodes for ferroelectric measurements. For the $\mathrm{e}_{31, \mathrm{f}}$ piezoelectric coefficient measurements, SRO was used as bottom electrodes and platinum was used as top electrodes.

\begin{tabular}{|c|c|c|c|c|c|}
\hline Ion & $\mathrm{Pb}^{2+}$ & $\mathrm{Ti}^{4+}$ & $\mathrm{Zr}^{4+}$ & $\mathrm{Nb}^{5+}$ & $\mathrm{Fe}^{3+}$ \\
\hline Ionic radius & 1.19 & 0.61 & 0.72 & 0.64 & 0.65 \\
\hline
\end{tabular}

Table 5.1 Ionic radius of different ions for coordination number 6.

\section{2 (110) orientated PZT films with $\mathrm{Nb}$ and Fe dopants}

\subsubsection{Sample fabrication and crystallographic structure}

The $500 \mathrm{~nm}$-thick $\mathrm{Nb}$ doped PZT and Fe doped PZT epitaxial thin films were grown on silicon substrates buffered with a $100 \mathrm{~nm}$-thick $\mathrm{SrRuO}_{3}$ (SRO) bottom electrode and a $30 \mathrm{~nm}$-thick YSZ layer. Different top electrodes were chosen for different measurement purposes. For piezoelectric coefficient $\left(\mathrm{e}_{31, f}\right)$, platinum was chosen as a top electrode ( $2 \times 8 \mathrm{~mm}^{2}$ structured by stencil mask) for its good electrical contact and laser reflection properties required by the four point bender set up, see section 2.4.4. ${ }^{17,18}$ The crystallographic properties and the compositions measurements, such as X-ray diffraction, scanning electrode microscopy, and X-ray fluorescence spectroscopy, were carried out on large silicon chips $\left(25 \times 25 \mathrm{~mm}^{2}\right)$ with $\mathrm{Pt} / \mathrm{PZT} / \mathrm{SRO} / \mathrm{YSZ} / \mathrm{Si}$ heterostructures. For ferroelectric and dielectric measurements, $\mathrm{SrRuO}_{3}$ was used as a top electrode. The $100 \times 100 \mu \mathrm{m}^{2}$ sized capacitors were patterned by a lithography process, and 
structured by argon etching for the SRO electrodes and wet etching (BHF and $\mathrm{HCI}$ ) for the PZT thin films.

(a)

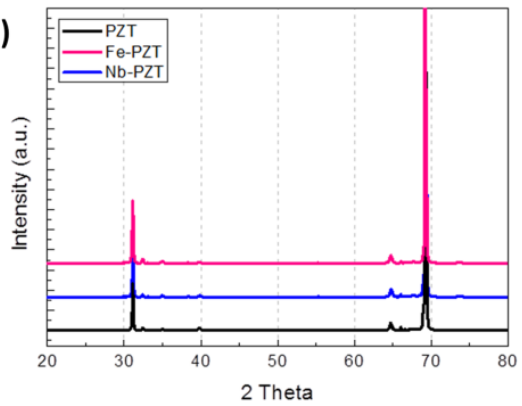

(c)

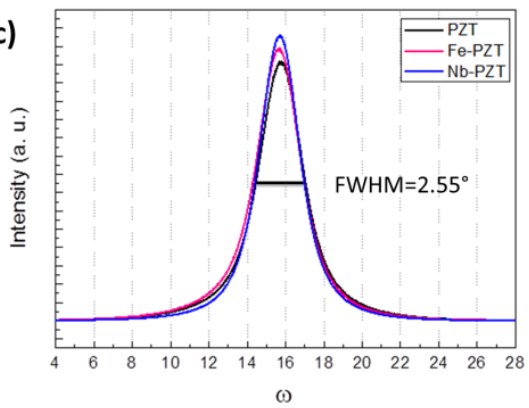

(b)

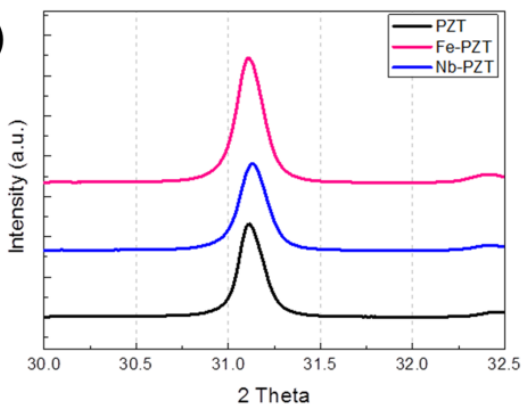

(d)

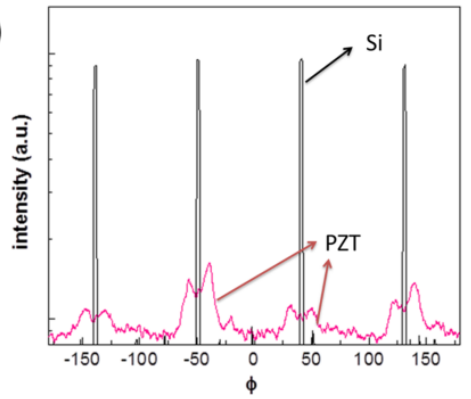

Figure 5.1 (a) Theta-2theta XRD pattern of non-doped PZT, Nb-PZT and Fe-PZT on SRO/YSZ/Si substrates. (b) is the zoom in (a) around (110) PZT peak. (c) Rocking curves recorded for the (110) PZT peak of those three samples. (d) Phi scan profiles of PZT (002) and silicon (202) reflections of the (110) PZT thin film.

Figure 1 (a) is the X-ray diffraction pattern of doped PZT thin films and nondoped PZT thin film. All these films show (110) orientated epitaxial growth. The SRO bottom electrodes are used to obtain epitaxial growth of PZT thin films. Figure 1 (b) is the zoom in peak of PZT (110) diffraction. Both $\mathrm{Nb}$ and Fe doped PZT films are well aligned at the same 2theta angle, which indicates that these two films have the same out of plane lattice parameters in crystal structure. The rocking curves around the (110) peaks are shown in figure 1 (c). The in-plane analysis of (110) orientated PZT thin films is done by Phi-scan, see, figure 1 (d). When the chi angle of the films are rotated by 45 degrees, both the silicon (202), and PZT (002) reflections can be reached. The four fold symmetry of the silicon substrate is shown in the phi scan, while for the PZT thin films, ten degrees 
rotation peaks in both directions are shown. A detailed discussion is presented in section 3.4. The phi scan curves of Nb-doped PZT and Fe-doped PZT thin films give the same results as the non-doped PZT films, and the curve is not shown here. The XRD results indicate a well oriented Nb-doped PZT and Fe-PZT thin films with $(110)$ orientation $\left(2\right.$ theta $\left.=31.12^{\circ}\right)$. The sharpness of the rocking curves at (110) diffraction peaks prove the film quality after growth. The FWHM of the rocking curve at (110) diffraction peak is about $2.55^{\circ}$. Figure 2 shows the cross section SEM images of $\mathrm{Nb}$ doped PZT thin film (without top electrode). It can be seen that the film grows in a columnar structure, with a high density and uniformity.

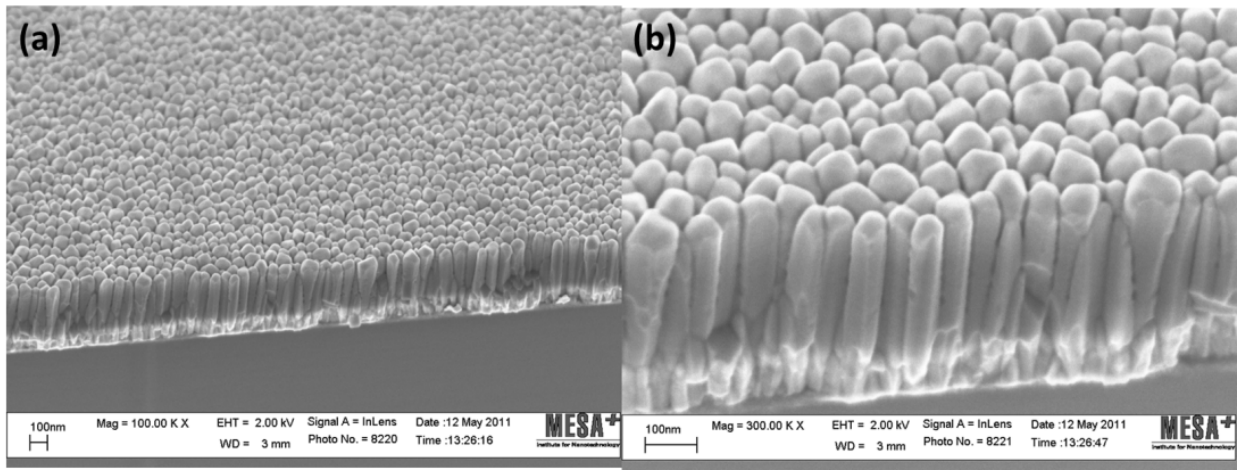

Figure 5.2 SEM images of cross sectional morphology of Nb doped PZT thin film with SrRuO3 and YSZ buffered on silicon surface.

To demonstrate the dopants in the PZT thin film, X-ray fluorescence spectroscopy (XRF) analysis is used. Figure 3 shows survey scans of $500 \mathrm{~nm}$ doped PZT thin films grown on silicon substrates with sample sizes of $25 \times 25$ $\mathrm{mm}^{2}$. Both $\mathrm{Nb}$-doped PZT and Fe-doped PZT thin films are analyzed and compared. Figure 3 (a) is the scan around the $\mathrm{Nb} \mathrm{L}$ line. A clear $\mathrm{Nb}$ peak is presented in Nb-doped PZT sample. Figure 3 (b) is the scan around the Fe K line, a qualitative difference was observed between the two samples. The $\mathrm{Fe}$ doped PZT thin film shows a sharper Fe peak in comparison with the other. Due to XRF sample preparations, there is always some inevitable Fe signal in the 
system. That is the reason we also see is a small Fe peak in Nb-doped PZT sample.

\subsubsection{Ferroelectricity and piezoelectricity}

From previous studies, we found that (110) PZT thin films with SRO top and bottom electrodes always show an improvement in remnant polarization $(\mathrm{Pr})$ when increasing the switching cycles ${ }^{19,}{ }^{20}$. In (110) orientated films, some spontaneous polarization is pinned by the defects at the interfaces between the two crystalline phase. In this case, we get both anti-ferroelectric and ferroelectric peaks in the initial polarization hysteresis $l o o p^{21}$. After repeated switching cycles, the defects are gradually removed, and the pinned spontaneous polarization will be free. Therefore the remnant polarization of (110) PZT thin films increased with increasing switching cycles.

The capacitors with SRO/PZT/SRO structures of Nb-doped PZT and Fe-doped PZT films were measured with the ferroelectric tester. Both of these samples show the polarization increasing behavior during switching cycles. Figure 4 shows the polarization hysteresis loops of the films measured after $10^{8}$ switching cycles. The remnant polarization and the coercive field $\left(\mathrm{E}_{\mathrm{c}}\right)$ of Nb-PZT is slightly higher than that of Fe-PZT, while the curve of non-doped PZT thin films is in the middle. The measurements were carried out at $1 \mathrm{kHz}$. 


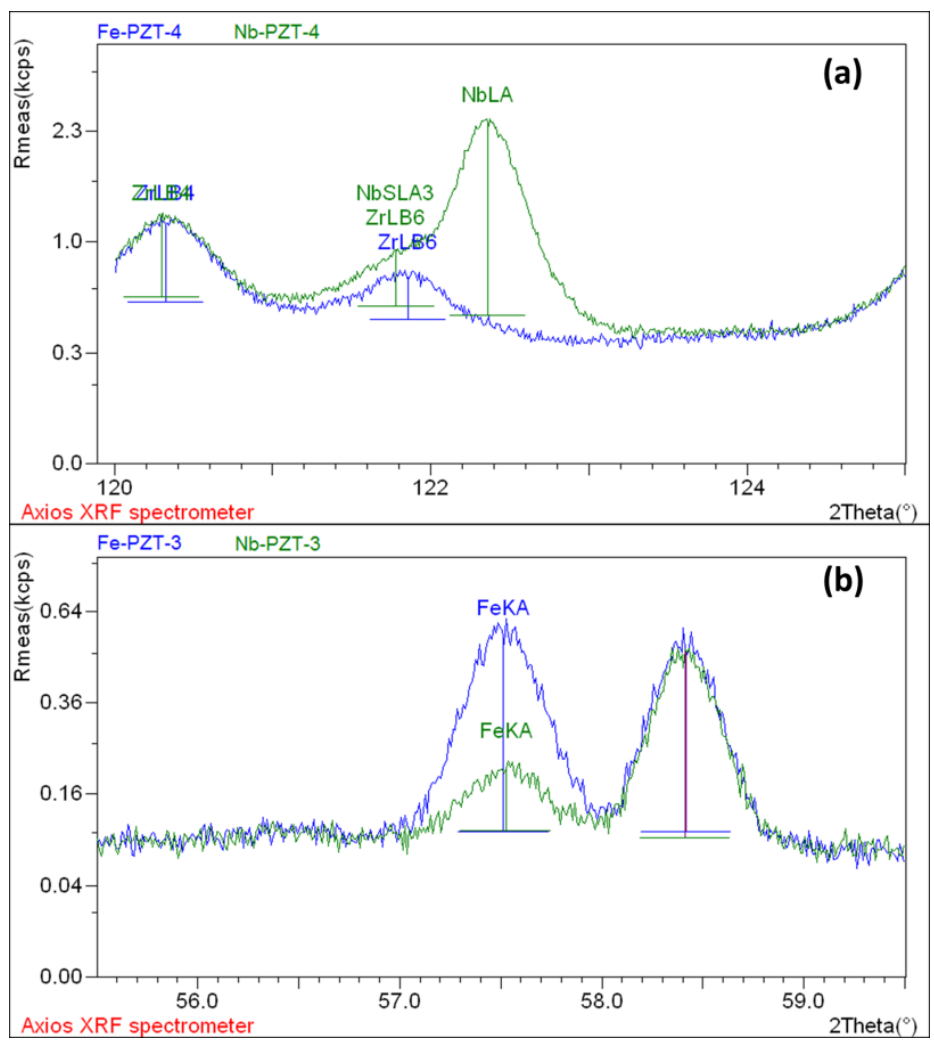

Figure 5.3 X-ray fluorescence spectroscopy analysis of Fe-PZT (blue line) and NbPZT (green line) thin films around (a) Nb-L line and (b) Fe-K line.

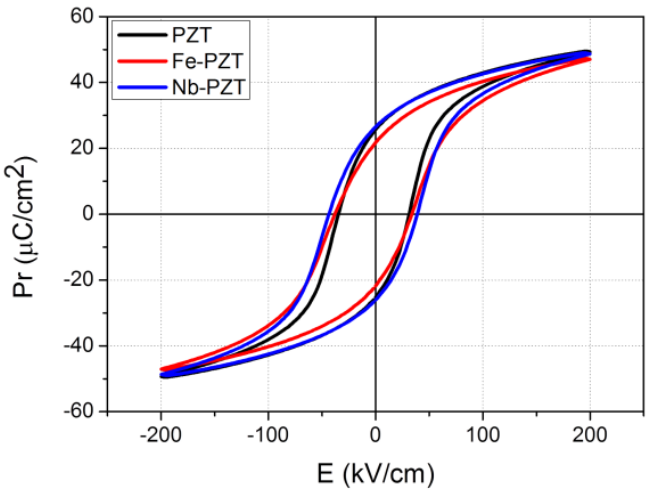

Figure 5.4 Polarization hysteresis loops of the SRO/doped PZT/SRO capacitors after $10^{8}$ cycles, measured at maximum driving field of $\pm 200 \mathrm{kV} / \mathrm{cm}$ and frequency of $1 \mathrm{kHz}$. 


\begin{tabular}{|l|l|l|l|}
\hline & Eielectric constant & $\mathrm{e}_{31, \mathrm{f}}\left(\mathrm{C} / \mathrm{m}^{2}\right)$ & $\mathrm{FOM}(\mathrm{Gpa})$ \\
\hline Non-doped PZT & 1250 & 9.2 & 7.7 \\
\hline (110) Nb-PZT & 1920 & 16.1 & 15.2 \\
\hline$(110)$ Fe-PZT & 1630 & 3.6 & 0.9 \\
\hline (001) Nb-PZT & 1715 & 16.5 & 18.0 \\
\hline
\end{tabular}

Table 5.2 Dielectric constant and piezoelectric coefficients of epitaxial PZT thin films with different dopants. Silicon substrates are used in each case.

The dielectric constants of PZT thin films with different dopants were obtained from CV measurements at a frequency of $10 \mathrm{kHz}$ and sweeping from -200 $\mathrm{kV} / \mathrm{cm}$ to $+200 \mathrm{kV} / \mathrm{cm}$. The dielectric constant of each sample at zero bias are given in table 5.2 The dielectric constant of $\mathrm{Nb}$-doped PZT is slightly higher than the non-doped PZT thin film and the Fe-doped PZT films. The out of plane displacements in the films were measured with the double beam laser Doppler interferometer (LDV). ${ }^{22}$ The longitudinal piezoelectric coefficient $\mathrm{d}_{33}$ at zero field is derived under small ac field $(8 \mathrm{kV} / \mathrm{cm})$ at $8 \mathrm{kHz}$, while the dc bias is sweeping at $\pm 200 \mathrm{kV} / \mathrm{cm}$. The $\mathrm{d}_{33}$ values are obtained as 120,116 and $105 \mathrm{pm} / \mathrm{V}$ for the non-doped PZT, Nb-doped PZT and Fe-doped PZT thin films respectively. The differences between each sample are not significant. However, when comparing the $\mathrm{e}_{31}$ values, which were measured with 4-point bender system on a pre-bended strip (see section 2.4.4), the piezoelectric coefficients $\left(\mathrm{e}_{31}\right)$ of these three samples are different. The $\mathrm{e}_{31, f}$ measurement of $\mathrm{Nb}$ doped PZT film gives an extremely high value $16.1 \mathrm{C} / \mathrm{m}^{2}$, while for the Fe doped PZT film, the $\mathrm{e}_{31, f}$ value is $3.6 \mathrm{C} / \mathrm{m}^{2}$, see table 5.2. From the calculation of the figure of merit in all the epitaxial (110) thin films, a high value is reached in $\mathrm{Nb}$ doped PZT, which is more suitable for harvesting devices, table 5.2.

\subsubsection{Discussions}

Both the crystallographic structure and the ferro-piezoelectric properties are investigated for doped epitaxial (110) orientated PZT thin films. The results of 
$\mathrm{X}$-ray fluorescence spectroscopy proved both the $\mathrm{Nb}$ and $\mathrm{Fe}$ are doped in the PZT thin films.

As described in literature ${ }^{4}$, the polarization of hard-doped PZT is smaller than the soft-doped PZT, and the polarization curves are slanted in hard PZT. In hard-doped PZT in bulk ceramics, the dipoles are randomly orientated in the individual grains, which could be any one of the six equivalent (100) directions. The polarization direction in a domain wall will be fixed by the defect dipole, which makes the domain wall difficult to move. Therefore, the ceramic becomes hard. The oxygen vacancy in hard-doped PZT is immobile compared to oxygen vacancies in the non-doped one ${ }^{23}$. However, the situation in an epitaxial thin film is different from bulk ceramic, since the films have a preferable growth orientation. In this case, all the doped and non-doped PZT thin films are grown on SRO/YSZ buffered silicon substrates with a (110) orientation. The dipoles are not orientated randomly, but follow the out of plane polarization direction. Thus the hardness decreases of epitaxial thin films is not as much as the bulk PZT. In figure 5.4, a degradation of remnant polarization and coercive electric field is observed in the Fe-doped PZT thin film, whereas the Nb-doped PZT film has a slightly large $\mathrm{E}_{\mathrm{c}}$.

The dielectric constant of Fe-doped PZT is slightly lower than that of Nb-doped PZT, the value being in agreement with literature ${ }^{24}$. The piezoelectric coefficient $\left(\mathrm{e}_{31, f}\right)$ of Nb-doped PZT film is much higher than the non-doped and Fe-doped PZT films. This is the softening effect as we discussed previously. One reason for the large $\mathrm{e}_{31, f}$ in soft-doped PZT is that the increase in $V_{P b}^{\prime \prime}$ and decrease in $V_{O}$ make the domains more mobile. When the film undergoes the same amount of stress, more charges can be generated in the films. 


\section{3 (001) orientated PZT films with $\mathrm{Nb}$ and Fe dopants}

\subsubsection{Sample fabrication and crystallographic structure}

In previous work ${ }^{19}$, it was shown that (001) PZT thin films have better ferroelectricity than (110) PZT films. In order to investigate the functional properties in epitaxial (001) orientated doped PZT thin films, both silicon substrates and $\mathrm{SrTiO}_{3}$ (STO) substrates are used in this section. First of all, (001) doped PZT thin films were grown on silicon with the $\mathrm{SrTiO}_{3}$ layer as buffer layer. The STO buffered layer was grown directly on a silicon substrate (380 $\mathrm{nm}$ ) by molecular beam epitaxy $(\mathrm{MBE})^{25}$. Afterwards, the SRO/PZT/SRO sandwich structures were grown and patterned for ferroelectric measurements, while Pt/PZT/SRO structures were grown for $\mathrm{e}_{31, f}$ measurements. Moreover, STO single crystals are used as substrates for ferroelectric properties studies.

Figure 5.5 shows the x-ray diffraction pattern of a $(001)$ orientated $\mathrm{Nb}$ doped PZT thin films and Fe doped thin films grown on STO buffered silicon substrates. Sharp (001) and (002) PZT diffraction peaks are observed. The peak position of $\mathrm{Nb}$ doped PZT films shifts to a smaller angle as compared to the same peak of Fe doped PZT films, which indicates the increase of the out of plane lattice paremeter in $\mathrm{Nb}$ doped PZT. The full width at half maximum (FWHM) values of the rocking curve in these samples are between $0.57^{\circ}$ to $0.59^{\circ}$, as shown in figure 5.5 (b). The epitaxial relationship between the films and the substrates were proved by X-ray diffraction. Good quality and single oriented films are grown on silicon substrates.

\subsubsection{Ferroelectricity and piezoelectricity}

Figure 5.6 shows the polarization hysteresis loops measured on doped PZT thin films grown on STO buffered silicon substrates. The black loop is the non-doped (001) PZT film. The hysteresis loop of Nb-doped PZT thin film is shifted to positive electric field, while the Fe-doped PZT is shifted to negative electric 
field. The horizontal shifts of the P-E loops are called imprint, which indicate the potential build-in bias in the films. The build-in bias for Nb-PZT films and FePZT films is in two different directions. Since more dipoles were induced by adding dopants, the alignments of the dipoles could be one of the reasons for the different imprint behavior.
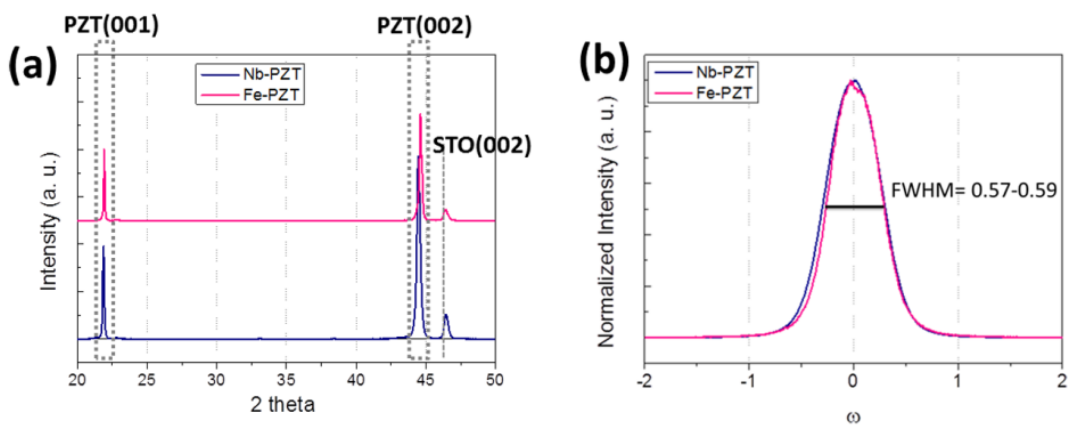

Figure 5.5 X-ray diffraction pattern of (001) orientated doped PZT thin films on STO buffered silicon substrates, where (a) is theta-2theta scan, (b) is the normalized rocking curve records for (002) PZT diffraction peaks.

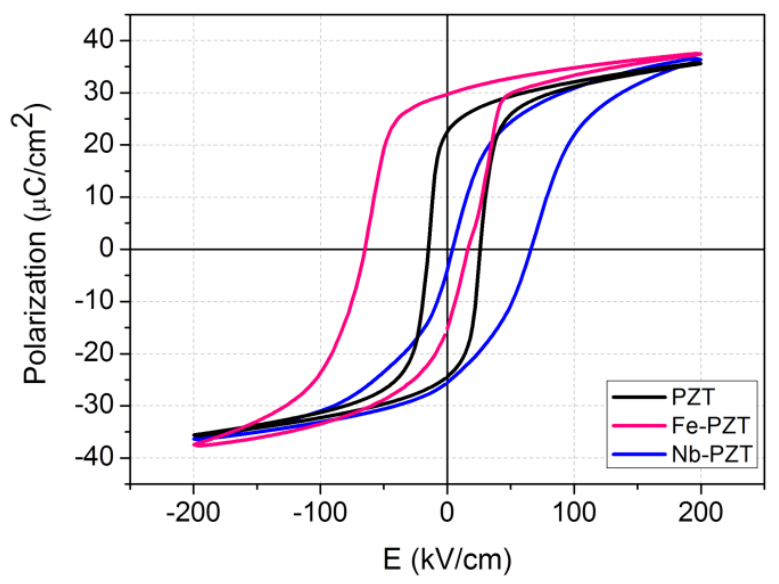

Figure 5.6 Polarization hysteresis loops of (001) Nb-PZT, non-doped PZT and FePZT capacitors grew on STO buffered silicon substrates. 
Moreover, to verify these results, both Nb-doped PZT and Fe-doped PZT thin films were grown directly on (001) STO substrates. Similar behavior was shown in figure 5.7. In this case, we again get P-E loops with imprint, as the Nb-doped PZT loop shifts to the positive side, and the Fe-doped PZT loop shifts to the negative side. In this case, a pinched loops is obtained in the Fe-doped PZT films with a higher polarization value. When (001) orientated doped-PZT thin films were grown textually or by sol-gel methods, no imprint behaviors in PE loops is observed as the same as in our work ${ }^{26,7,8,27}$. The build-in bias in piezoelectric thin films is an unique property for doped (001) epitaxial thin films with oxide electrodes.

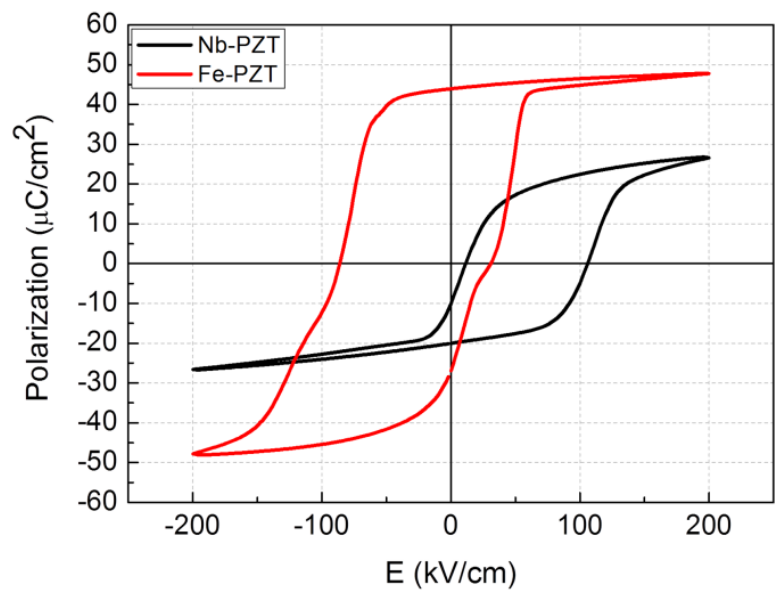

Figure 5.7 Polarization hysteresis loops of (001) Nb-PZT and Fe-PZT capacitors grew on STO substrates.

Piezoelectric coefficients $\left(\mathrm{e}_{31, f}\right)$ are measured in (001) Nb-PZT and Fe-PZT thin films grown on STO buffered silicon substrates, with the sandwich structures $\mathrm{Pt} / \mathrm{PZT} / \mathrm{SRO}$. These measurements are not performed on doped PZT grown on STO single crystal substrates, because first of all, $\mathrm{SrTiO}_{3}$ is a brittle material and not suitable for applying a pre stress in 4-point bender system; secondly, a special substrate geometry is required. For the piezoelectric measurements of (001) orientated doped PZT thin film, we obtained $\mathrm{e}_{31, f}$ values of $16.5 \mathrm{C} / \mathrm{m}^{2}$ for $\mathrm{Nb}$-doped PZT, and $3.8 \mathrm{C} / \mathrm{m}^{2}$ for Fe-doped PZT. The results are comparable 
with the values for the (110) orientated doped PZT thin films, see table 5.2. However, as we observed a giant imprint in the PE loops in (001) cases, we can expect a big shift in either positive or negative directions in the $\mathrm{CV}$ measurements. By applying a DC bias during the capacitance measurements, the center of the buffer fly loops will also move left or right. The dielectric constant is coupled with capacitance by $C=\varepsilon_{r} \varepsilon_{0} \frac{A}{d}$. Thus when we extract the dielectric constant at zero bias, the value is lower than the center value. As we discussed previously, the figure of merit is calculated by $F O M=\frac{e_{31, f}^{2}}{\varepsilon}$. In this case, the build-in bias in piezoelectric thin films are beneficial for harvesting devices. An enhanced power output can be expected. Figure 5.8 shows the dielectric constants of (001) orientated Nb-doped PZT thin films. Due to the build in bias, the dielectric constant is reduced from 1930 to 1715 . When we calculated the figure of merit, we got FOM=18.0 GPa.

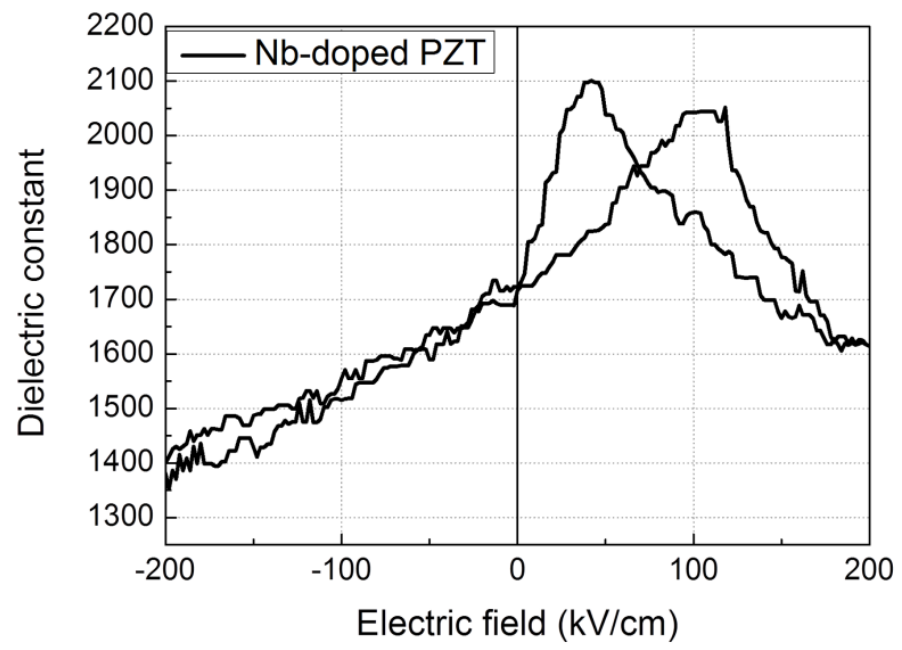

Figure 5.8 Dielectric constant of (001) Nb-doped PZT thin film measured as a function of electric field.

\subsubsection{Mechanisms of imprint effects}


To understand the physical mechanisms behind the imprint effects, we first go through the literature about imprint behavior in ferroelectric fields. The imprint is a phenomenon of the preference of a certain polarization state, which causes the asymmetry in the polarization loops. A variety of imprint loops have been observed in different situations, which is attributed to different mechanisms. Warren et al. ${ }^{28}$ discussed the occurrence of imprint in ferroelectric capacitors. He assumed the defect dipoles and oxygen vacancies play a role in the imprint behavior. Abe et al. ${ }^{29,30}$ attributed the imprint loops to a non-switching layer between the electrode and the ferroelectric films. These dead layers were formed due to strain relaxations in the heteroepitaxial thin films. Domain pinning was first used in experiments to explain the imprint in PE loop ${ }^{31,32}$. The asymmetry behavior in ferroelectric films has also been studied in a Landau free energy ${ }^{33}$. The polarization imprint in vertical direction was discussed by Ma et al. ${ }^{34}$. Hong et al. ${ }^{35}$ did AFM studies on the ferroelectric domains and growth during the polarization switching. The growth models of both forward domains and sideways domains were investigated. Different electrodes materials in ferroelectric capacitors can cause a small shift in polarization loops ${ }^{36}$; while the imperfect surface layer can also lead to the asymmetric nature in thin films ${ }^{37}$. All together, we can conclude that the physical mechanisms behind the imprint of the PE loop are not yet well understand. We notice that, the imprint behavior discussed in the literatures did not show as large a shift in positive or negative direction as was observed in our work. Thus, a general and precise physical mechanism is essential for the epitaxial doped PZT thin films.

Zhou et al. ${ }^{38}$ introduce a model to explain the large horizontal imprint in hysteresis loops. Three main effects are considered as followed: (1) stress induced by lattice mismatch or clamping effects, (2) domain pinning and defect dipoles, (3) degradation of the ferroelectric properties induced by graded dead layers. The third situation is not applicable in our case, since we did not observe degradation in case of remnant polarization, dielectric permittivity, etc. For a perfect epitaxial thin film, strain effects always exist, which could be caused by lattice mismatch, thermal expansion differences, etc. For non-doped (001) orientated epitaxial PZT thin film, misfit strain $\left(\mathrm{S}_{\mathrm{m}}\right)$ is calculated in case of 
different substrates ${ }^{39}$. When a dopant is added in PZT materials, extra dipoles will be generated. In a bulk ceramics, those dipoles can lying randomly in one of these six orientations. But in a single orientated thin films, all those dipoles can be aligned in a preferable direction. This is very likely to happen at the bottom interface, since most of the strain happens in the interface, and it will relax a bit during film growth. If we assume that most of the dipoles at the interface are aligned in one direction, domain pinning effects will be observed near the film and bottom electrode interface. In this case, electrons are trapped as a result of the dipole alignments, and a bias is built in the piezoelectric thin films. Thus, we observe the giant imprint effects in the epitaxial (001) orientated doped PZT thin films.

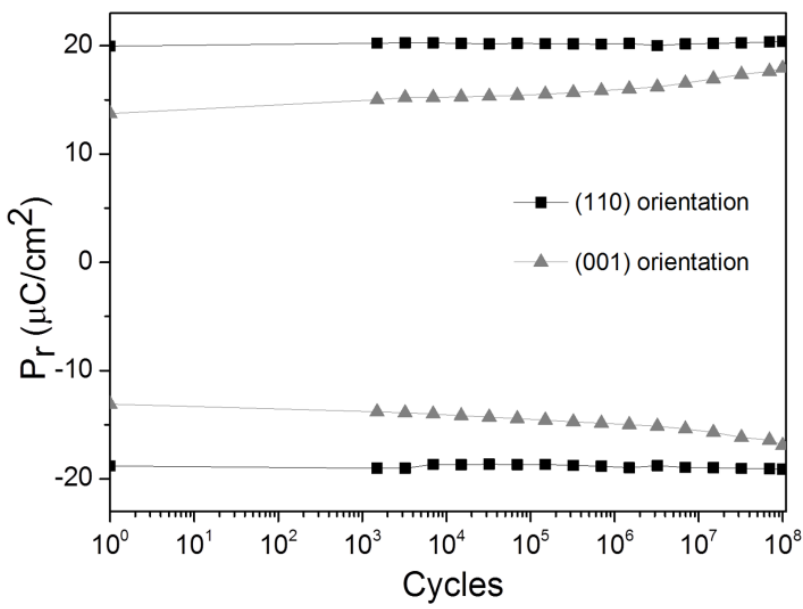

Figure 5.9 Different ferroelectric behavior $\left(P_{r}\right)$ of (110) and (001) orientated nondoped PZT thin films as a function of switching cycles.

Note that the epitaxial (001) orientated PZT thin films are different from the (110) orientated one. Previous work shows the different ferroelectric behavior in terms of fatigue measurements, especially, for the case of oxide electrode. ${ }^{21}$ As we learned from previous studies, conductive oxide electrodes (SRO) consume the accumulated oxygen vacancies during polarization switching. Therefore, our epitaxial PZT thin films show essentially no fatigue behavior. The remnant 
polarization does not decrease with the number of switching cycles. However, we also notice the different switching behavior between the (001) and (110) orientated films. The $\mathrm{P}_{\mathrm{r}}$ of (001) orientated PZT/SRO capacitor keeps constant with increasing the switching cycles. And the $\mathrm{P}_{\mathrm{r}}$ of (110) orientated PZT/SRO capacitor increases with the increasing of the switching cycles, as shown in figure 5.9. The reason is that in (110) orientated PZT thin films, some defects exist at the interface or grain boundaries, which can lock some spontaneous polarizations. Those defects are gradually removed to the interfaces between the film and oxide electrode during the switching cycles. When the locked polarization becomes free, the remnant polarization is increased. But because of the existing defects in the interface of (110) orientated PZT films, aligned dipoles cannot form in the same location. Thus no imprint behavior is observed in (110) epitaxial doped PZT thin films. On the other hand, it is confirmed that the giant imprint effects in hysteresis loops only happen in a pure, less-defect interfaces, with a perfect growth mode.

To confirm the interface influence on the build in bias of polarization properties, doped/non-doped PZT heterostructures with (001) orientation were studied. Two batches of samples were grown on STO substrate with both top and bottom SRO electrodes. Sample one was with a 100nm Nb-PZT layer on the bottom and 400 nm PZT layer on top; while sample two was with $400 \mathrm{~nm}$ PZT films at the bottom and $100 \mathrm{~nm} \mathrm{Nb-PZT} \mathrm{thin} \mathrm{film} \mathrm{on} \mathrm{top,} \mathrm{as} \mathrm{shown} \mathrm{in} \mathrm{figure} \mathrm{5.10.} \mathrm{After}$ lithography and patterning, both samples were characterized. In sample one, we observed a shifted P-E loop, which is comparable with the P-E loop of 500nm (001) Nb-PZT thin film, but enhanced the remnant polarization. In sample two, we got a slanted nearly symmetric P-E loop with a degraded polarizations which is not shifted,, see figure 5.11. Moreover, the P-E loop of sample two has a small opening by the end of PE loop in both sides, which indicates much leakage current in this sample. The large build-in bias in sample one is approximately the same as in the fully $\mathrm{Nb}$-doped sample. 


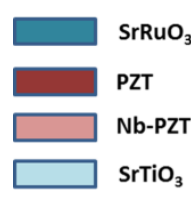

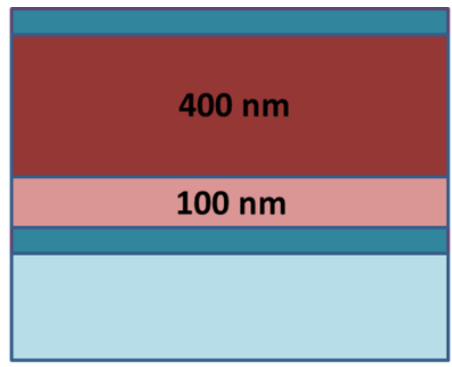

Sample 1

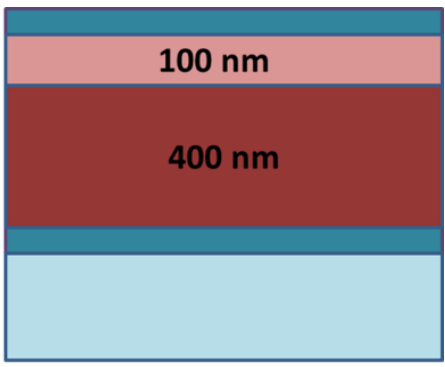

Sample 2

Figure 5.10 Schematic drawing of the layer growth in sample 1 and sample 2.

The results are in agreement with our previous discussions. For sample one, the dipoles are aligned at the bottom interface, which causes a build in bias in the films, while the pure-PZT thin films on top enhance the polarization. For sample two, epitaxial non-doped PZT thin films were grown first with a thickness of $400 \mathrm{~nm}$. When the Nb-doped PZT thin films are grown on top of that, the nondoped PZT thin films roughen the interface with the columnar growth structure. Therefore the defect dipoles cannot align in one direction. In this case, many defects are induced at the interface between the non-doped PZT and the Nbdoped PZT films, which degrade the ferroelectric properties. Based on the observations, we believe the imprint effects are caused by dipoles realignment at the bottom interface.

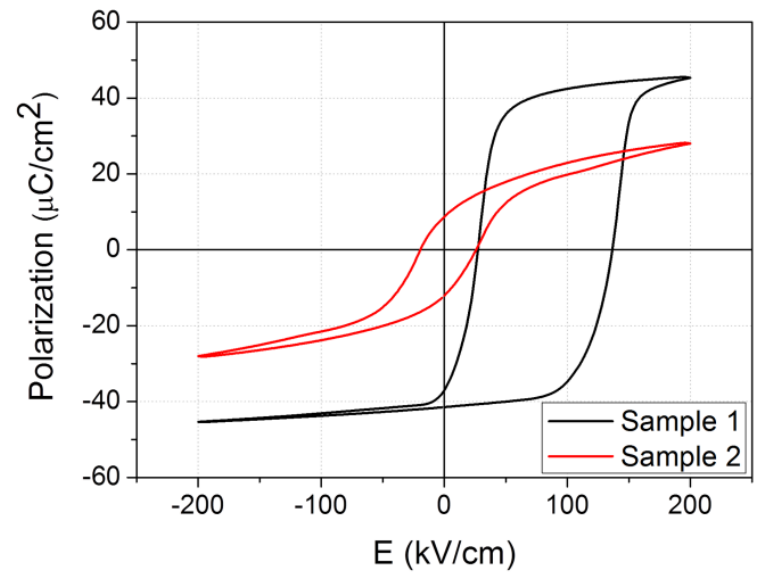

Figure 5.11 Polarization hysteresis loops of sample 1 and sample 2. 


\subsection{Conclusions and outlook}

In this chapter, different dopants were introduced in epitaxial PZT thin films with both (110) and (001) orientations. Ferroelectric and piezoelectric properties were studied in each case. For device applications, the FOM is compared for the various situations. A modification in piezoelectric films makes it more suitable for energy harvesting devices. Moreover, based on the observations, an accurate physical mechanisms is suggested, which explain the imprint behavior in epitaxial films. The epitaxial growth mode engender the alignment of defect dipoles, which causes a large horizontal shift in hysteresis loops. The build in bias also reduce the dielectric constant at zero bias. Both effects benefits the figure of merit for harvester devices. In the field of sensor and harvester devices, the epitaxial piezoelectric films with giant imprint behavior can lead to a significant increase in FOM, which is essentially important for applications.

This work describes the doping behaviors in both soft doping and hard doping, which cause extra lead vacancies and oxygen vacancies. The differences in piezoelectric properties are explained by the change of domain mobility. The following experiments are suggested for further studies into the doping mechanism in PZT films:

1. Oxygen vacancies and lead vacancies densities are interested to measured and studied both quantitatively and qualitatively in epitaxial films.

2. The mobility of oxygen vacancies and lead vacancies is a crucial point in understanding the soft and hard doping model.

3. Growth parameters, such as oxygen pressure, can be related to the alignment of induced dipoles. Since the growth and annealing oxygen pressure can change the oxygen vacancy in films, it should be possible to tune the alignment dipoles by modified the interface growth. 


\subsection{References}

S. Roundy, P. K. Wright, and J. M. Rabaey, Energy scavenging for wireless sensor networks. (Kluwer Academic Publishers Group, 2004).

D. Isarakorn, École Polytechnique Fédérale de Lausanne, 2011.

D. Isarakorn, D. Briand, P. Janphuang, A. Sambri, S. Gariglio, J. M. Triscone, F. Guy, J. W. Reiner, C. H. Ahn, and N. F. de Rooij, Smart Materials and Structures 20 (2), 025015 (2011).

D. Damjanovic, in The Science of Hystersis (2005), Vol. 1, p. 337.

Maxim I. Morozov and Dragan Damjanovic, Journal of Applied Physics 104 (3), 034107 (2008).

K. W. Kwok, R. C. W. Tsang, H. L. W. Chan, and C. L. Choy, Journal of Sol-Gel Science and Technology 47 (2), 148 (2008).

E. C. F. Souza, A. Z. Simões, M. Cilense, E. Longo, and J. A. Varela, Materials Chemistry and Physics 88 (1), 155 (2004).

W. Bai, X. J. Meng, T. Lin, L. Tian, C. B. Jing, W. J. Liu, J. H. Ma, J. L. Sun, and J. H. Chu, Journal of Applied Physics 106 (12), 124908 (2009).

S. R. Sangawar, B. Praveenkumar, H. H. Kumar, and D. K. Kharat, Materials Science and Engineering: B 176 (3), 242 (2011).

L. Kozielski, M. Adamczyk, and M. Pawełczyk, Phase Transitions 83 (10-11), 790 (2010).

L. Feigl, E. Pippel, L. Pintilie, M. Alexe, and D. Hesse, Journal of Applied Physics 105 (12), 126103 (2009).

B.; Jaffe, W. R. Cook, and H. L. Jaffe, Piezoelectric ceramics. (1971).

B.; Cook Jaffe, W. R.; and Jaffe, H. , Piezoelectric Ceramics. (New York, 1971).

D. Damjanovic, Reports on Progress in Physics 61.

K.; Haerdtl Carl, K. H., Ferroelectrics 17, 473 (1978).

U.; Arlt Robels, G., Journal of Applied Physics 73, 3454 (1993).

Klaus; Tiedke Prume, Stephan; Schmitz-Kempen, Thorsten, Mikroniek 4, 31 (2010). 
Klaus; Muralt Prume, Paul; Schmitz-Kempen, Thorsten; Tiedke, Stephan, Proceedings of SPIE 6526 (65260G) (2007).

Matthijn Dekkers, Minh D. Nguyen, Ruud Steenwelle, Paul M. te Riele, Dave H. A. Blank, and Guus Rijnders, Applied Physics Letters 95 (1), 012902 (2009).

Minh D. Nguyen, Matthijn Dekkers, Evert Houwman, Ruud Steenwelle, Xin Wan, Andreas Roelofs, Thorsten Schmitz-Kempen, and Guus Rijnders, Applied Physics Letters 99 (25), 252904 (2011).

Minh D. Nguyen, University of Twente, 2010.

Romain Herdier, David Jenkins, Elhadj Dogheche, Denis Rèmiens, and Miroslav Sulc, Review of Scientific Instruments 77 (9), 093905 (2006).

H. Meštrić, R. A. Eichel, T. Kloss, K. P. Dinse, So Laubach, St Laubach, P. Schmidt, K. Schönau, M. Knapp, and H. Ehrenberg, Physical Review B 71 (13) (2005).

Li Jin, Viktor Porokhonskyy, and Dragan Damjanovic, Applied Physics Letters 96 (24), 242902 (2010).

$30 \mathrm{~nm} \mathrm{SrTiO}_{3}$ buffer layer was deposited on $380 \mathrm{~nm}$ silicon substrates by molecular beam evaporation; samples provided by D. G. Schlom, Cornell university, USA.

M. D. Nguyen, X. Wan, E. Houwman, and G. Rijnders.

T. Haccart, D. Remiens, and E. Cattan, Thin Solid Films 423, 235 (2003).

W. L.; Tuttle Warren, B. A.; Dimos, D.; Pike, G. E.; Al-Ahareef, H. N.; Ramesh, R.; Evans, J. T. , Journal of Applied Physics 35, 1521 (1996).

Kazuhide Abe and Shuichi Komatsu, Journal of Applied Physics 77 (12), 6461 (1995).

K. Abe, N. Yanase, T. Yasumoto, and T. Kawakubo, Journal of Applied Physics 91 (1), 323 (2002).

D.; Nozawa H. Nagasawa, (1999).

W. G.; Ko Liu, J,; Zhu, W. G., (2001).

C. L.; Zhang Wang, W. L.; Zhong W. L.; Zhang, P. L., (1998).

Wenhui Ma and Dietrich Hesse, Applied Physics Letters 84 (15), 2871 (2004). 
Seungbum Hong, E. L. Colla, Eunah Kim, D. V. Taylor, A. K. Tagantsev, P. Muralt, Kwangsoo No, and N. Setter, Journal of Applied Physics 86 (1), 607 (1999).

J. Lee, C. H. Choi, B. H. Park, T. W. Noh, and J. K. Lee, Applied Physics Letters 72 (25), 3380 (1998).

Tianquan Lü and Wenwu Cao, Microelectronic Engineering 66 (1-4), 818 (2003).

Y. Zhou, H. K. Chan, C. H. Lam, and F. G. Shin, Journal of Applied Physics 98 (2), 024111 (2005).

M. D. Nguyen, M. Dekkers, E. Houwman, R. Steenwelle, X. Wan, A. Roelofs, T. Schmitz-Kempen, and G. Rijnders, Applied Physics Letters 99 (25) (2011). 
Chapter 5

Page | 94 


\title{
Chapter 6
}

\section{Integration of epitaxial PZT thin films into energy harvesting devices}

\begin{abstract}
In this chapter, the fabrication and testing of the epitaxial $\mathrm{PbZr}_{0.4} \mathrm{Ti}_{0.6} \mathrm{O}_{3}$ vibration harvesting devices are discussed. The results are compared with textured PZT harvester and AIN harvester. The maximum power output in epitaxial harvester is $78 \mu \mathrm{w}$ at $0.75 \mathrm{~g}$ acceleration, with a resonance frequency of $624 \mathrm{~Hz}$. The sensitivity of this devices is $124.45 \mu \mathrm{W} / \mathrm{g}$, which is significant higher than present devices. After normalizing the power output, a comparison between different devices can be drawn. A $\mathrm{P}_{\text {norm }}$ of $33 \%$ is reached in unpackaged epitaxial PZT harvesters, which is five times higher than the unpackaged AIN harvester. Thus epitaxial PZT thin films are proven to be a promising material in the field of vibration energy harvesting.
\end{abstract}




\subsection{Introduction}

In the past few years, the idea of harvesting energy from ambient has drawn significant interests in research and development ${ }^{1,2}$. Piezoelectric harvester gives an outstanding performance in transferring the spare vibration energy into an useful electric output ${ }^{3,4}$. Enabled by the energy harvesting technology, a desired portable, wireless and self-powered electronics can be foreseen, which will potentially replace the traditional battery driven electronics. Generally speaking, this kind of energy harvesting devices can be used in lots of applications, for example, remote monitor, home automation, implantable sensors, long range tracking, etc. In particular, depending on different resonant frequency and power output, various applications were studied ${ }^{5}$.

Various piezoelectric materials can be used in piezoelectric harvesters, such as $\mathrm{AlN}^{6}, \mathrm{ZnO}^{7}, \mathrm{PZT}$, etc. Because of material compatibility, a lot of work has been done using AlN materials by sputter depositions ${ }^{8,9,10}$. However, in term of piezoelectric coefficient, PZT is a promising material to give a significant increasing in power output ${ }^{11,12}$. As we discussed in chapter 4 and chapter 5, different growth modes in the thin film lead to different material properties. Epitaxial thin films give better piezoelectric performance than textured or sol-gel films ${ }^{13}$. In order to achieve the optimum power output, the figure of merit $\left(\mathrm{FOM}=\mathrm{e}_{31}{ }^{2} / \varepsilon\right)$ was measured among PZT with different dopants, see table 4.1 and table 5.2. The most optimal piezoelectric materials will be used in the device fabrication.

In this work, $\mathrm{PbZr}_{0.4} \mathrm{Ti}_{0.6} \mathrm{O}_{3}$ materials were used in both textured thin films and epitaxial thin films growth. In the textured harvesting devices, the films were grown and fabricated in $150 \mathrm{~mm}$ silicon on insulator (SOI) wafers, while in epitaxial harvesting devices, all the films were grown on the individual SOI chips with the size of $10 \times 12 \mathrm{~mm}^{2}$. In the epitaxial films, after integration and patterning the sandwich structure $\mathrm{YSZ} / \mathrm{SRO} / \mathrm{PZT} / \mathrm{SRO} / \mathrm{Pt}$ on the SOI substrates, 
the chips were processed into free standing devices. Figure 6.1 shows a schematic drawing of a packaged energy harvester ${ }^{9}$. When the devices are placed in a vibrational environment, the mass on the beam moves up and down. This movement introduces stress in the piezoelectric thin films and electric power is generated and can be measured.

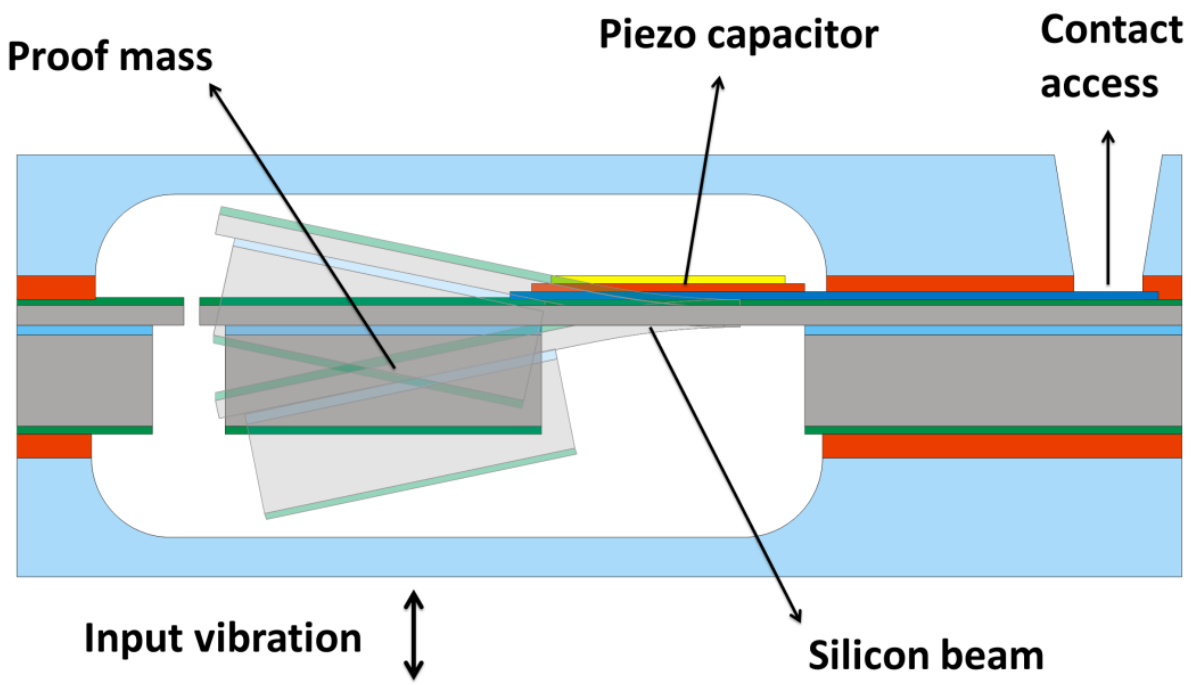

Figure 6.1 Schematic drawing of packaged energy harvester device.

\subsection{Generic vibration model}

The general model, which describes the conversion of vibration energy of a mass into electrical power has been proposed by Williams and Yates ${ }^{1}$. In their theory, two contributions of damping will contribute to the total effect. One is the electrically induced damping, and the other is the mechanical damping. Both of them will contribute to the total quality factors $\left(\mathrm{Q}_{\mathrm{t}}\right)$. Therefore,

$$
\frac{1}{Q_{t}}=\frac{1}{Q_{e}}+\frac{1}{Q_{m}}
$$


Where $\mathrm{Q}_{\mathrm{e}}$ is the electrical quality factor, and $\mathrm{Q}_{\mathrm{m}}$ is the mechanical quality factor. In Williams and Yates' model, the physical behavior of piezoelectric generator is described as a mechanical damping vibrator with a mass spring system and a driving force. The maximum power output $\mathrm{P}_{\max }$ can be obtained by,

$$
P_{\text {max }}=\frac{m Q_{t}^{2}}{2 \omega_{0} Q_{e}} A^{2}
$$

Where $\mathrm{A}$ is the acceleration, $\omega_{0}$ is the resonance frequency and $\mathrm{m}$ is the mass. According to this equation, if the mass, frequency and quality factor are taken to be constants, the output power is proportional to a quadratic function of acceleration. Furthermore, when the acceleration, frequency and quality factor are fixed, the power is linearly proportional to the mass. Last but not least, the total power output has also a relation with the quality factor. The electrical quality factor can be tuned with different load resistances. From the equation, it is clear shown than in order to reach a maximum power, a high $\mathrm{Q}_{\mathrm{t}}$, and low $\mathrm{Q}_{\mathrm{e}}$ are needed, which means a higher mechanical quality factor is important.

\subsection{Fabrication and experimental procedure}

Figure 6.2 shows the process flow of PZT energy harvester fabrication. The devices were fabricated on a $675 \mu \mathrm{m}$ thick SOI wafer, with a $50 \mu \mathrm{m}$ device layer and a $1 \mu \mathrm{m}$ BOX layer in between. $2500 \mathrm{~nm}$ thermal oxide layers were grown on the as-received SOI wafers. The back side silicon dioxides are used as a back side mask for deep reactive ion etching (DRIE). After removing the top side silicon oxide, alignment marks were patterned on the top side. Those alignment marks included both the individual alignments for every chips, and also the front to back alignment for the whole wafer. The alignment mark etching is performed with reactive ion etching (Plamsa Therm 790). It is an isotropic etching process, and the etching depth is around $4 \mu \mathrm{m}$.

Same as the top side, the back side silicon dioxide layers were patterned with the front to back alignment steps and etched by Plasma Therm 790. Before growing 
the device layer, the wafer was diced into small chips in order to fit for deposition chamber and get homogeneous growth. For the PZT capacitors, the bottom electrodes were grown in a separate run with the PZT and top electrode, since the bottom electrodes were pre-patterned to avoid shorts during wire bonding. The capacitor area is $5 \mathrm{~mm}^{2}$, with a SRO/PZT/SRO/YSZ sandwich structures. After functional testing, the piezo area is protected by a thick photoresist layer, see figure 6.2. Both front side and back side silicon were etched by DRIE (Adixen SE), with the gas $\mathrm{SF}_{6}$ and $\mathrm{C}_{4} \mathrm{~F}_{8}$. The principle of Silicon etching is as follows:

$$
\begin{gathered}
e+S F_{6} \rightarrow S F_{5}^{*}+F+e \\
S i+4 F \rightarrow S i F_{4}
\end{gathered}
$$

In order to reach high aspect ratio in anisotropic etching, the Bosch process was used $^{14}$. In this reaction, two different gas compositions are alternated in the reactor. The first gas $\left(\mathrm{C}_{4} \mathrm{~F}_{8}\right)$ composition creates a polymer on the surface of the substrate, and the second gas $\left(\mathrm{SF}_{6}\right)$ etches the substrate. The polymer is immediately sputtered away on the horizontal surfaces, but not the sidewalls. This is because the polymer dissolves very slowly in the chemical part of the etching, it builds up on the sidewalls and protects them from etching. As a result, high aspect ratios can be achieved, which is crucial for etching completely through a silicon substrate. BOX layer was also etched by DRIE (Adixen DE). When the devices are etched through, the top side photoresists were removed by oxygen plasma. The devices were wire bonded on a small PCB board and glue on an epoxy board, see figure 6.9. 


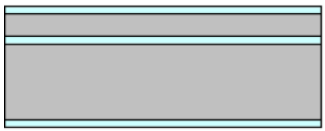

1.Grow $2500 \mathrm{~nm}$ $\mathrm{SiO}_{2}$ on both sides, removed top $\mathrm{SiO}_{2}$ by $\mathrm{BHF}$

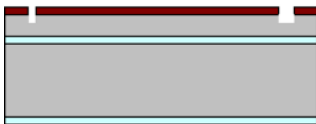

2.Etching Si top (4000nm not through)

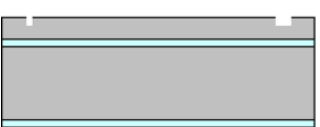

3.Resist strip

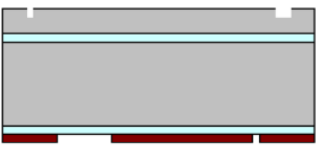

4. Use photoresist to pattern the back side oxide.

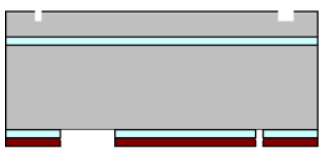

5. RIE etching for $\mathrm{SiO}_{2}$ With

Gas $\mathrm{CHF}_{3}, \mathrm{O}_{2}$

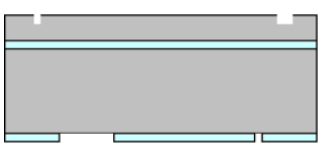

6. Remove the photoresist.

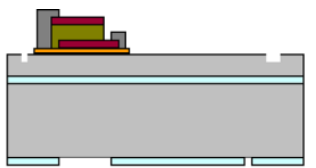

7. Grow PZT and electrode layers on the piezo patch area

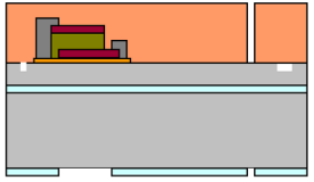

8. Use photo resist to protect the device area.

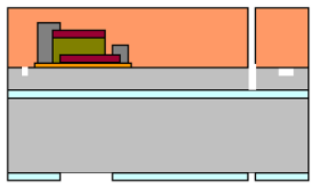

9. Front size etching (YSZ and $\mathrm{Si}$ ), stop on the oxide.

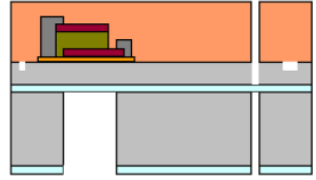

10. Silicon back side etching.

Adixen (Dry etching), anisotropic

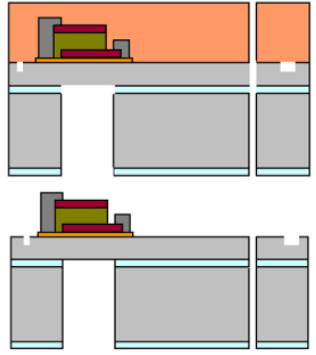

11. $\mathrm{SiO}_{2}$ etching

12. Remove the Photoresist and do wire bonding.

Figure 6.2 PZT energy harvester fabrication process flow 


\subsection{Stress compensation}

Before starting calculating the stress in the films, we first go back to the basic formula given by Gerald Stoney in 1909. Gerald Stoney's works are about tension of metallic film depositions ${ }^{15,16}$, and estimated the residual stress from a change in radius of curvature, which is written as,

$$
\sigma=\left(\frac{E_{s}}{1-v_{s}}\right) \frac{t_{s}^{2}}{6 R t_{f}}
$$

Where $\mathrm{E}_{\mathrm{s}}$ is the substrates Young's modulus, $v_{s}$ is the poisson's ratio, $\mathrm{t}_{\mathrm{s}}$ is the substrates thickness, $t_{f}$ is the film thickness, and $\mathrm{R}$ is the radius of curvature. The radius curvature can be calculated by,

$$
R=\frac{L^{2}}{2 \xi}
$$

Where $\mathrm{L}$ is the length of cantilever, and $\xi$ is the deflection. From the equations, the residual stress of the devices can be determined from the static deflection of the cantilevers or the radius of wafers curvature from the stress measurements ${ }^{16}$. On the other hand, when the thin film stresses are known, the pre-bending of the devices can be calculated.

For an optimal energy harvesting device, a minimal pre-bending is required in a free standing device. Therefore the stress compensation become an essential part when we integrate the thin films stack on a SOI wafer. As we know, silicon dioxide typically shows a compressive stress, while silicon nitride gives a tensile stress when grown on silicon substrates ${ }^{17}$. However, for our epitaxial piezo thin films, we do not need amorphous layers as a buffer layer, and the back side silicon dioxide will be etched away in the process (see section 6.3). From our previous work ${ }^{18}$, we measured the static deflection of epitaxial $\mathrm{PbZr}_{0.4} \mathrm{Ti}_{0.6} \mathrm{O}_{3}$ thin films grown on silicon cantilevers. The stress of our piezo oxide films are in the range of 200 to $300 \mathrm{MPa}$, which give a tensile stress in the device. In order to compensate, $\mathrm{Pt}$ was chosen as an stress composition material, as the stresses of $\mathrm{Pt}$ various a lot with temperature ${ }^{19}$. Typically, above $300^{\circ} \mathrm{C}, \mathrm{Pt}$ films show a tensile stress, while deposited at room temperature, a compressive stress is 
obtained in Pt films. For our piezo stack, we keep oxide electrode (SRO) for both the top and bottom electrodes to achieve the perfect growth mode and optimal properties ${ }^{20}$. However, Pt can still be an excellent contact material, especially for wire bonding. Moreover, the Pt layers are grown as the last step at room temperature. No heating step performed after the Pt deposition. Therefore, the last Pt layer induces a compressive stress, which will compensate the tensile stress from the oxide films. By adding this extra step, we got non-bended harvester devices after release etching.

\subsection{Electric measurements}

The equipment setup is shown and discussed in figure 2.10 in chapter 2. A shaker system is used to provide the input vibration to a harvester. A signal generator provides a required AC signal to a power amplifier. During the vibration, the mass on the harvester displaces with certain amplitude and generates stress in the piezoelectric film. Thus a voltage along the capacitor will be measured.

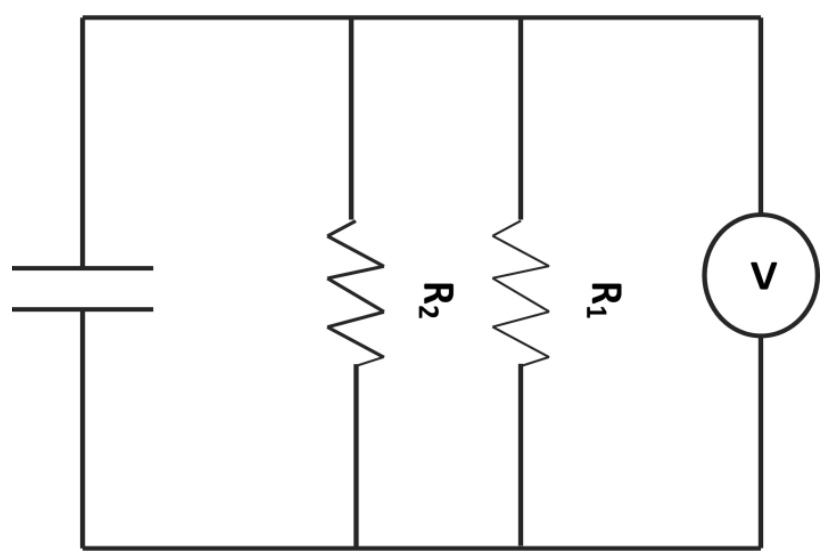

Figure 6.3 Electrical scheme for voltage measurements. $R_{1}$ is the load resistance and $\mathbf{R}_{\mathbf{2}}$ is the internal resistance of voltage meter. 
The voltage measurement method is used. The principle is given in figure 6.3. A load resistor $\left(R_{1}\right)$ is connected in parallel to the harvester. Moreover, an internal resistance $\left(R_{2}\right)$ is considered from the voltage meter. Therefore, when taken into account of the system resistance $\left(R_{2}\right)$, the total resistance is,

$$
\mathrm{R}_{\text {total }}=\frac{\mathrm{R}_{1} \mathrm{R}_{2}}{\mathrm{R}_{1}+\mathrm{R}_{2}}
$$

When the voltage is measured as an RMS value, the generated power can now be calculated,

$$
\mathrm{P}=\mathrm{V}_{\mathrm{RMS}}^{2}\left(\frac{\mathrm{R}_{1}+\mathrm{R}_{2}}{\mathrm{R}_{1} \mathrm{R}_{2}}\right)
$$

Before mounting the sample on the shaker, an impedance analyzer is used for electrical characterization of capacitance, impedance, and resonance frequency of the device. When the same device is mounted on the shaker, the resonance frequency is also measured using with the white noise excitations. In this case, the harvester will be excited with all the present frequencies, but mostly respond to its resonance frequency. Secondly, a load optimization is needed to optimize the power output. By changing load resistances (from the range of $1 \mathrm{k} \Omega$ to $400 \mathrm{k} \Omega$ ), a maximum power output and a minimum total quality factor are expected at the optimal load resistance. Next, when fixing the optimal load, the power output of the harvester device is measured versus the resonance frequency curve at various input acceleration levels, see section 6.6. A maximal power can be determined in the peak position with certain acceleration. The quality factor $\mathrm{Q}$ can be determined by calculated the FWHM of the resonance frequency curve. Figure 6.4 (a) shows a typical measurement curve of PZT harvester device. The maximum power output was achieved at the resonance frequency. An acceleration of $0.16 \mathrm{~g}$ is applied, and the $\mathrm{Q}$ factor can be calculated. From those data, the displacement of the mass center $\delta$ can also be calculated by,

$$
\delta=\frac{Q a}{\left(2 \pi \cdot f_{\text {res }}\right)^{2}}
$$

For example, when the devices are measured at $2 \mathrm{~g}$ acceleration, with a $\mathrm{Q}$ factor of 197 , and the $f_{\text {res }}=427$, the calculated tip displacement is $993 \mu \mathrm{m}$. Figure 6.4 (b) shows a real displacement during the measurements, which was captured by a 
microscope camera. The photo was taken at the resonance frequency, which means at the peak of the power output.

\subsection{Measurements of energy harvester}

\subsubsection{The properties of energy harvesters with textured PZT films}

Energy harvester with textured PZT thin films were investigated which were fabricated on a wafer scale. As discussed in chapter 2, textured film deposition is a type of growth with coherency in out-of-plane, but not in in-plane. Those randomly in-plane orientation in the film allows different domains and grain boundaries, when compared with coherency in-plane growth. Moreover, the densities and film qualities are also diminished in textured PZT films. However, since the growth temperature of textured PZT thin film is lower than the epitaxial one, it is more easy to process a wafer scale growth. In this case, within one run, more chips will be produced with textured PZT energy harvesters.

Two batches of texture PZT harvesters were grown and fabricated together with SolMates and Holst Centre. Figure 6.5 shows the first chips before wire bonding, which were fabricated in 6 inch wafer. Different chips dimensions are presented on one wafer. Textured PZT films sandwiched with $\mathrm{LaNiO}_{3}$ (LNO) as both top and bottom electrodes. $\mathrm{SiO}_{2}$ and $\mathrm{Pt} / \mathrm{Ti}$ layers are buffered between the silicon surface and the bottom electrode. Pt top electrode are used as a good contact layer for wire bonding. The SOI wafer is with $10 \mu \mathrm{m}$ device layer, $500 \mathrm{~nm}$ BOX layer and $380 \mu \mathrm{m}$ handle. $0.5 \mu \mathrm{m}$ silicon oxide layers were grown on both side of the SOI wafer. After processing, only top silicon dioxide layer will remain. 

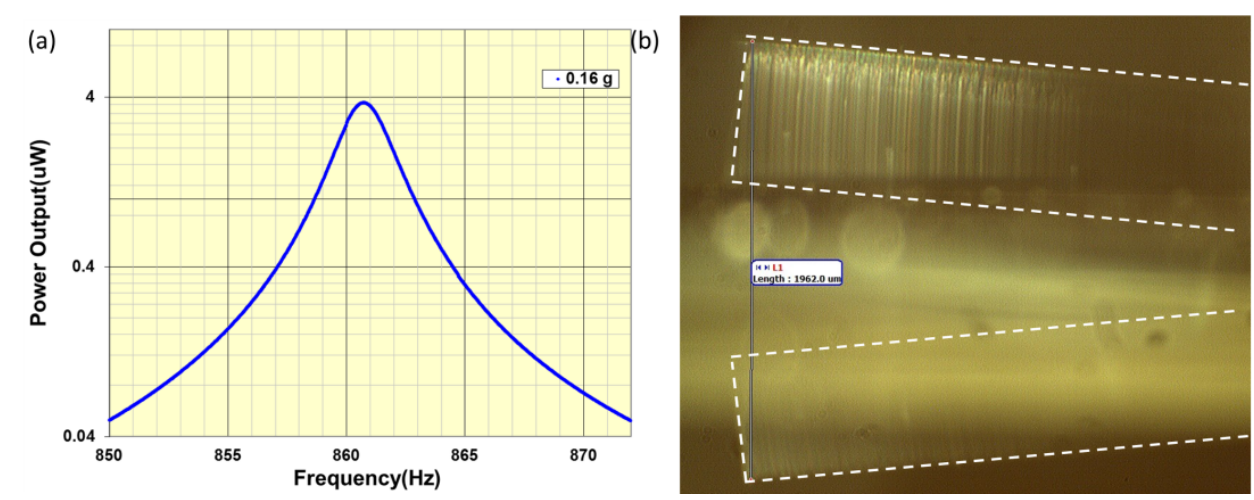

Figure 6.4 (a) A typical resonance curve of harvester device, with a maximum power of $3.70 \mu \mathrm{W}$ at an acceleration of $0.16 \mathrm{~g}$. The $\mathrm{Q}$ factor is 336. (b) A live photo which was captured during the vibration measurements at the resonance frequency. The distance from the top to the bottom tells us the maximum displacement in this device.

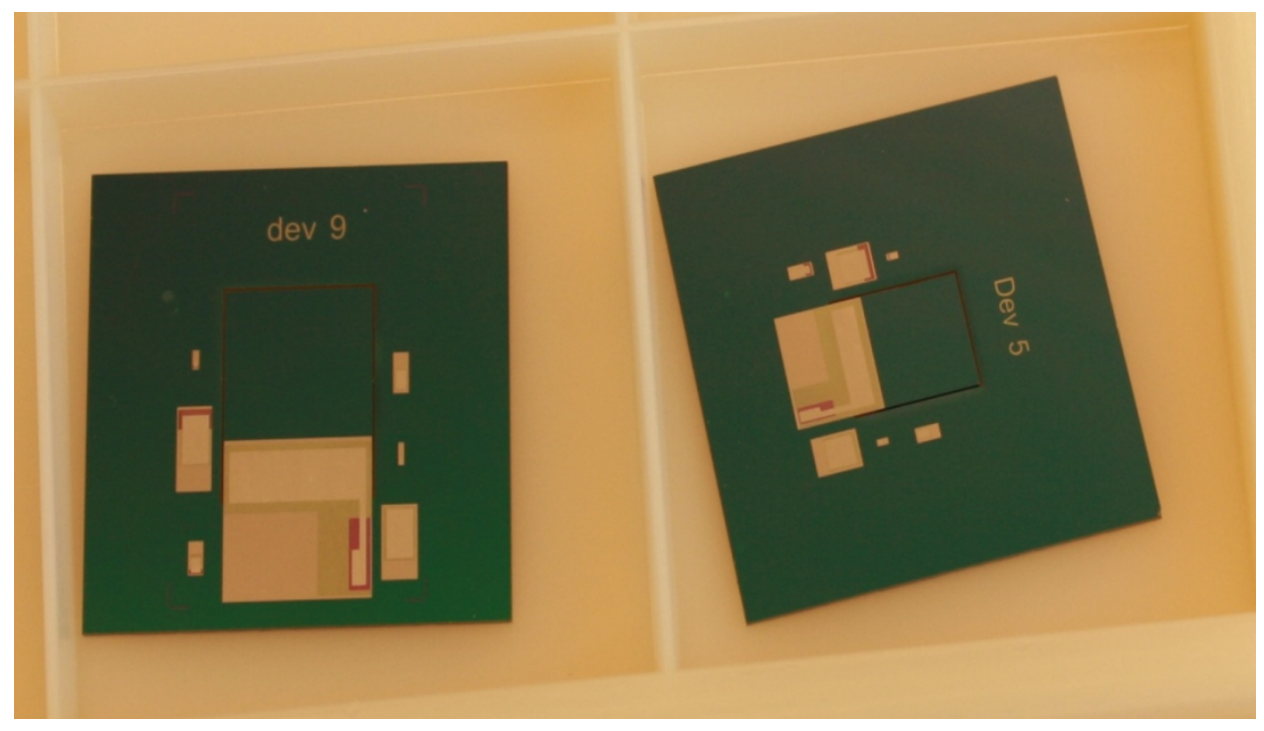

Figure 6.5 texture PZT harvesting devices before wire bonding.

However, the measurements of the harvesters from the first wafer did not show a good power output. A couple of reasons could influence the measurements:

1. Those harvesters are fabricated in a $10 \mu \mathrm{m}$ thick device layer, which gives a relatively low resonance frequency (around $50 \mathrm{~Hz}$ ). 
2. Less stress in the PZT films, lead to less power output.

3. The released devices are bending downwards, due to the high compressive stress from silicon oxide on top (see 6.4 stress compensation).

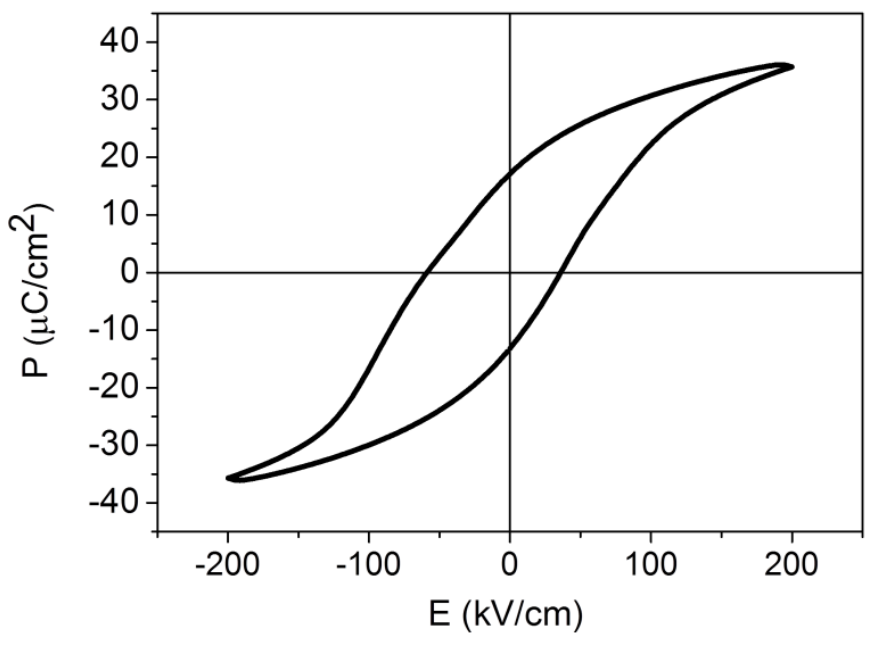

Figure 6.6 A typical PE loop of texture $\mathrm{PbZr}_{0.4} \mathrm{Ti}_{0.6} \mathrm{O}_{3}$ thin films after $10^{6}$ cycles.

To overcome the problems above, a SOI wafer with a $50 \mu \mathrm{m}$ device layer was used. Different thickness of silicon dioxides layer was used to compensate the stress. $\mathrm{PbZr}_{0.4} \mathrm{Ti}_{0.6} \mathrm{O}_{3}$ textured films are grown and fabricated. Figure 6.6 shows a typical PE loop of textured PZT thin film after $10^{6}$ cycles. The curve is a bit asymmetric, with a relatively low polarization value. As we observed ${ }^{13,20}$, the fabrication process has an influence on the development of the PE loop. The PE loops of epitaxial films are more square and have a less slanted shape with a relatively larger remnant polarization than the texture films, see figure 6.8. This is due to grains and grain boundaries are forming in textured films, which make the switching behaviors different. 

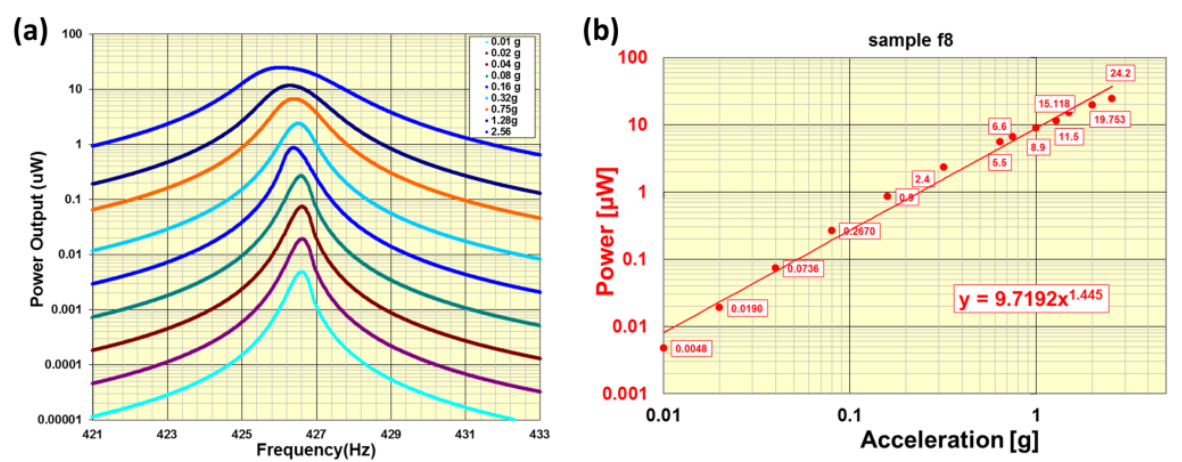

Figure 6.7 (a) Resonance curve of textured PZT harvester performed at different acceleration. (b) power as a function of applied acceleration.

Figure 6.7 (a) shows the resonance curve of a textured harvesting device with different acceleration levers from $0.01 \mathrm{~g}$ to $2.56 \mathrm{~g}$. In this device, a maximum power of $24.2 \mu \mathrm{W}$ is measured at $2.56 \mathrm{~g}$ acceleration. The quality factor is about 750 at low acceleration, and it decrease with an increase of acceleration. From the shape of the resonance curve, we can also see, the peak is less sharp in high acceleration. This is due to the increasing air damping effect at large mass displacements ${ }^{9}$.

For the same device, the power output as a function of the acceleration at the resonance frequency is plotted in figure 6.7 (b). As we discussed in section 6.2, an ideal power output $(\mathrm{P})$ is proportional to acceleration square $\left(\mathrm{A}^{2}\right)$. But in the real case, at high acceleration levers, the function between $\mathrm{P}$ and $\mathrm{A}$ change from quadratic to linear relation. The variation in frequency with different acceleration levers also indicates the increasing damping effect in large $\mathrm{g}$. The maximum tip displacement from the center mass is $580 \mu \mathrm{m}$ in this device. A real vibration photo is shown in figure 6.4 (b). 


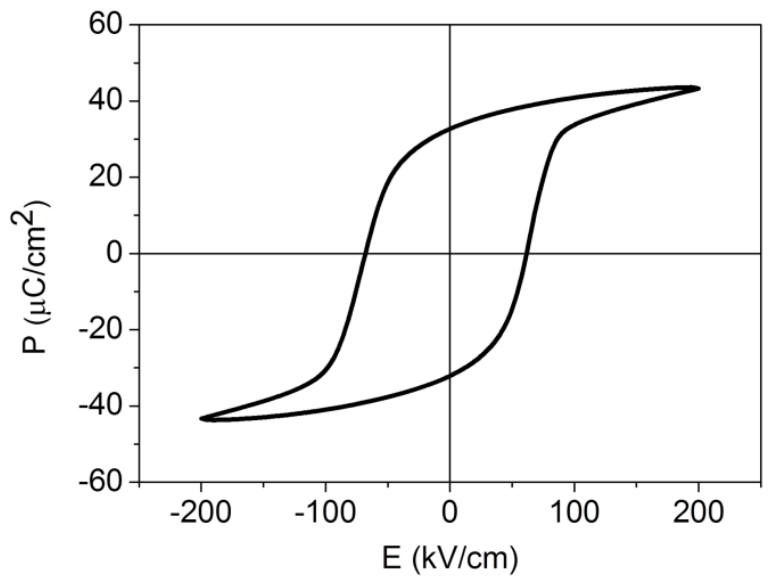

Figure 6.8 $\mathrm{PE}$ loop of epitaxial $\mathrm{PbZr}_{0.4} \mathrm{Ti}_{0.6} \mathrm{O}_{3}$ thin films after $10^{6}$ cycles.

6.6.2 The properties of energy harvesters with epitaxial PZT films

An epitaxial PZT thin films harvester was fabricated on the same kind of SOI wafers. Every chip was deposited and fabricated individually. $\mathrm{PbZr}_{0.4} \mathrm{Ti}_{0.6} \mathrm{O}_{3}$ material was chosen as a target material. The thickness of piezoelectric layer is $500 \mathrm{~nm}$. $\mathrm{SrRuO}_{3}$ was used as both top and bottom electrodes with a thickness of $100 \mathrm{~nm}$. Pt layer was used as a good adhesion layer for contact bonding wires. Figure 6.9 is a photo of a harvesting device. The size of the chip is $10 \mathrm{~mm}$ by $12 \mathrm{~mm}$. the device is glued to a PCB board and can be connected to an electric measurement circuit. The epoxy board is mounted on the shaker, and an accelerator is placed on one side of the device.

Polarization loops are measured on this device for both the as-grown films and the free standing devices after back side etching. No different are observed, indicating the dry etching and lithograph steps did not influence the film qualities. Figure 6.8 shows the typical PE loop of epitaxial PZT thin films after $10^{6}$ cycles. The measurements were done on a $5 \mathrm{~mm}^{2}$ capacitor. Clear switching 
behavior and square loops are obtained, which indicated better film quality as compared to the textured films.

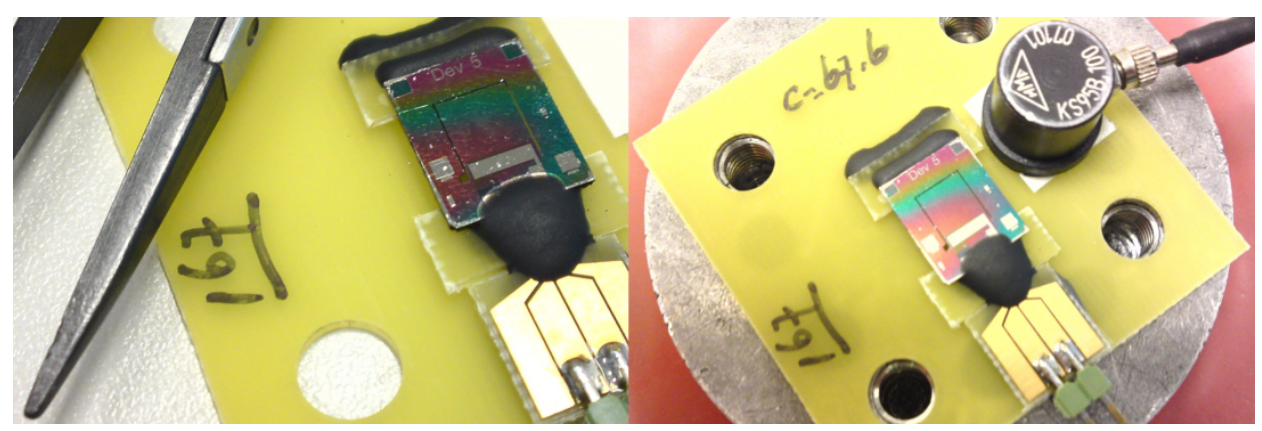

Figure 6.9 A Photo of a real device after fabrications. The right photo shows the mounting of the device on a shaker with an accelerator on the side.

The resonance curves of epitaxial harvesting device are measured with the acceleration from $0.01 \mathrm{~g}$ to $0.75 \mathrm{~g}$, see figure 6.10 (a). A maximum power of 78 $\mu \mathrm{w}$ is achieved at $0.75 \mathrm{~g}$ acceleration. The same type of device with AlN piezoelectric thin films were measured by Rene et al. ${ }^{8}$, see figure 6.11 . The measurements of AlN harvester were performed from $0.25 \mathrm{~g}$ to $2 \mathrm{~g}$ acceleration, where the maximum power of $58.8 \mu \mathrm{W}$ was achieved at $2 \mathrm{~g}$. When we make a comparison with these two devices, the power output shows three times higher in PZT harvester within the same acceleration. However, for this device, we did not manage to go to high acceleration, since the center mass displacement will exceed $400 \mu \mathrm{m}$. The quality factor of PZT harvester is 460 in the low acceleration, and it decreased with increasing the accelerations. As we can see from the resonance curve, when we go to high acceleration with an increasing tip displacement, asymmetric curves are presented. This is probably due to the problems in fabrication steps. Even though the device is released and in a free vibration state, there are still some remaining silicon dioxide residues on the frame side wall. During the vibration movements, any small residue can randomly influence the vibration and damping results, which cause the jump in the curve, especially in the high accelerations. 


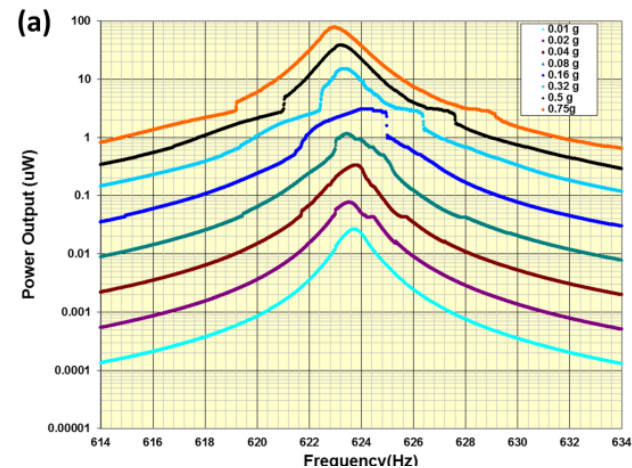

(b)

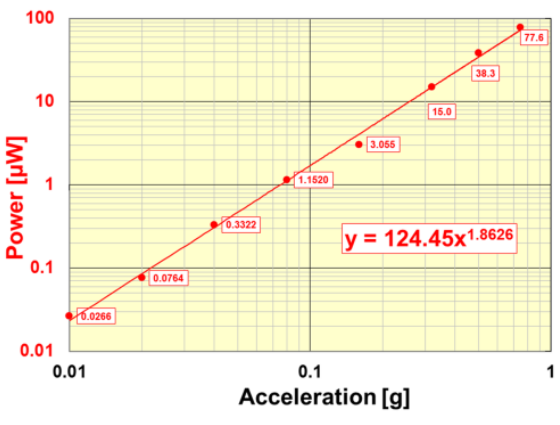

Figure 6.10 (a)Resonance curve of epitaxial PZT harvester (Dev 5) performed at different acceleration. (b) Power as a function of applied acceleration.

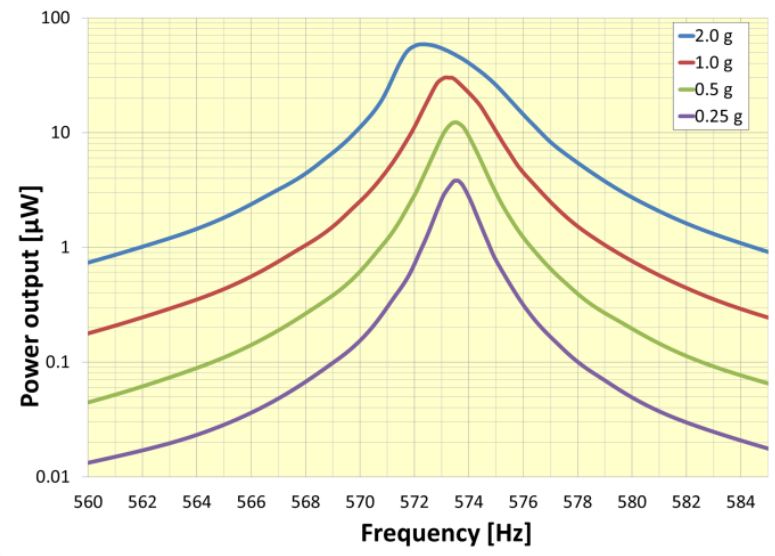

Figure 6.11 Resonance curve of AIN harvester (Dev 5) performed at different acceleration.

Figure 6.10 (b) shows the power output as a function of the acceleration at the resonance frequency. From the slope of this double logarithmic plot, we can see a quadratic relation between the output power and the acceleration, as discussed in section 6.2. From this function plot, the sensitivity of the device can be calculated as $\frac{P}{A}=124.45(\mu \mathrm{W} / \mathrm{g})$, which means under $1 \mathrm{~g}$ acceleration, $124 \mu \mathrm{W}$ power output can be reached. Compared with the present devices, the epitaxial PZT harvester shows a significant high value in terms of sensitivity and power output. 
Here we should notice that, we cannot simply compare the power output of the epitaxial harvester with the textured one, since those two devices are in different resonance frequency range with various device dimensions. The quality factors of those two films are also different. To make a fair comparison between different devices, a power normalization is done by $P_{\text {norm }}=P_{\text {meas }} / P_{\text {max }}$. As described in literature ${ }^{2,21}, \mathrm{P}_{\max }$ are calculated from,

$$
P_{\text {max }}=\frac{1}{2} Y Z \omega^{3} m
$$

Where, $\mathrm{Y}$ is the excitation amplitude, $\mathrm{Z}$ is the maximum displacement, $\omega$ is the frequency and $\mathrm{m}$ is the proof mass. The excitation amplitude can be calculated from the accelerations, by equation,

$$
a=Y \omega^{2}
$$

Thus, from all the measurements parameters, the maximum power can be calculated in each case. For epitaxial PZT harvester devices, we got a $\mathrm{P}_{\max }=230$ $\mu \mathrm{W}$. When we do the normalization, a value of $33 \%$ is obtained in this device. Table 6.1 shows an overview comparison for epitaxial PZT harvester, textured PZT harvester and the AlN unpackaged harvester. The higher $\mathrm{P}_{\text {morm }}$ values indicates the better devices performances. Figure 6.12 gives an overview of havesters from electromagnetic (EM), electrostatics (ES) and piezoelectric (PZ) in literature, while our devices are also plotted on the same graph. First of all, from the literature results, it can be seen that the smallest devices have poor effectiveness. However, the unpackaged epitaxial PZT harvester in our work shows a high effectiveness value within a low device volume. The $\mathrm{P}_{\text {norm }}$ shows an outperformance compared with other devices. Moreover, the $\mathrm{P}_{\text {norm }}$ of packaged AIN harvesters approaches a better performance than the unpackaged AlN devices. Since the packaged devices are measured in vacuum without damping effects, the measurements values are closer to the ideal case. 


\begin{tabular}{|l|l|l|l|l|l|l|l|l|}
\hline Samples & $\begin{array}{l}\text { Resonan } \\
\text { ce } \\
\text { frequenc } \\
\mathrm{y}(\mathrm{Hz})\end{array}$ & $\begin{array}{l}\text { Proof } \\
\text { Mass } \\
\left(10^{-5} \mathrm{~kg}\right)\end{array}$ & $\begin{array}{l}\text { Displace } \\
\text { ment } \\
(\mu \mathrm{m})\end{array}$ & $\begin{array}{l}\mathrm{P}_{\text {meas }} \\
(\mu \mathrm{W})\end{array}$ & $\begin{array}{l}\text { Accel } \\
\text { eratio } \\
\mathrm{ns} \\
\left(\mathrm{m} / \mathrm{s}^{2}\right)\end{array}$ & $\begin{array}{l}\text { Sensiti } \\
\text { vities } \\
(\mu \mathrm{W} / \mathrm{g}\end{array}$ & $\mathrm{P}_{\text {norm }}$ & FOM \\
\hline Epitaxial PZT & 624 & 3.98 & 315 & 77.6 & 0.75 & 124.4 & $33.0 \%$ & 24 \\
\hline Textured PZT & 426 & 7.12 & 639 & 6.6 & 0.75 & 9.7 & $1.2 \%$ & $3.6^{22}$ \\
\hline $\begin{array}{l}\text { AlN } \\
\text { (unpackaged) }\end{array}$ & 573 & 4.10 & 648 & 30.2 & 1 & 30.2 & $5.1 \%$ & $13^{23}$ \\
\hline
\end{tabular}

Table 6.1 Comparison of effectiveness of energy harvester with various piezoelectric films.

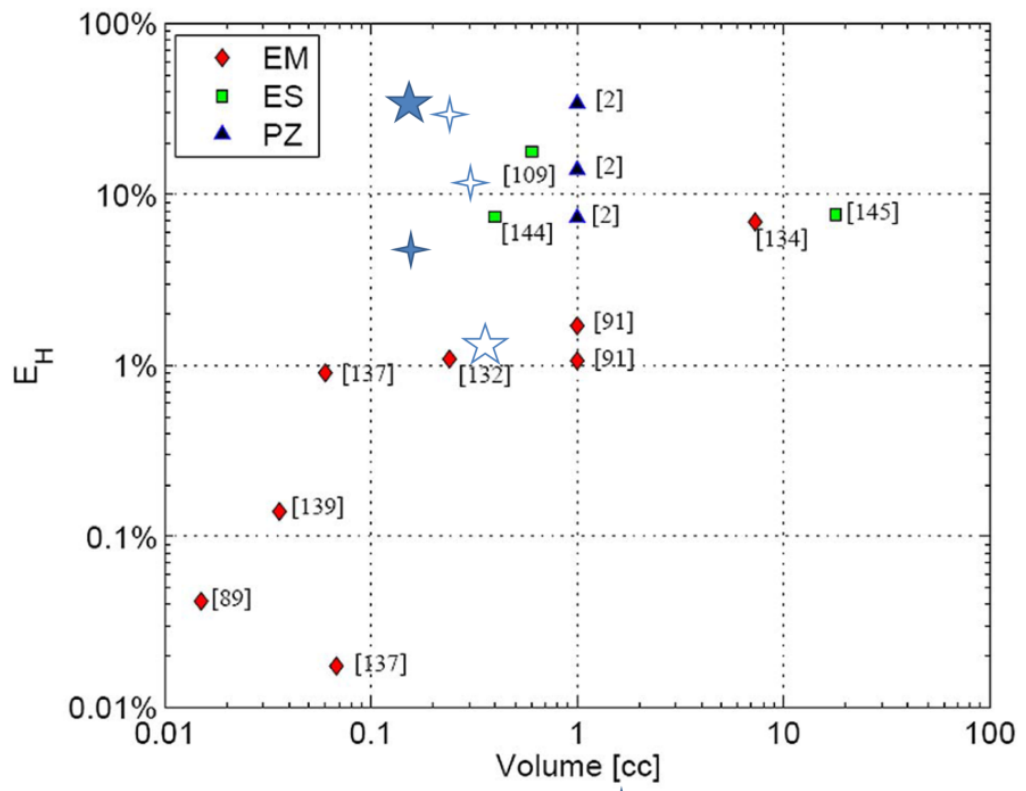

${ }^{\wedge}$ Unpackaged harvester with textured PZT films † Unpackaged harvester with AIN films

Unpackaged harvester with epitaxial PZT films $p$ packaged harvester with AIN films

Figure 6.12 Harvester effectiveness comparison between our devices and reported devices $^{2}$. 


\subsection{Conclusions}

In this chapter, a generic vibration model is described. Various mechanical parameters related to the optimum device design and power output are discussed. After modifying the process flow, epitaxial PZT harvesters are fabricated and compared with textured PZT harvester and AlN harvester. When the load resistance is optimized, the resonance curve is measured with different accelerations. The resonance frequency is $624 \mathrm{~Hz}$. The maximum power output is $78 \mu \mathrm{w}$ at $0.75 \mathrm{~g}$ acceleration. The sensitivity of this devices is $124.45 \mu \mathrm{W} / \mathrm{g}$, which is significant higher than the present devices. After power normalization, a comparison between different devices can be drawn. A $\mathrm{P}_{\text {norm }}$ of $33 \%$ is reached in unpackaged PZT harvesters, with a volume of $0.16 \mathrm{cc}$. As we discussed previously, the vacuum packaged harvester has a better ideal performance than the unpackaged one. It can be expected more energy power output in packaged epitaxial PZT devices. Epitaxial PZT thin films are proved to be a premium and exciting materials in the field of piezo energy harvesting. 


\subsection{References}

C.B. Williams and R.B. Yates, Sensor and Actuators 52, 8 (1996).

P. D. Mitcheson, E. M. Yeatman, G. Kondala Rao, A. S. Holmes, and T.C. Green, Proceedings of the IEEE 96 (9), 1457 (2008).

R. J. M. Vullers, R. van Schaijk, I. Doms, C. Van Hoof, and R. Mertens, Solid-State Electronics 53 (7), 684 (2009).

Robert Andosca, T. Gus McDonald, Vincent Genova, Steven Rosenberg, Joseph Keating, Cole Benedixen, and Junru Wu, Sensors and Actuators A: Physical 178, 76 (2012).

S. Roundy, P. K. Wright, and J. M. Rabaey, Energy scavenging for wireless sensor networks. (Kluwer Academic Publishers Group, 2004).

K. Karakaya, M. Renaud, M. Goedbloed, and R. van Schaijk, Journal of Micromechanics and Microengineering 18 (10), 104012 (2008).

Y. Hu, Y. Zhang, C. Xu, L. Lin, R. L. Snyder, and Z. L. Wang, Nano Letters 11 (6), 2572 (2011).

R. Elfrink, T. M. Kamel, M. Goedbloed, S. Matova, D. Hohlfeld, Y. van Andel, and R. van Schaijk, Journal of Micromechanics and Microengineering 19 (9), 094005 (2009).

R. Elfrink, M. Renaud, T. M. Kamel, C. de Nooijer, M. Jambunathan, M. Goedbloed, D. Hohlfeld, S. Matova, V. Pop, L. Caballero, and R. van Schaijk, Journal of Micromechanics and Microengineering 20 (10), 104001 (2010).

T. M. Kamel, R. Elfrink, M. Renaud, D. Hohlfeld, M. Goedbloed, C. de Nooijer, M. Jambunathan, and R. van Schaijk, Journal of Micromechanics and Microengineering 20 (10), 105023 (2010).

Paul Muralt, Journal of the American Ceramic Society 91 (5), 1385 (2008).

Nicolas Ledermann, Paul Muralt, Jacek Baborowski, Sandrine Gentil, Kapil Mukati, Marco Cantoni, Andreas Seifert, and Nava Setter, Sensors and Actuators A: Physical 105 (2), 162 (2003).

M. D. Nguyen, E. Houwman, M. Dekkers, Hung N. Vu, and G. Rijnders, (2013).

F. Laermer and A. Schilp, Patent No. US5501893 A (1996). 
G. G. Stoney, Proceedings of the Royal Society A: Mathematical, Physical and Engineering Sciences 82 (553), 172 (1909).

Sangmin Jeon and Thomas Thundat, Applied Physics Letters 85 (6), 1083 (2004).

E. P. EerNisse, Applied Physics Letters 35 (1), 8 (1979).

H. Nazeer, M. D. Nguyen, L. A. Woldering, L. Abelmann, G. Rijnders, and M. C. Elwenspoek, Journal of Micromechanics and Microengineering 21 (7), 074008 (2011).

R. M. Tiggelaar, R. G. P. Sanders, A. W. Groenland, and J. G. E. Gardeniers, Sensors and Actuators A: Physical 152 (1), 39 (2009).

Matthijn Dekkers, Minh D. Nguyen, Ruud Steenwelle, Paul M. te Riele, Dave H. A. Blank, and Guus Rijnders, Applied Physics Letters 95 (1), 012902 (2009).

P. D. Mitcheson, E. K. Reilly, T. Toh, P. K. Wright, and E. M. Yeatman, Journal of Micromechanics and Microengineering 17 (9), S211 (2007).

M. Jambunathan, R. Elfrink, M. Goedbloed, and R. Van Schaijk, (2013).

K. Karakaya, M. Renaud, M. Goedbloed, and R. Van Schaijk, Journal of Micromechanics and Microengineering (2008). 
Page | 116 


\section{Summary}

Piezoelectric materials are excellent materials to transfer mechanical energy into electrical energy, which can be stored and used to power other devices. PiezoMEMS is a good way to combine silicon wafer processing and piezoelectric thin film technology and lead to a variety of miniaturized and premium devices. To understand the material performance in piezoMEMS devices, the knowledge of a couple of characteristic properties, such as the electro-mechanical properties, the dielectric constant and the piezoelectric coefficients, become much more crucial. In this thesis, energy harvesters are made, based on epitaxial PZT thin films with enhanced material properties. These vibration energy-harvesting devices consists of a bulk mass attached to a cantilever. Before fabricate the device, the material properties are tailored to reach the optimal electrical output. In particular, epitaxial PZT thin films with different compositions and different dopants are studied and a variety of dielectric and piezoelectric properties are discussed. In the end, the epitaxial vibration-harvesting devices are fabricated, which are able to generate energy at microWatt scale with low vibration state. Furthermore, after power normalization, a comparison is made between different vibration harvester. It is concluded that the epitaxial PZT thin film harvester devices outperform the textured PZT and AlN thin film harvesters. 
The state of the art of the piezoMEMS is discussed in chapter 2. The fundamental knowledge to bring the ferroelectric and piezoelectric materials to real devices is given. A model of energy vibration harvesting devices with its potential application in industry is described in details, where the 31 -mode is typically used in energy harvesters. Furthermore, for epitaxial thin films, the difference in strain and stress conditions lead to different behaviors in crystallographic structure, mechanical and electrical properties.

Pulsed laser deposition (PLD) is an important technique to fabricate epitaxial thin films. The easy and precise stoichiometric material transfer from the target to the substrate make the PLD technique more suitable for device fabrications. The principles of the structural and compositional analysis are given and the electrical and mechanical analysis techniques are described. In a word, with a thorough understanding of piezoMEMS devices, from the physical principles up to device fabrication, a systematic overview and framework is built up in this thesis.

To understand the thin film growth and crystallographic structure, X-ray diffraction (XRD) is used in this study. In chapter 3, the domain structure and domain tilting of (110) $\mathrm{PbZr}_{\mathrm{x}} \mathrm{Ti}_{(1-\mathrm{x})} \mathrm{O}_{3}$ epitaxial thin films were studied by XRD. Both $\mathrm{SrTiO}_{3}$ and silicon substrates are used. Different crystallographic properties are obtained under substrate induced strain. For (110) $\mathrm{PbZr}_{\mathrm{x}} \operatorname{Ti}_{(1-\mathrm{x})} \mathrm{O}_{3}$ epitaxial thin films grown on $\mathrm{SrTiO}_{3}$ substrates, 6 different domain tilting directions are observed in the tetragonal phase. For (110) $\mathrm{PbZr}_{\mathrm{x}} \mathrm{Ti}_{(1-\mathrm{x})} \mathrm{O}_{3}$ epitaxial thin films grown on silicon substrates, 2 types of domain tilting, with a 10 degrees in plane rotations are presented. Furthermore, both the lattice parameters and the tilt angles of various compositions of $\mathrm{PbZr}_{\mathrm{x}} \mathrm{Ti}_{(1-\mathrm{x})} \mathrm{O}_{3}$ thin films are calculated and compared. A nano-domain region is observed in $\mathrm{x}=0.4-0.45$ in (110) PZT films grown on silicon substrates.

In order to increase the performance of energy harvesters, both intrinsic and extrinsic properties in the thin film play a role. For increasing the power output of the devices, we need to seek for piezoelectric thin film with both enhanced Page $\mid 118$ 
piezoelectric coefficient and a lower dielectric constant. Material with a high figure-of-merit (FOM) will be used for energy harvester fabrication. In this work, two ways are used to modify the PZT thin films. First of all, different properties are studied by changing the ratios of $\mathrm{Zr}$ and $\mathrm{Ti}$. Secondly, the introduction of additional dopants make the properties of piezoelectric thin film change significantly.

In chapter 4, piezoelectric, ferroelectric and structural properties of epitaxial pseudocubic (110) oriented $\mathrm{PbZr}_{\mathrm{x}} \mathrm{Ti}_{1-\mathrm{x}} \mathrm{O}_{3}$ thin films were studied as function of composition. The $\mathrm{x}$-dependence of the measurement data can be explained by an abrupt transition from the rhombohedral $r$-phase to the tetragonal $c_{45} / a$-phase if $\mathrm{x}$ becomes smaller than $x \approx 0.40$. In the $r$-phase the polarization vector easily rotates in the (110)-plane, perpendicular to the substrate under the influence of an external electrical or stress field, resulting in a rapidly increasing measured piezoelectric parameter $e_{31, \mathrm{f}}$ and dielectric parameter $\varepsilon_{33}$, peaking near the $r-c_{45} / a$ phase boundary. This interpretation is consistent with earlier models for multidomain (001)- oriented clamped films described in literature. The reliable growth of (110) oriented films with a large $e_{31, f}$ is of great significance for Sibased piezoMEMS. The largest value of the FOM for such devices is found for $x=0.4, F O M=e_{31}^{2} / \epsilon_{0} \epsilon_{33}=24.0 \mathrm{GPa}$.

Another way to modify the properties of piezoelectric thin films is by inducing dopants. In chapter 5, the functional properties of $\mathrm{Nb}$-doped and Fe-doped PZT thin films are discussed. In this study, both (110) orientated and (001) orientated films were grown on silicon substrates. A FOM was calculated for each film. Nb-doped PZT films gave the highest piezoelectric coefficient $\mathrm{e}_{31, f}$, while $\mathrm{Fe}$ doped PZT gives the lowest $\mathrm{e}_{31, f}$. A giant imprint behavior was obtained in (001) orientated epitaxial thin films. Under the epitaxial growth, the defect dipoles, which were induced by dopants, were aligned in one direction giving rise to typical imprint PE loops. Here, a build-in bias reduces the dielectric constant at zero bias. In this case, the highest FOM is obtained in (001) oriented Nb-doped PZT thin films grown on STO buffered silicon substrates. 
In the last chapter, the fabrication and testing of the epitaxial $\mathrm{PbZr}_{0.4} \mathrm{Ti}_{0.6} \mathrm{O}_{3}$ vibration harvesting devices are discussed. The results were compared with textured PZT harvester and AIN harvester. The maximum power output in epitaxial harvester is $78 \mu \mathrm{w}$ at $0.75 \mathrm{~g}$ acceleration, with a resonance frequency of $624 \mathrm{~Hz}$. The sensitivity of this device is $124.45 \mu \mathrm{W} / \mathrm{g}$, which is significantly higher than the devices described in literature. After normalizing the power output, a comparison between different devices is described. A $\mathrm{P}_{\text {norm }}$ of $33 \%$ is reached in unpackaged epitaxial PZT harvesters, which is five times higher than the unpackaged AlN harvester. Thus epitaxial PZT thin films are proven to be promising materials in the field of vibration energy harvesting.

To conclude, epitaxial PZT thin film based vibration energy harvesting devices were successfully designed and fabricated. From the material point of view, the crystallographic structure and functional properties of the epitaxial PZT thin films were investigated thoroughly. The physical mechanisms are discussed in each case. Those studies enabled the device specific optimization of the epitaxial PZT thin films. From the application point of view, vibration energy harvester devices with epitaxial piezoelectric thin films were investigated. The strong piezoelectric activity and the outstanding power output in these epitaxial harvesters open the possibility for industrial applications. 


\section{Samenvatting}

Piezoelektrische materialen zijn zeer geschikt om mechanische energie om te zetten in elektrische energie. Die energie kan worden opgeslagen en gebruikt in andere apparatuur. In PiezoMEMS devices kunnen we silicium wafer technologie combineren met piezoelektrische dunne film technologie. Dit opent de weg naar een groot scala aan geminiaturiseerde, hoog-technologische devices. Om het gedrag van de materialen in PiezoMEMS devices te begrijpen, is kennis van een aantal karakteristieke materiaaleigenschappen, zoals de elektromechanische eigenschappen, de diëlektrische constante en de piezoelektrische coëfficienten, noodzakelijk. In dit proefschrift wordt de ontwikkeling en fabricage van zogenaamde energy harvesters beschreven, die zijn gemaakt op basis van epitaxiale PZT dunne films met verbeterde materiaal eigenschappen. Deze piezoelectrische vibratie energy harvesters bestaan uit een bulk massa, die is bevestigd aan een cantilever (een dunne balk). Voor fabricage van het device zijn de materiaaleigenschappen geoptimaliseerd om de optimale elektrische opbrengst te verkrijgen. De PZT dunne films zijn met name met verschillende composities en doping onderzocht en worden hun diëlektrische en piezoelektrische eigenschappen beschreven. Daarna zijn epitaxiale energy harvesters gefabriceerd, waarmee energie op $\mu \mathrm{W}$-niveau gegenereerd kan worden door middel van een kleine vibratie. Na normalisering van de energie- 
opbrengsten van verschillende type devices, is een vergelijking met andere energie harvesters gemaakt. De conclusie is dat epitaxiale PZT dunne film energy harvesters veel beter functioneren dan harvesters op basis van een getextureerde, dunne film van PZT of AlN.

De state-of-the-art van PiezoMEMS technologie wordt besproken in hoofdstuk 2, evenals de basiskennis die nodig is om ferroelektrische en piezoelektrische materialen te kunnen gebruiken in echte devices. Een model van vibratie energie harvesters en hun mogelijke toepassingen in de industrie wordt gepresenteerd, waarbij de 31-mode typisch is voor dergelijke harvesters. In epitaxiale dunne films kunnen verschillen in mechanische spanning en rek condities aanleiding zijn tot veranderingen in de kristallografische structuur en mechanische en elektrische eigenschappen.

Pulsed laser deposite (PLD) is een belangrijke techniek voor de fabricage van epitaxiale dunne films, omdat het materiaal op een makkelijke en precieze manier materiaal in de juiste stochiometrische verhouding van het target naar het substraat wordt overgebracht. De principes van structuur en compositie analyse technieken en van elektrische en mechanische meettechnieken worden beschreven.

X-ray diffractie is gebruikt om de dunne film groei en kristallografische structuur te onderzoeken. In hoofdstuk 3 is het onderzoek naar de kristallografische domein structuur en domein tilting in epitaxiale, (110)geörienteerde, dunne $\mathrm{PbZr}_{\mathrm{x}} \mathrm{Ti}_{(1-\mathrm{x})} \mathrm{O}_{3}$ films op zowel $\mathrm{SrTiO}_{3}$ als silicium substraten beschreven. Verschillende kristallografische eigenschappen zijn waargenomen ten gevolg van de door het substraat geïnduceerde spanning. Epitaxiale (110)-geörienteerde $\mathrm{PbZr}_{\mathrm{x}} \mathrm{Ti}_{(1-\mathrm{x})} \mathrm{O}_{3}$ dunne films, gegroeid op $\mathrm{SrTiO}_{3}$ substraten, zijn allemaal in de tetragonale fase, met domeinen in 6 verschillende tilt richtingen. (110)-geörienteerde $\mathrm{PbZr}_{\mathrm{x}} \mathrm{Ti}_{(1-\mathrm{x})} \mathrm{O}_{3}$ epitaxiale dunne films gegroeid op silicium substraten vertonen 2 types domein tilting, maar bovendien is er in-vlak twinning, ten gevolg van 10 graden rotaties van de kristal structuur. De rooster constanten en tilt hoeken van verschillende $\mathrm{PbZr}_{\mathrm{x}} \mathrm{Ti}_{(1-\mathrm{x})} \mathrm{O}_{3}$ dunne film 
composities zijn bepaald en vergeleken. In (110) PZT films gegroeid op silicium substraten met $\mathrm{x}=0.4-0.45$ observeren we een fase met domeinen met afmetingen in het nanometer bereik.

Zowel intrinsieke als extrinsieke eigenschappen van dunne films zijn van belang om het rendement van energy harvesters te vergroten. Om het uitgangsvermogen te verhogen, zijn piezoelektrische materialen nodig met zowel een hoge piezoelektrische coëfficient als een lage diëlektrische constante. Materialen met een hoge waarde van de figure-of-merit (FOM) worden gekozen voor de fabricage van energie harvesters. In deze studie zijn twee manieren gebruikt om de eigenschappen van de PZT dunne films te veranderen. Ten eerste is de Zr:Ti verhouding veranderd, en ten tweede zijn additionele doteringen toegevoegd om de eigenschappen van de films significant te veranderen.

In hoofdstuk 4 wordt het onderzoek naar de piezoelektrische, ferroelektrische en structurele eigenschappen van epitaxiale, pseudokubisch (110)-georienteerde $\mathrm{PbZr}_{\mathrm{x}} \mathrm{Ti}_{1-\mathrm{x}} \mathrm{O}_{3}$ dunne films als functie van de compositie beschreven. De afhankelijkheid van de meet data van de $\mathrm{Zr}$-fractie $\mathrm{x}$ wordt verklaard door een abrupte overgang van de rhombohedrische $r$-fase naar de tetragonale $c / a$-fase als $\mathrm{x}$ kleiner wordt dan ongeveer 0.40 . In de $r$-fase kan de polarisatie-vector makkelijk roteren in het (11̄0) kristal vlak, loodrecht op het substraat, onder invloed van een extern aangelegd elektrisch veld of mechanische spanning. Dit resulteert in een snelle toename van de gemeten piezoelektrische parameter $e_{31, \mathrm{f}}$ en diëlektrische parameter $\varepsilon_{33}$, die een maximum bereiken bij de $r-c_{45} / a$ fase grens. Deze interpretatie is consistent met eerdere modellen uit de literatuur voor multi-domein, (001)-geörienteerde films, geklemd op het substraat. Reproduceerbare groei van (110)-geörienteerde films met een grote $e_{31, \mathrm{f}}$ is van groot belang voor piezo-MEMS op Si. De hoogste door ons bepaalde FOM waarde is voor $\mathrm{x}=0.4: \mathrm{FOM}=e_{31}^{2} / \epsilon_{0} \epsilon_{33}=24.0 \mathrm{GPa}$

Een andere manier om de eigenschappen van piezoelektrische dunne films te veranderen is de introductie van dopants. In hoofdstuk 5 zijn de functionele 
eigenschappen van met $\mathrm{Nb}$ en Fe gedoteerde PZT dunne films beschreven. In deze studie zijn zowel (110)-, als (001)-geörienteerde films gegroeid op silicium substraten. De FOM waarde is bepaald voor elke film. Nb-gedoteerde films hebben de hoogste piezoelektrische coëfficient $\mathrm{e}_{31, f}$, en de Fe-gedoteerde PZT films de laagste. Een zeer grote imprint is geobserveerd in de (001)geörienteerde, epitaxiale films. Onder epitaxiale groei condities, richten de defect dipolen, die door de doping zijn geïntroduceerd, zich in één richting, wat de typische imprint (verschuiving van de elektrische veld as) in de polarisatieloops veroorzaakt. De ingebouwde bias spanning reduceert de diëlektrische constante bij nul veld. In dat geval wordt de hoogste FOM-waarde verkregen in (001)-geörienteerde, Nb-gedoteerde, PZT dunne films op silicium substraten met een STO bufferlaag.

In het laatste hoofdstuk is de fabricage en het testen van epitaxiale $\mathrm{PbZr}_{0.4} \mathrm{Ti}_{0.6} \mathrm{O}_{3}$ vibratie energy harvesters beschreven. De resultaten worden vergeleken met die van harvesters op basis van getextureerde PZT films en AlN films. Het maximale uitgangsvermogen is $78 \mu \mathrm{W}$ bij een versnelling van $0.75 \mathrm{~g}$, en een resonantiefrequentie van $624 \mathrm{~Hz}$. De gevoeligheid is $124.45 \mu \mathrm{W} / \mathrm{g}$, hetgeen aanzienlijk meer is dan dat van harvesters beschreven in de literatuur. $\mathrm{Na}$ normalisatie van het uitgangsvermogen kunnen we verschillende harvesters met elkaar vergelijken. Een $\mathrm{P}_{\text {norm }}$ van $33 \%$ is bereikt in epitaxiale PZT-film harvesters zonder omhulsel (package), hetgeen vijf keer meer is dan voor AlN harvesters zonder omhulsel. Hiermee is aangetoond dat epitaxiale PZT dunne films zeer veelbelovend zijn voor de toepassing in vibratie energy harvesters.

Concluderend kunnen we stellen dat we met succes epitaxiale PZT dunne film gebaseerde vibratie energie harvesters hebben ontworpen en gefabriceerd. De kristallografische structuur en de functionele eigenschappen van epitaxiale PZT dunne films zijn grondig onderzocht en de fysische mechanismes zijn beschreven. Dit onderzoek maakte het mogelijk om de epitaxiale PZT dunne film te optimaliseren voor de specifieke toepassing op het gebied van vibratie energy harvesters. De hoge piezoelektrische activiteit en het zeer grote uitgangsvermogen bieden zicht op industriële toepassingen. 


\section{Acknowledgments}

In the last part of my thesis I would like to express my gratitude to all the people who have supported, encouraged and companied me during the last six and a half years. Beginning with a Master of Science in Chemistry and Technology of Material, and ending as a Doctor of Philosophy, I have been going through important and unforgettable stages in my life, where I have the fortunate to meet lots of wonderful person.

First, I would like to give my deep sense of gratitude to my promotor, Prof. Guus Rijnders, for giving me the opportunity to carry out a master project, and later on to become a Ph.D student in the IMS group. It is appreciative to get the advices, encouragement and motivation from you in different stage of my Ph.D. I would like to express my sincere thanks to Prof. Dave Blank. It is grateful to talk with you in both scientific life and the social events. Thanks to Dr. Gertjan Koster for being my assistant promotor, and the thesis corrections. You are always open for discussion in many aspects. I would like to thanks all other members of my doctoral graduation committee for making time to evaluate this work, especially to those travelling from abroad. I would also express thanks to Dr. Evert Houwman, who, time and again, helped me to overcome the challenges in our project. I am appreciate your suggestions, modeling and writing corrections.

The last part of my Ph.D project is conducted in Holst Centre/IMEC-NL. I am deeply grateful to Dr. Rob van Schaijk and Dr. Ruud Vullers. Thanks for the extensive collaborations and the inspirational discussions. I have learned a lot at the Holst Centre in the scientific perspective, as well as in the industrial approach of working. I would like to thanks to Dr. Koray Karakaya for taking me into the project and sharing all the knowledge. Thanks to Madhu Jambunathan and Rene Elfrink for their helps on device fabrication and measurements. I would like to say thanks to all my colleagues in Holst Centre for their supports and making me a nice stay in Eindhoven. 
Many work described in this thesis results from some excellent collaborations. I am grateful to our piezo-team: Minh, Ruud, Evert and Matthijn, with whom I shared many inspirational discussions in the meeting room, as well as in the lab. Thanks to our technicians, Frank, Jose, Henk, Dominic, Gerrit and Dick for all the helps in the lab and in the cleanroom. Thanks Marion for helping with all the paperwork I have to deal with as a foreign student. Thanks for all the helps from nanolab staffs. My officemates Hans, Peter, Josee, Alim and Anirban, deserve a big thank you for making the work fun. I am thankful to all the IMS group colleagues, Mark, Andre, Bernard, Jeroen, Brian, Bouwe, Joska, PeterB, Gerard, Sjoerd, Wouter, Pablo, Werner, Maarten, Rik, Nirupam, Anuj, Debakanta, Rogier, Michelle, Huiyu, Kurt and David for all the invaluable assistance and friendly atmosphere they created around me.

The support and company of my friends enriched my life in the Netherlands. Thanks Sinie for being my Dutch grandma, you make me feel home in Twente. Thanks for my friends from California, Joni, Li, Arturas, Lan, and my cousin Jiaying. The world becomes small, and we are able to see each other every now and then. Thanks for all the friends I met in Enschede, Lanti and Hao, Xiao and Zheng, Songyue and Yifan, Wilfred and Yuko, Linlin and Dennis, Shan and Yuguo, Jing, Henny and Wim, Qi and Yujie, Yuying and Xiaofeng, ChienChing and Kaifan, Weiqing, Shuo, Yiping, Yanbo, Xuexin, Wei, Elia and Luisa, Chunlin and Huaqiong, and many others, we had a lot of enjoyable time together and thank you all for your friendship.

I would like to give special thanks to my family in China. Much I owe to my grandparents and my parents, who give me their unconditional support all through these years! Finally and the most importantly, Tian and Kevin, thanks for all the encouragement, support and endless love.

\section{Xin Wan}

April, 2013 